\title{
SUPERCONDUCTOR CRITICAL CURRENT STANDARDS FOR FUSION APPLICATIONS
}

L.F. Goodrich

J.A. Wiejaczka

A.N. Srivastava

T.C. Stauffer 



\section{SUPERCONDUCTOR CRITICAL CURRENT STANDARDS FOR FUSION APPLICATIONS}

L.F. Goodrich

J.A. Wiejaczka

A.N. Srivastava

T.C. Stauffer

Electromagnetic Technology Division

Electronics and Electrical Engineering Laboratory

National Institute of Standards and Technology

Boulder, Colorado 80303

Prepared for

Office of Fusion Energy

Department of Energy

Washington, DC 20545

and

Plasma Fusion Center

Massachusetts Institute of Technology

NW16-164

Cambridge, MA 02139

November 1994

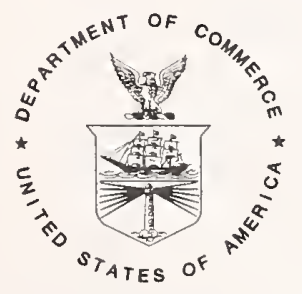

U.S. DEPARTMENT OF COMMERCE, Ronald H. Brown, Secretary

TECHNOLOGY ADMINISTRATION, Mary L. Good, Under Secretary for Technology

NATIONAL INSTITUTE OF STANDARDS AND TECHNOLOGY, Arati Prabhakar, Director 


\section{FOREWORD}

This is the final progress report for the nine month period from October 1993 to July 1994. We were asked to help design, participate in, perform research studies on, and report on the first International Thermonuclear Experimental Reactor (ITER) interlaboratory comparison of $\mathrm{Nb}_{3} \mathrm{Sn}$ critical current measurements. This report contains: a comparison of results from the U.S. laboratories, a comparison of results from a number of international laboratories, a homogeneity study of one $\mathrm{Nb}_{3} \mathrm{Sn}$ wire, observations on the standard specimen mandrel design, a commentary on the future possibility of creating a $\mathrm{Nb}_{3} \mathrm{Sn}$ Reference Wire, and a compilation of Data Format Sheets from U.S. Laboratories.

The authors extend their thanks to M. Takayasu (Massachusetts Institute of Technology, MIT) for his contribution in the design of the common mandrel, J. Minervini (MIT) for his organization of the interlaboratory comparison, U.S. ITER Home Team for their cooperation, W.P. Dubé for assisting with experiment design, and L.T. Medina for assisting with this work. This work was supported by the U.S. Department of Energy Office of Fusion Energy and the MIT Plasma Fusion Center. 


\section{Contents}

Page

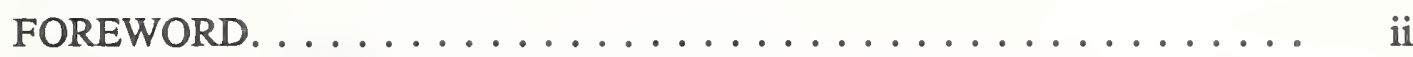

1. COMPARISON OF CRITICAL CURRENT MEASUREMENTS

FROM U.S. LABORATORIES . . . . . . . . . . . . . . . . . 2

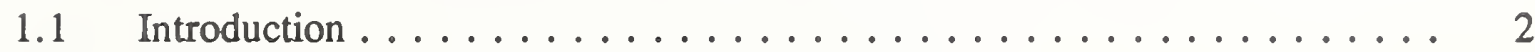

1.2 Standardized Mandrels and Attachment Procedure . . . . . . . . . . . . 3

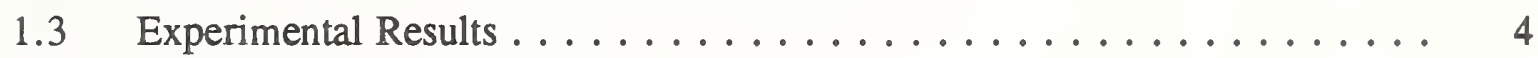

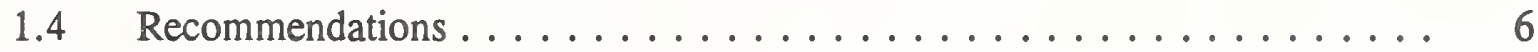

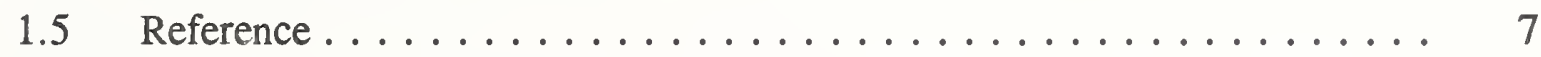

2. COMPARISON OF CRITICAL CURRENT MEASUREMENTS FROM INTERNATIONAL LABORATORIES . . . . . . . . . . . . . . . 21

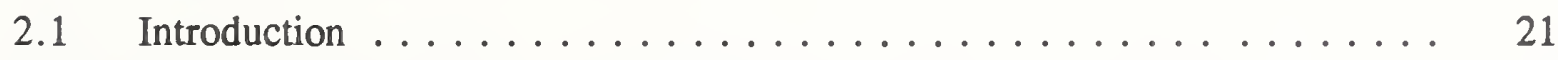

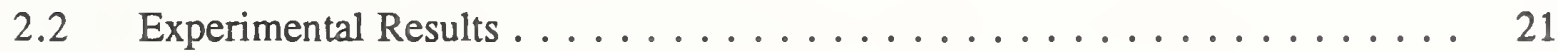

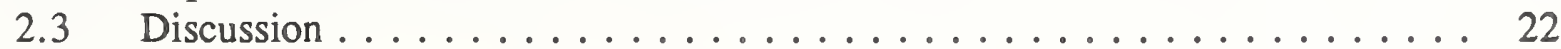

3. CRITICAL CURRENT HOMOGENEITY OF A Nb $\mathrm{Nb}_{3}$ WIRE . . . . . . 30

3.1 Experimental Details of the Homogeneity Study . . . . . . . . . . . . . . . 30

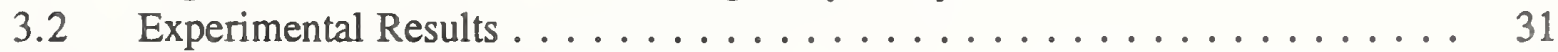

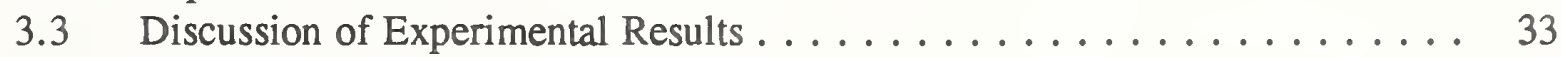

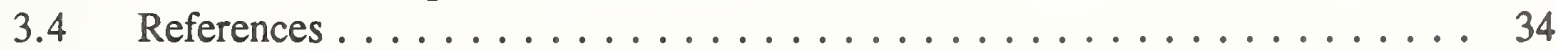

4. OBSERVATIONS AND RECOMMENDATIONS ON THE CRITICAL CURRENT MEASUREMENT PROCEDURE . . . . . . . . . . . . 51

4.1 Critical Current Measurement Apparatus . . . . . . . . . . . . . . 51

$4.2 \quad$ Current Contacts . . . . . . . . . . . . . . . . . . . . . . 52

4.3 Electrolytic Method for Removing Cr Plating from Reacted $\mathrm{Nb}_{3} \mathrm{Sn}$ Wires . . 53

4.4 Superconductivity of the Ti-6Al-4V Measurement Mandrel . . . . . . . . . 53

4.5 Critical Current Measurements on the Nb-Ti Wire SRM-1457 . . . . . . . 55

4.6 Observations on the Standard Specimen Mandrel . . . . . . . . . . . . . 55

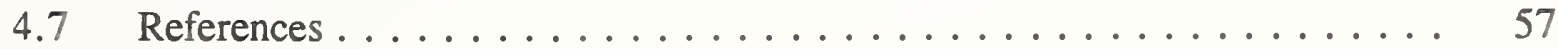


5. COMMENTARY ON A Nb ${ }_{3}$ Sn REFERENCE WIRE . . . . . . . . 65

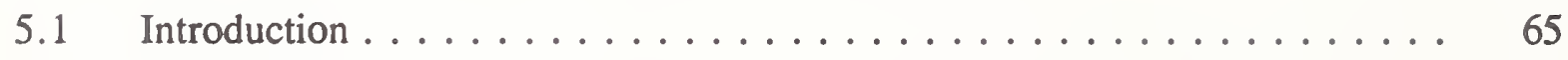

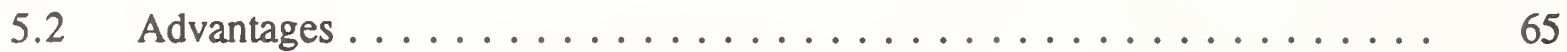

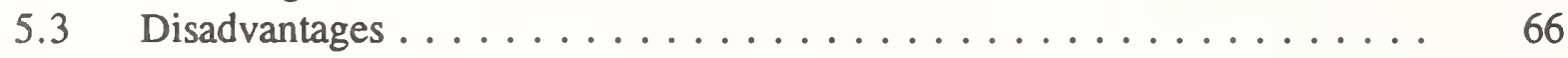

5.4 Recommendation...................... 67

Appendix A. STANDARDIZED LABORATORY REPORTING

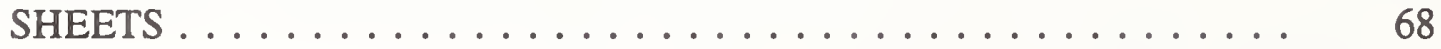

Appendix B. A SIMPLE AND REPEATABLE TECHNIQUE FOR MEASURING THE CRITICAL CURRENT OF $\mathrm{Nb}_{3} \mathrm{Sn}$ WIRES. . . . . . . . 92 


\title{
SUPERCONDUCTOR CRITICAL CURRENT STANDARDS FOR FUSION APPLICATIONS
}

\author{
October 1993-July 1994
}

\author{
L.F. Goodrich, J.A. Wiejaczka, A.N. Srivastava, and T.C. Stauffer \\ Electromagnetic Technology Division \\ Electronics and Electrical Engineering Laboratory \\ National Institute of Standards and Technology \\ Boulder, CO 80303
}

This report describes research conducted to help establish a standard critical current measurement technique for the $\mathrm{Nb}_{3} \mathrm{Sn}$ superconducting wires that may be used in fusion applications. The main part of this report is a detailed presentation of results from the first ITER international interlaboratory comparison of $\mathrm{Nb}_{3} \mathrm{Sn}$ critical current measurements. A common procedure and a common reaction and measurement mandrel were used by U.S. laboratories in this comparison, whereas no common procedure was followed by the international laboratories. The largest difference in $I_{c}$ measurements of two laboratories that did not use a common procedure was $23 \%$. The largest difference in $I_{c}$ measurements of two laboratories that did use a common procedure was $6.5 \%$. There may still be room for improvement, but this indicates the strong need for a common detailed procedure. Results on the homogeneity of one of the $\mathrm{Nb}_{3} \mathrm{Sn}$ wires used in this study and a commentary on creating a $\mathrm{Nb}_{3} \mathrm{Sn}$ Reference Wire are also presented.

Key words: critical current; homogeneity; interlaboratory comparison; $\mathrm{Nb}_{3} \mathrm{Sn}$; $\mathrm{Nb}$ - $\mathrm{Ti}$; $\mathrm{n}$-value; standard mandrel; standards 


\title{
1. COMPARISON OF CRITICAL CURRENT MEASUREMENTS FROM U.S. LABORATORIES
}

\begin{abstract}
An interlaboratory comparison of critical current measurements was made on $\mathrm{Nb}_{3} \mathrm{Sn}$ strand wires for the ITER application. The results for the United States (U.S.), Japan (JA), Russian Federation (RF), and European Community (EC) samples are shown as measured by six U.S. laboratories. The laboratories are listed in the text as Lab A through $F$ to avoid directly identifying data with the laboratory that obtained them. Likewise the samples will be listed as $W, X, Y$, and $Z$. This is a brief presentation of these results.
\end{abstract}

\subsection{Introduction}

The data presented here are critical current $I_{c}$ and $n$-value measurements made during an interlaboratory comparison in which a common mandrel with standardized design was used for reaction and measurement. Titanium alloy (Ti-6Al-4V; composition is in mass percent) mandrels were chosen because they can be used for both reaction and measurement, thus eliminating the need to transfer the delicate sample from the reaction to the measurement mandrel. This reduced a major source of variability. The Ti alloy mandrels have other advantages: they are inexpensive and nonmagnetic, and have low thermal expansion, high electrical resistivity, and low resistivity ratio.

The thermal contraction of this $\mathrm{Ti}$ alloy is $0.17 \%$ from 295 to $4 \mathrm{~K}$. Differential thermal contraction causes the $\mathrm{Nb}_{3} \mathrm{Sn}$ wire to tighten onto the mandrel as it cools to the measurement temperature. This tightened state reduces sample motion and the need for a binding agent to hold the sample, as long as the Lorentz force is directed into the mandrel. Differential contraction also puts the wire into hoop strain, and creates a transverse stress gradient and slight bending strain. We think that the hoop strain is the most significant strain effect. Tensile hoop strain will slightly increase the $I_{c}$ from the intrinsic value.

Incoloy was not selected for the mandrel material, even though it would have less differential contraction with the $\mathrm{Nb}_{3} \mathrm{Sn}$ wire, because of the complicating issues of the magnetism of Incoloy, its limited availability, and higher cost.

The low temperature electrical resistivity of this Ti alloy is $147 \mu \Omega \mathrm{cm}$, which is quite high compared to Incoloy or stainless steel (approximately $53 \mu \Omega \mathrm{cm}$ ). This high resistivity reduces the effect of current sharing in the measurement mandrel that would affect the determination of $I_{c}$ and n-value.

We conducted preliminary measurements to test the conductivity of the Ti mandrel and discovered that this mandrel is superconducting at $4.2 \mathrm{~K}$ and magnetic fields below $2 \mathrm{~T}$. Thus, reliable $\mathrm{I}_{\mathrm{c}}$ measurements can be obtained only at fields higher than $2 \mathrm{~T}$ at $4.2 \mathrm{~K}$ with this mandrel material. 
The superconducting properties of this alloy depend on the annealing and machining of the mandrel.

All $\mathrm{Nb}_{3} \mathrm{Sn} \mathrm{I}_{\mathrm{c}}$ measurements reported here were made at magnetic fields of $6 \mathrm{~T}$ and above, where the Ti alloy mandrel is a normal metal and will not have a significant current-sharing effect. The normal state resistance of the machined (not annealed) mandrel is about $460 \mu \Omega$ between the current contacts.

Winding and reacting processes were conducted at MIT. The specimens were subsequently distributed to six U.S. laboratories. The laboratories that participated were: Teledyne Wah Chang Albany, MIT Francis Bitter National Magnet Laboratory, MIT Plasma Fusion Center, University of Wisconsin Applied Superconductivity Center, Brookhaven National Laboratory, and the National Institute of Standards and Technology. The laboratories are listed in the text as Laboratory A through $\mathrm{F}$ to avoid directly identifying data with the laboratory that obtained it. Likewise the samples will be listed as W, X, Y, and Z.

\subsection{Standardized Mandrels and Attachment Procedure}

The procedure for mounting the sample to the mandrel and mounting the mandrel to the test fixture is given below.

The reaction mandrel consists of three Ti alloy parts: a main tube (barrel), and two removable end rings. The main tube has a threaded groove ( 8 threads/in, 3.15 threads $/ \mathrm{cm}$ ) with a groove angle of $90^{\circ}$. The end rings are held onto the main tube with a stainless steel wire (spring clip) through mating holes in the main tube and end cap. The end rings are not threaded; their outer diameter was machined to hold the sample at the same coil diameter as when seated in the grooves of the main tube. A small diameter retaining wire is used to tie the specimen to each end ring and thus hold the wire coil on the reaction mandrel.

After reaction, the end rings are removed and Cu current contact rings are put on and held in place with stainless steel wire. It is important that the $\mathrm{Cu}$ ring fit correctly on the main $\mathrm{Ti}$ tube so that the sample is not strained in the transition region between the $\mathrm{Cu}$ ring and the $\mathrm{Ti}$ tube. If there is a $\mathrm{Cr}$ coating on the $\mathrm{Nb}_{3} \mathrm{Sn}$ wire, it is removed from the region of the current contacts and voltage taps. One end of the sample is clamped and the sample is seated into a groove starting from the clamp end and proceeding along the wire to the far end which is then clamped. The sample is then soldered to the $\mathrm{Cu}$ current contact rings, and voltage tap wires are soldered to the sample. At this stage, the sample is a fully instrumented and self-contained unit, which we will call an instrumented sample.

Other laboratories prepared its own specimens and followed a procedure similar to that described here. There are still some differences, such as the geometry of the Cu current contact rings. These details and procedures may be further standardized in the future. No bonding material was 
used to hold the specimen on the measurement mandrel. The $I_{c}$ measurements were made with the Lorentz force directed into the mandrel.

We also standardized the way the instrumented sample is attached to the test fixture. In all cases, the current contact to the instrumented sample was made by pressure contacts to each end (each $\mathrm{Cu}$ ring). The pressure contact mechanism must be designed so that it does not torque the instrumented sample when the pressure is applied. This makes the instrumented samples selfcontained and interchangeable; this will allow interlaboratory comparisons to be made in a classical round-robin where each sample is measured by each laboratory. This approach would reduce variability due to sample inhomogeneity and handling, thus allowing more precise interlaboratory comparisons. The classical round robin approach in combination with each laboratory instrumenting samples could be used to identify and separate mounting effects from sample inhomogeneity and measurement conditions.

\subsection{Experimental Results}

The test results given in this section are in the form of tables and figures. Raw data from each laboratory for each sample are given in the tables as well as statistical summaries of the results of the intercomparison. Extra digits are provided for precise interpolation. The figures illustrate trends for each sample and each laboratory.

$\mathrm{The}_{3} \mathrm{Sn}$ samples measured here were not intended to meet a given specification; in fact, they had different wire diameters.

Table 1-1 is a summary of critical current measurements on $\mathrm{Nb}_{3}$ Sn strand Sample W at $10 \mu \mathrm{V} / \mathrm{m}$ $(0.1 \mu \mathrm{V} / \mathrm{cm}$ ) and $12 \mathrm{~T}$. The table indicates the raw critical current (as measured), the temperature at which the measurement was made, and the critical current at a temperature of $4.2 \mathrm{~K}$. The data for each laboratory were corrected to a temperature of $4.20 \mathrm{~K}$ using the temperature dependence measured at Laboratory $\mathrm{C}$. The temperature correction equation used was:

$I_{c}(B, T)=I_{c r}\left(B, T_{r}\right)\left[\left(T_{c}{ }^{*}(B)-T\right) /\left(T_{c} *(B)-T_{r}\right)\right]$, where

$\mathrm{T}_{\mathrm{c}}{ }^{*}$ is defined by $\mathrm{I}_{\mathrm{c}}(\mathrm{B}, \mathrm{T})=\mathrm{I}_{\mathrm{c} 0}(\mathrm{~B})\left[1-\mathrm{T} / \mathrm{T}_{\mathrm{c}}{ }^{*}(\mathrm{~B})\right]$.

$\mathrm{T}_{\mathrm{c}}{ }^{*}$ is the effective transition temperature, and $\mathrm{I}_{\mathrm{cr}}$ is the measured critical current at a reference temperature $T_{r}$. The $n$-values are also shown for each laboratory and each specimen. Average critical currents at $4.2 \mathrm{~K}$ are also shown. A few extreme outliers (see footnotes) were omitted from the calculated averages and standard deviations.

Tables 1-2 to 1-4 have the same format as Table 1-1, except that they are for Samples X, Y, and $\mathrm{Z}$, respectively. Figure 1-1 illustrates the critical current measurements from each laboratory for each sample; the average critical current for each sample is shown by a horizontal line. 
Table 1-5 shows statistics on the critical current and $n$-value determined for each of the four samples using data from all six laboratories. The coefficient of variation is the standard deviation divided by the average expressed in percent. The statistics for Sample W used 11 measurements of $I_{c}$ and 10 measurements of $n$. The statistics for the other samples used 12 measurements of $I_{c}$ and $n$. These statistics are illustrated in Figures 1-4 to 1-7. Figure 1-4 shows the percent difference of the measured critical current for each laboratory from the overall average for each sample, as a function of sample. Figure 1-5 is the same as Figure 1-4 with a more sensitive scale; Sample $\mathrm{W}$ had two extreme outliers that are off scale. Figure 1-6 illustrates the percent difference of the determined value of $n$ for each laboratory from the average $n$-value for each sample, as a function of sample. Figure 1-7 is the same as Figure 1-6 but on a more sensitive scale. The sample which had extreme outliers for the $I_{c}$ measurements also had three outlying n-values which are off scale in Figure 1-7.

Table 1-6 shows measurement statistics for each laboratory that participated in the intercomparison. These measurement statistics are relative to the average value for each of the four samples. For this table, the percentage differences between the results of a laboratory's measurements on a given sample and the overall average for that sample are calculated. The range of these percent differences in $I_{c}$ for all samples is shown in the row of the table labeled $I_{c}$ Range $(\%)$. The average of these percent differences for a given laboratory and all samples is shown in the row of the table labeled $I_{c}$ Average Bias (\%). Thus, the average bias of $I_{c}$ indicates the average position of a laboratory's results relative to the overall averages, and the $I_{c}$ range indicates the variability of a laboratory's results for two specimens of each of four samples. These measurement statistics are best illustrated in Figures 1-2 and 1-3. Figure 1-2 shows the variation in $I_{c}$ measurements made by a given laboratory for each sample. There were outlying measurements made by Laboratories A and B. We suspect that Laboratory A's outlier is due to a damaged sample, while Laboratory B's outlier is due to a short circuit in the cryostat. Laboratory A remeasured this suspect specimen using two pairs of voltage taps and found that nearly all of the voltage drop was coming from part of the specimen, which is consistent with sample damage. Laboratory B's suspect specimen was remeasured, and the measured value of $I_{c}$ fell by about $30 \%$. The other laboratories values were clustered around 0. Figure 1-3 is the same as Figure 1-2 but on a more sensitive scale excluding these outliers. The statistics on the n-value measurements were done in the same way and are illustrated in Figures 1-8 and 1-9, with Figure 1-9 having a more sensitive scale. This analysis was used to attempt to quantify the results from each laboratory, and it is not an independent evaluation because the overall averages were used.

Table 1-7 shows the $I_{c}$ coefficients of variation for various laboratory subsets. These subsets were selected to illustrate the influence of some measured values on the overall statistics. There might be an indication of a significant effect for Sample X, whose coefficient of variation increases by a factor of 2 in going from four to six laboratories. Most of the changes for the other samples were not unusual. However, there is an indication that some of the laboratories had problems measuring some samples. 
Table 1-8 shows Laboratory C's critical current and n-value measurements versus magnetic field at $4.2 \mathrm{~K}$ and the approximate temperature-dependent coefficients $T_{c}{ }^{*}$ for two specimens of each of the four wires. These data are provided to allow comparisons at other fields, temperatures, and electric field criteria.

\subsection{Recommendations}

Based on these results, we recommend the following methods for enhancing the quality of the critical current measurements:

1. For critical current measurements, we recommend that critical currents, as opposed to critical current densities, be reported by all laboratories participating in the interlaboratory comparison. The critical current density reports have a higher uncertainty since they are composed of uncertainties due to the critical current measurement and uncertainties due to the measurement of the conductor's cross-sectional area.

2. Standardize the test procedure, the test fixtures, and the analysis methods. Also, select a method that does not require the sample to be transferred from reaction to measurement mandrel. A standard procedure for making the critical-current measurements was proposed by L.F. Goodrich during the Versailles Project on Advanced Materials and Standards (VAMAS) interlaboratory comparisons of critical currents [1]. That experiment showed that the variability in the measurement could be significantly reduced by adopting a standardized system. Due to the scale of the ITER project, the test procedure must be scalable so that a large number of samples can be accommodated. This has to be balanced with high data reliability which can be achieved with the no-transfer method and Ti alloy mandrel described here. We think that the approach presented here is viable for ITER.

3. Control the tension of the conductor before reaction and before measurement. A standard tension will aid in reducing the variability of the measurement between laboratories. This is expected to be the case for all types of reaction and measurement mandrel materials unless a rigid bonding material is used. Rigid bonding materials for measurement mandrels, such as solder or epoxy, have other negative side effects. A paper on the effects of conductor tension on the measurement mandrel is included as Appendix B.

4. Use standardized reporting sheets (see Section 6). The experimenter can use these sheets to document the conditions under which the $I_{c}$ measurements were made.

5. Avoid soldering more than about 0.8 turn of the specimen onto the current contact. A multiple-turn contact can carry a current induced by a changing background magnetic field. This current will oppose the change in the background magnetic field. This current will decay slowly with time, creating a time-varying magnetic field on the sample; this leads to time dependent $I_{c}$ measurements. 
6. Avoid making $I_{c}$ measurements with the Lorentz force directed outward, since this can strain the specimen and alter subsequent measurements. If measurements with the Lorentz force directed outward are useful for diagnostic purposes, they should be done after all measurements with the Lorentz force directed inward are completed.

7. Instrument the sample with a pair of voltage taps spanning the entire length of the sample and the current contacts. The pressure current contact in this design should also be included between these voltage taps. A single measurement of the voltage-current characteristic of this tap pair will contain information on the contact resistance and performance of the entire sample length. This information will indicate the total amount of sample heating and possible limiting sections of the sample that are outside the main voltage tap pair. Likewise, multiple voltage tap pairs along the sample can be useful to indicate the local homogeneity of the specimen.

\subsection{Reference}

[1] Wada, H.; Itoh, K. Cryogenics 32 ICMC Supplement. p.557; 1992. 
Table 1-1. Summary of critical current measurements on $\mathrm{Nb}_{3} \mathrm{Sn}$ strand.

Sample W: $10 \mu \mathrm{V} / \mathrm{m}, 12 \mathrm{~T}$

\begin{tabular}{||c|c|c|c|c|c|c|c|c|c|c||}
\hline Lab & \multicolumn{2}{|c|}{$\begin{array}{c}\text { Specimen } \\
\text { number }\end{array}$} & \multicolumn{2}{|c|}{$\begin{array}{c}\text { Raw critical } \\
\text { current (A) }\end{array}$} & \multicolumn{2}{c|}{$\begin{array}{c}\text { Temperature } \\
(K)\end{array}$} & \multicolumn{2}{c|}{$\begin{array}{c}\text { Critical } \\
\text { current (A) } \\
@ 4.20 \mathrm{~K}^{\mathrm{a}}\end{array}$} & \multicolumn{2}{|c|}{ n-value } \\
\hline A & W 2-5 & W 4-6 & 72.8 & 120.4 & $4.23-4.24$ & 73.29 & 121.22 & 9.1 & 28.6 \\
\hline B & W 2-3 & W 4-4 & 119 & $\begin{array}{c}154 \\
(125)^{\mathrm{b}}\end{array}$ & 4.229 & $\begin{array}{c}4.229 \\
(4.205)\end{array}$ & 119.67 & $\begin{array}{c}154.87 \\
(125.12)\end{array}$ & 32 & $\begin{array}{l}17 \\
(59)\end{array}$ \\
\hline C & W 2-2 & W 4-1 & 115.67 & 117.15 & 4.200 & 4.200 & 115.67 & 117.15 & 30.1 & 30.4 \\
\hline D & W 2-6 & W 4-2 & 116.5 & 118 & 4.200 & 4.200 & 116.5 & 118 & 21 & 28 \\
\hline E & W 2-1 & W 4-3 & 110 & 116 & 4.187 & 4.187 & 109.45 & 115.71 & 32 & 30 \\
\hline F & W 2-4 & W 4-5 & 120.4 & 120.9 & 4.213 & 4.224 & 120.70 & 121.46 & 30.0 & 29.3 \\
\hline Aver. & & & & & & & $118.24^{\mathrm{b}, \mathrm{c}}$ & $29.14^{\mathrm{b}, \mathrm{c}}$ \\
\hline
\end{tabular}

${ }^{a} \mathrm{~T}_{\mathrm{c}}{ }^{*}$ used for correction was $9.39 \mathrm{~K}$.

b Sample was remeasured and the second value (125.12 A) was used to compute the average value.

${ }^{c}$ Averages do not include Lab A's measurement of W 2-5, or Lab B's n-values for W 4-4.

Table 1-2. Summary of critical current measurements on $\mathrm{Nb}_{3} \mathrm{Sn}$ strand.

Sample $\mathbf{X}: 10 \mu \mathrm{V} / \mathrm{m}, 12 \mathrm{~T}$

\begin{tabular}{|c|c|c|c|c|c|c|c|c|c|c|}
\hline Lab & \multicolumn{2}{|c|}{$\begin{array}{c}\text { Specimen } \\
\text { number }\end{array}$} & \multicolumn{2}{|c|}{$\begin{array}{l}\text { Raw critical } \\
\text { current (A) }\end{array}$} & \multirow{2}{*}{\multicolumn{2}{|c|}{$\begin{array}{c}\begin{array}{c}\text { Temperature } \\
\text { (K) }\end{array} \\
4.23-4.24 \\
\end{array}$}} & \multicolumn{2}{|c|}{$\begin{array}{c}\text { Critical } \\
\text { current(A) } \\
@ 4.20 \mathrm{~K}^{\mathrm{a}} \\
\end{array}$} & \multicolumn{2}{|c|}{ n-value } \\
\hline $\mathrm{A}$ & $\times 2-5$ & $\times 4-3$ & 212.3 & 202.7 & & & 213.47 & 203.82 & 27.0 & 25.9 \\
\hline $\mathrm{B}$ & $\times 2-2$ & $\times 4-6$ & 208 & 207 & 4.205 & 4.205 & 208.16 & 207.16 & 28 & 26 \\
\hline $\mathrm{F}$ & $\times 2-3$ & X 4-5 & 210.40 & 215.08 & 4.200 & 4.200 & 210.40 & 215.08 & 28.3 & 28.9 \\
\hline D & X 2-4 & X 4-4 & 222 & 223 & 4.200 & 4.200 & 222 & 223 & 36 & 29 \\
\hline $\mathrm{F}$ & $\times 2-6$ & $\times 4-2$ & 213 & 213 & 4.187 & 4.187 & 212.57 & 212.57 & 32 & 31 \\
\hline $\mathrm{F}$ & X 2-1 & X 4-4 & 205.0 & 229.1 & 4.216 & 4.220 & 205.52 & 229.82 & 26.6 & 27.3 \\
\hline Aver. & & & & & & & 213 & & & .83 \\
\hline
\end{tabular}

${ }^{a} \mathrm{~T}_{\mathrm{c}}$ * used for correction was $10.57 \mathrm{~K}$. 
Table 1-3. Summary of critical current measurements on $\mathrm{Nb}_{3} \mathrm{Sn}$ strand.

Sample Y: $10 \mu \mathrm{V} / \mathrm{m}, 12 \mathrm{~T}$

\begin{tabular}{|c|c|c|c|c|c|c|c|c|c|c|}
\hline Lab & \multicolumn{2}{|c|}{$\begin{array}{c}\text { Specimen } \\
\text { number }\end{array}$} & \multicolumn{2}{|c|}{$\begin{array}{l}\text { Raw critical } \\
\text { current (A) }\end{array}$} & \multicolumn{2}{|c|}{$\begin{array}{l}\text { Temperature } \\
\text { (K) }\end{array}$} & \multicolumn{2}{|c|}{$\begin{array}{c}\text { Critical } \\
\text { current (A) } \\
@ 4.20 \mathrm{~K}^{\mathrm{a}} \\
\end{array}$} & \multicolumn{2}{|c|}{ n-value } \\
\hline $\mathrm{A}$ & Y $2-6$ & Y 4-2 & 141.7 & 145.8 & 4.23 & 4.24 & 142.70 & 146.83 & 29.2 & 30.2 \\
\hline B & Y $2-3$ & Y 4-1 & 135 & 142 & 4.229 & 4.229 & 135.79 & 142.83 & 27 & 24 \\
\hline $\mathrm{C}$ & Y $2-2$ & Y 4-6 & 138.08 & 136.03 & 4.200 & 4.200 & 138.08 & 136.03 & 28.9 & 29.1 \\
\hline D & Y 2-1 & Y $4-3$ & 156.5 & 141.5 & 4.200 & 4.200 & 156.5 & 141.5 & 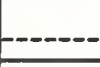 & 24.4 \\
\hline E & Y 2-4 & Y 4-5 & 136 & 139 & 4.187 & 4.187 & 135.72 & 138.72 & 30 & 27 \\
\hline E & Y $2-5$ & Y 4-4 & 137.0 & 136.7 & 4.224 & 4.226 & 137.66 & 137.42 & 29.5 & 27.6 \\
\hline Aver. & & & & & & & 140 & & & .90 \\
\hline
\end{tabular}

${ }^{\mathrm{a}} \mathrm{T}_{\mathrm{c}}$ * used for correction was $9.18 \mathrm{~K}$.

Table 1-4. Summary of critical current measurements on $\mathrm{Nb}_{3} \mathrm{Sn}$ strand.

Sample Z: $10 \mu \mathrm{V} / \mathrm{m}, 12 \mathrm{~T}$

\begin{tabular}{|c|c|c|c|c|c|c|c|c|c|c|}
\hline Lab & \multicolumn{2}{|c|}{$\begin{array}{l}\text { Specimen } \\
\text { number }\end{array}$} & \multicolumn{2}{|c|}{$\begin{array}{l}\text { Raw critical } \\
\text { current (A) }\end{array}$} & \multicolumn{2}{|c|}{$\begin{array}{c}\text { Temperature } \\
\text { (K) }\end{array}$} & \multicolumn{2}{|c|}{$\begin{array}{c}\text { Critical } \\
\text { current (A) } \\
\text { @ } 4.20 \mathrm{~K}^{\mathrm{a}}\end{array}$} & \multicolumn{2}{|c|}{ n-value } \\
\hline $\mathrm{A}$ & Z 2-4 & Z 4-5 & 83.3 & 83.9 & 4.23 & 4.24 & 83.70 & 84.31 & 14.0 & 14.1 \\
\hline B & Z 2-5 & Z 4-3 & 83 & 84 & 4.205 & 4.205 & 83.06 & 84.06 & 14 & 15 \\
\hline $\mathrm{C}$ & Z 2-6 & Z 4-1 & 83.69 & 84.35 & 4.200 & 4.200 & 83.69 & 84.35 & 14.2 & 14.2 \\
\hline D & Z 2-3 & Z 4-2 & 88.25 & 87.75 & 4.200 & 4.200 & 88.25 & 87.75 & 15.7 & 15 \\
\hline E & Z 2-1 & Z 4-6 & 82 & 79 & 4.187 & 4.187 & 81.85 & 78.86 & 17 & 16 \\
\hline $\mathrm{F}$ & Z 2-2 & Z 4-3 & 83.6 & 84.8 & 4.222 & 4.220 & 83.85 & 85.03 & 17.0 & 17.1 \\
\hline Aver. & & & & & & & & & & .28 \\
\hline
\end{tabular}

${ }^{a} \mathrm{~T}_{\mathrm{c}}$ * used for correction was $11.48 \mathrm{~K}$. 
Table 1-5. Summary statistics for each sample measured by six laboratories at $4.2 \mathrm{~K}$ and $12 \mathrm{~T}$.

\begin{tabular}{||c|r|r|r|r|}
\hline & Sample W & Sample X & Sample Y & Sample Z \\
\hline \hline$I_{c}$ average (A) & 118.24 & 213.63 & 140.82 & 84.06 \\
\hline $\begin{array}{c}I_{c} \text { standard deviation } \\
(A)\end{array}$ & 4.11 & 7.80 & 6.01 & 2.44 \\
\hline $\begin{array}{c}I_{c} \text { coefficient of } \\
\text { variation (\%) }\end{array}$ & 3.48 & 3.65 & 4.27 & 2.90 \\
\hline \hline $\begin{array}{c}\text { n-value average } \\
\text { n-value standard } \\
\text { deviation }\end{array}$ & 29.14 & 28.83 & 27.90 & 15.28 \\
\hline $\begin{array}{c}\text { n-value coefficient } \\
\text { of variation (\%) }\end{array}$ & 10.74 & 10.16 & 7.63 & 1.25 \\
\hline \multicolumn{1}{|c|}{} & 3.13 & & 2.13 & 8.18 \\
\hline
\end{tabular}

Table 1-6. Statistical summary of laboratory measurements of critical currents and $\mathrm{n}$-values relative to the average value for each of the four samples at $4.2 \mathrm{~K}$ and $12 \mathrm{~T}$.

\begin{tabular}{||c|c|c|c|c|c|c||}
\hline & Lab A & Lab B & Lab C & Lab D & Lab E & Lab F \\
\hline \hline $\begin{array}{c}I_{c} \text { average } \\
\text { bias (\%) }\end{array}$ & 0.47 & -0.24 & -1.17 & 3.45 & -3.06 & 0.60 \\
\hline$I_{c}$ range (\%) & 8.86 & 9.39 & 4.08 & 12.61 & 6.93 & 11.38 \\
\hline $\begin{array}{c}\text { n-value } \\
\text { average } \\
\text { bias (\%) }\end{array}$ & -3.07 & -4.32 & -0.02 & -2.57 & 6.45 & 2.29 \\
\hline $\begin{array}{c}n-\text { value range } \\
(\%)\end{array}$ & 18.41 & 23.79 & 11.36 & 52.79 & 14.52 & 19.70 \\
\hline
\end{tabular}

Table 1-7. $I_{c}$ coefficients of variation at $4.2 \mathrm{~K}$ and $12 \mathrm{~T}$ for various laboratory subsets.

\begin{tabular}{|c|r|r|r|r||}
\hline \hline $\begin{array}{c}I_{c} \text { coefficient of } \\
\text { variation (\%) }\end{array}$ & Sample W & Sample X & Sample Y & Sample Z \\
\hline \hline Labs A,B,C,E & 4.23 & 1.79 & 2.94 & 2.24 \\
\hline Labs A,B,C,E,F & 3.84 & 3.45 & 2.67 & 2.13 \\
\hline Labs A,B,C,D,E & 3.67 & 2.86 & 4.55 & 3.19 \\
\hline Labs A,B,C,D,E,F & 3.48 & 3.65 & 4.27 & 2.90 \\
\hline
\end{tabular}


Table 1-8. Laboratory C's critical current and n-value measurements versus field and the temperature dependance of the critical current.

\begin{tabular}{|c|c|c|c|c|c|c|c|c|}
\hline \multirow[b]{2}{*}{$\mu_{0} \mathrm{H}, \mathrm{T}$} & \multicolumn{4}{|c|}{ Sample Y } & \multicolumn{4}{|c|}{ Sample X } \\
\hline & $\begin{array}{l}I_{c}, A \\
(2-2) \\
\end{array}$ & $\begin{array}{l}I_{c}, A \\
(4-1) \\
\end{array}$ & $\begin{array}{c}\mathrm{T}_{\mathrm{c}}{ }^{*}, \mathrm{~K} \\
\text { (avg) }\end{array}$ & $\begin{array}{c}\mathrm{n} @ 4.2 \mathrm{~K} \\
\text { (avg) }\end{array}$ & $\begin{array}{c}I_{c}, A \\
(2-3)\end{array}$ & $\begin{array}{c}I_{c}, A \\
(4-5) \\
\end{array}$ & $\begin{array}{c}\mathrm{T}_{\mathrm{c}}{ }^{*}, \mathrm{~K} \\
\text { (avg) }\end{array}$ & $\begin{array}{c}\text { n@4.2 K } \\
\text { (avg) }\end{array}$ \\
\hline 8 & 374.33 & 377.34 & 13.242 & 41.39 & & & & \\
\hline 7 & 308.93 & 311.32 & 12.617 & 39.79 & & & & \\
\hline 8 & 255.78 & 257.89 & 11.874 & 38.04 & 431.51 & 438.59 & 13.244 & 32.68 \\
\hline 8 & 211.78 & 213.69 & 11.295 & 36.26 & 363.18 & 369.64 & 12.589 & 31.66 \\
\hline 10 & 174.64 & 176.39 & 10.600 & 34.37 & 304.76 & 310.50 & 11.900 & 30.90 \\
\hline 11 & 142.95 & 144.58 & 10.020 & 32.43 & 254.30 & 259.51 & 11.217 & 29.87 \\
\hline 12 & 115.67 & 117.15 & 9.385 & 30.21 & 210.40 & 215.08 & 10.574 & 28.57 \\
\hline
\end{tabular}

\begin{tabular}{|c|c|c|c|c|c|c|c|c|}
\hline \multirow[b]{2}{*}{$\mu_{0} \mathrm{H}, \mathrm{T}$} & \multicolumn{4}{|c|}{ Sample Y } & \multicolumn{4}{|c|}{ Sample Z } \\
\hline & $\begin{array}{c}I_{c}, A \\
(2-2)\end{array}$ & $\begin{array}{c}I_{c}, A \\
(4-6) \\
\end{array}$ & $\begin{array}{c}\mathrm{T}_{\mathrm{c}}{ }^{*}, \mathrm{~K} \\
\text { (avg) }\end{array}$ & $\begin{array}{c}\mathrm{n} @ 4.2 \mathrm{~K} \\
\text { (avg) }\end{array}$ & $\begin{array}{c}I_{c}, A \\
(2-6) \\
\end{array}$ & $\begin{array}{c}I_{c}, A \\
(4-1) \\
\end{array}$ & $\begin{array}{c}\mathrm{T}_{\mathrm{c}}{ }^{*}, \mathrm{~K} \\
\text { (avg) }\end{array}$ & $\begin{array}{c}\text { n@4.2 K } \\
\text { (avg) }\end{array}$ \\
\hline 6 & 515.40 & 511.20 & 13.940 & 50.55 & 217.37 & 219.98 & 16.334 & 12.05 \\
\hline 7 & 421.33 & 417.64 & 13.080 & 46.42 & 185.05 & 187.10 & 15.595 & 12.44 \\
\hline 8 & 343.90 & 340.67 & 12.252 & 42.27 & 158.19 & 159.86 & 14.682 & 12.83 \\
\hline 9 & 279.18 & 276.30 & 11.482 & 38.77 & 135.50 & 136.82 & 13.972 & 13.20 \\
\hline 10 & 224.45 & 221.87 & 10.669 & 35.53 & 115.92 & 116.97 & 13.202 & 13.55 \\
\hline 11 & 177.84 & 175.51 & 9.881 & 32.22 & 98.80 & 99.71 & 12.436 & 13.91 \\
\hline 12 & 138.08 & 136.03 & 9.132 & 28.98 & 83.69 & 84.35 & 11.479 & 14.19 \\
\hline
\end{tabular}




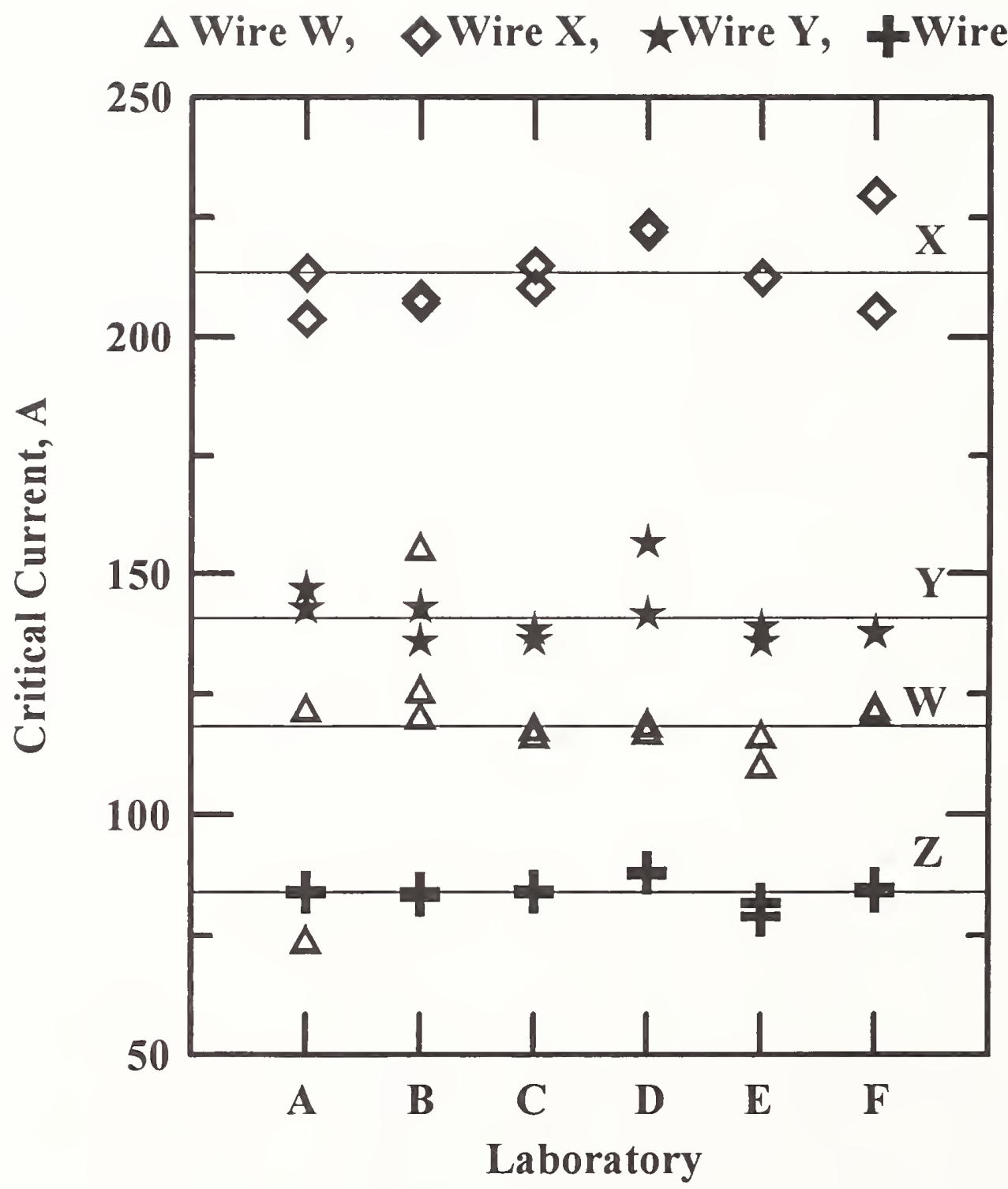

Figure 1-1. Critical current versus laboratory for each of the four samples. The horizontal lines show the average $I_{c}$ for each sample. 


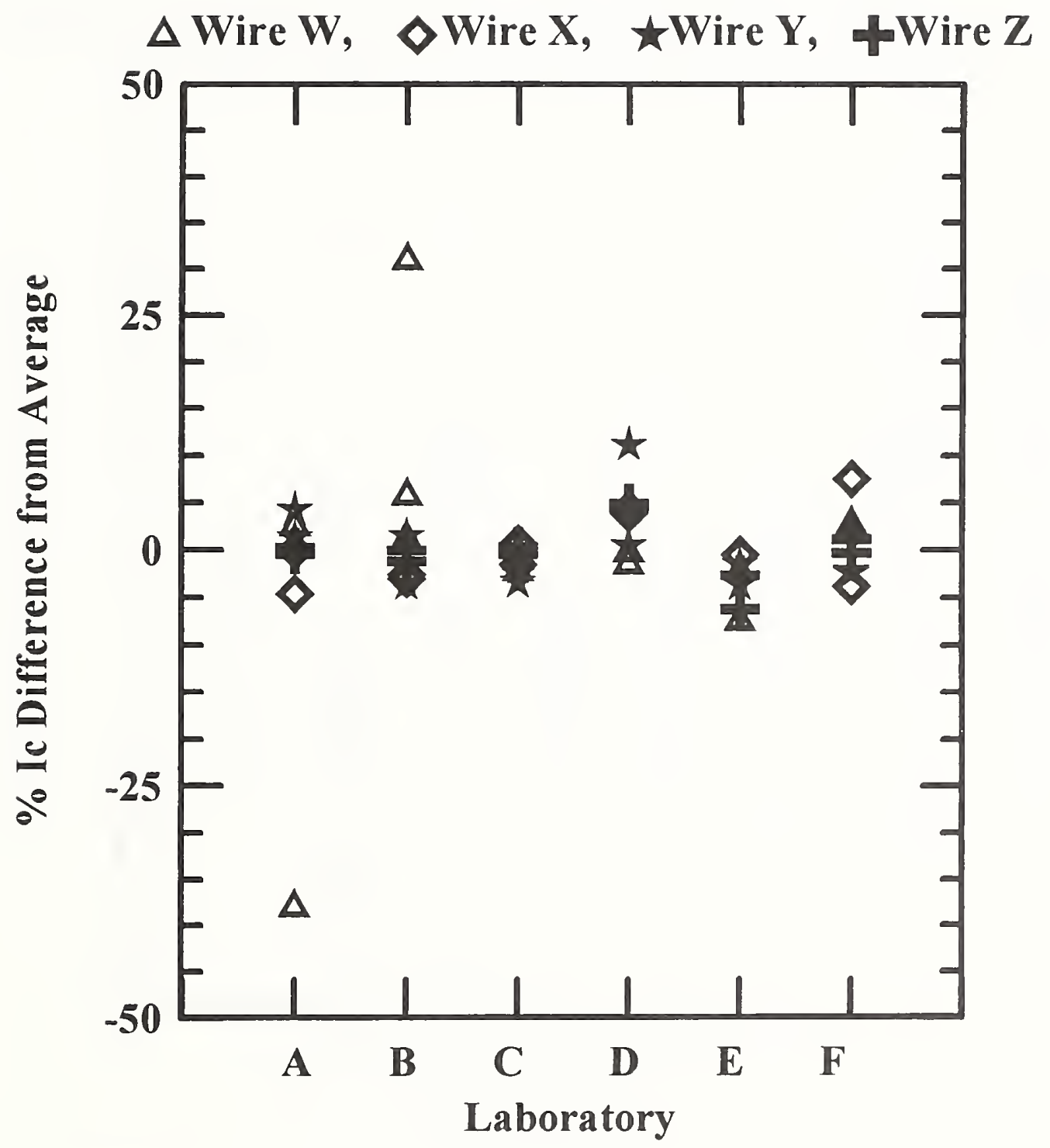

Figure 1-2. Percent difference of critical current versus laboratory for each sample measured. 


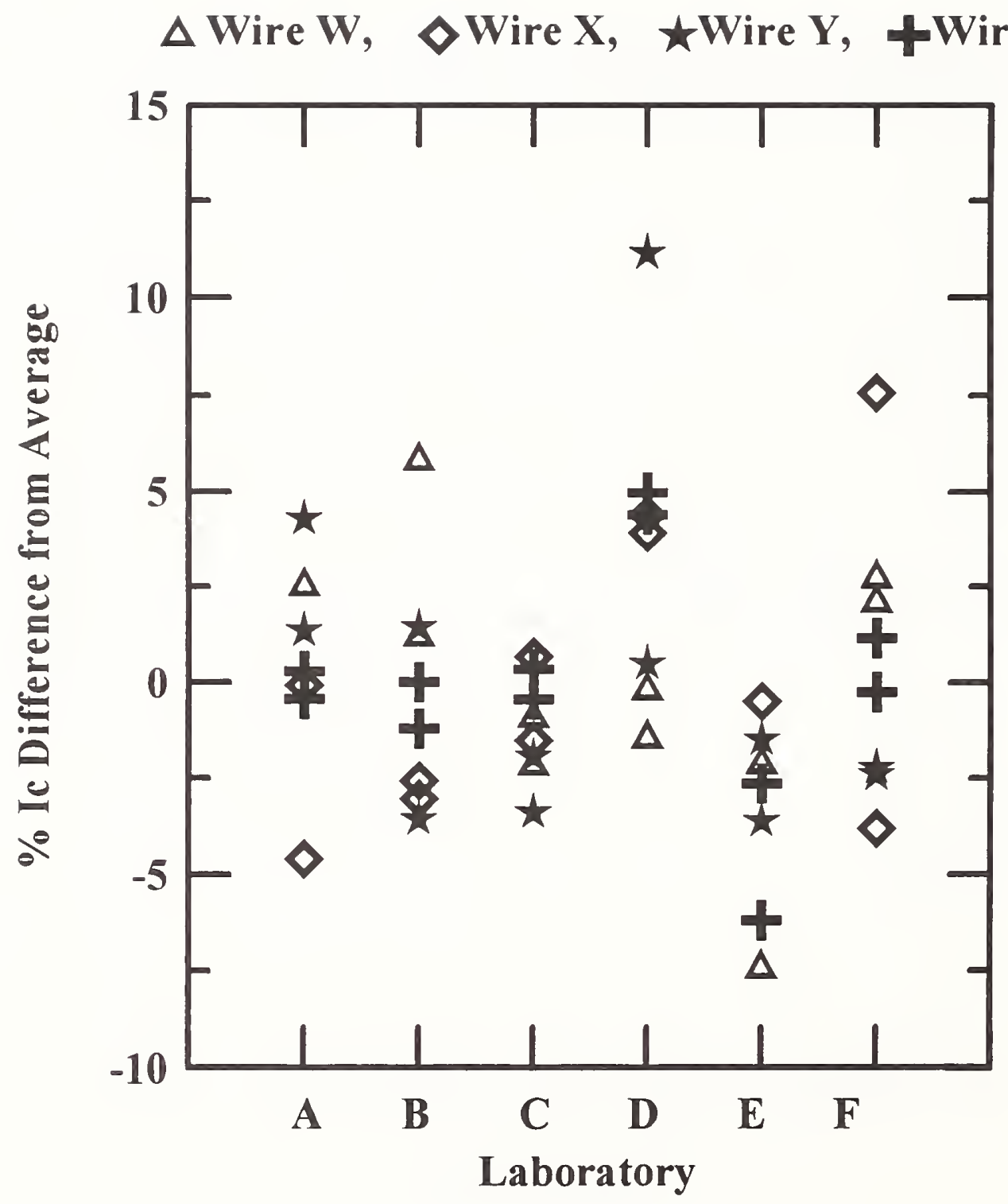

Figure 1-3. Percent difference of critical current versus laboratory for each sample measured. This plot is the same as Figure 1-2 except on a more sensitive scale excluding two outliers. 


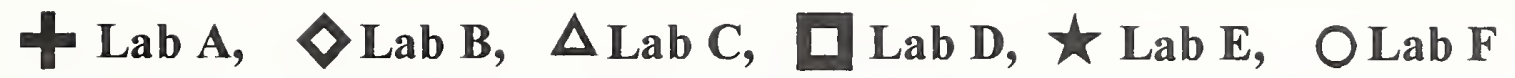

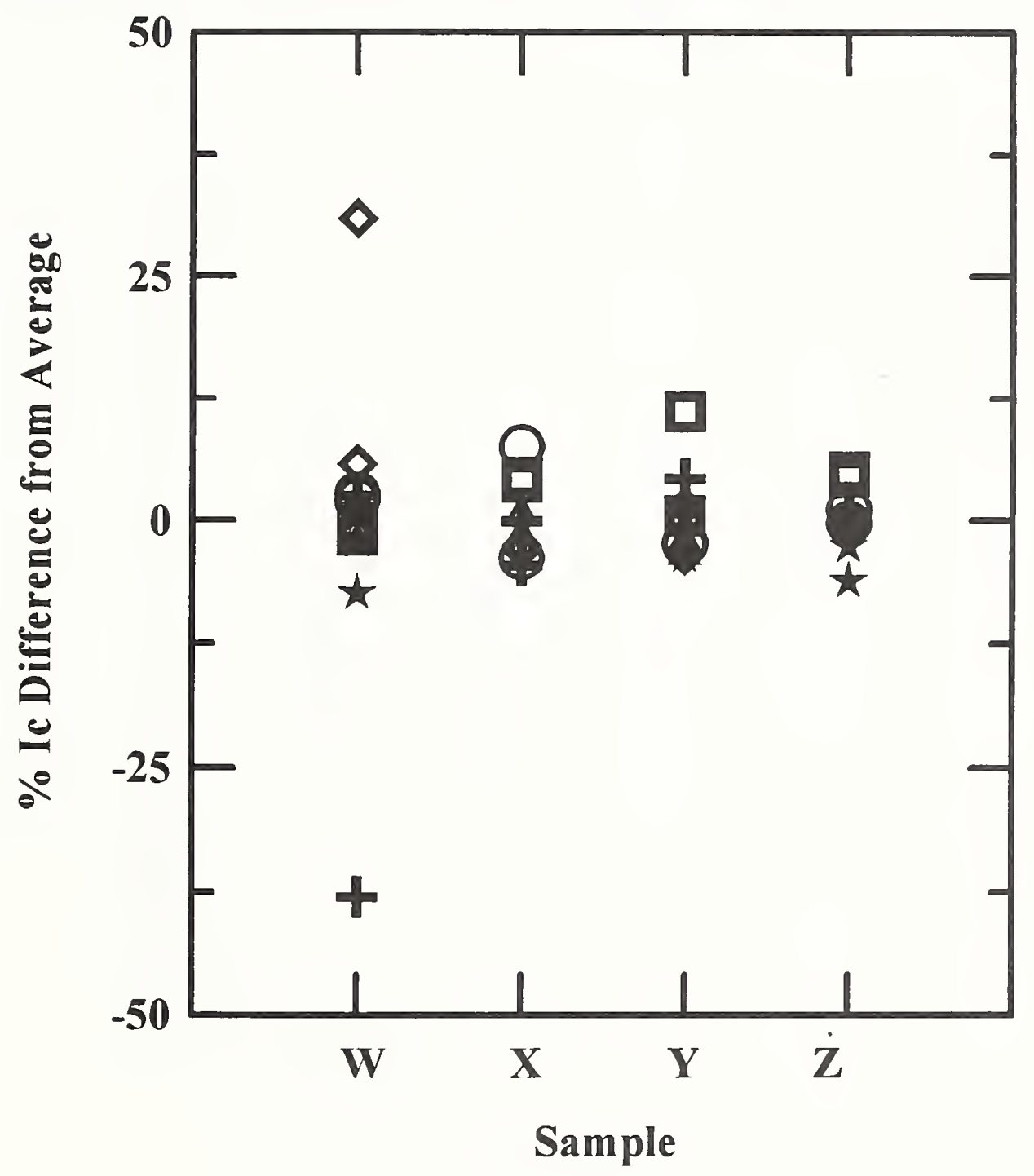

Figure 1-4. Percent difference of critical current versus sample for each laboratory. 
+ Lab A, $\nabla_{\text {Lab B, }} \Delta_{\text {Lab C, }} \quad \square$ Lab D, $\star$ Lab E, O Lab F

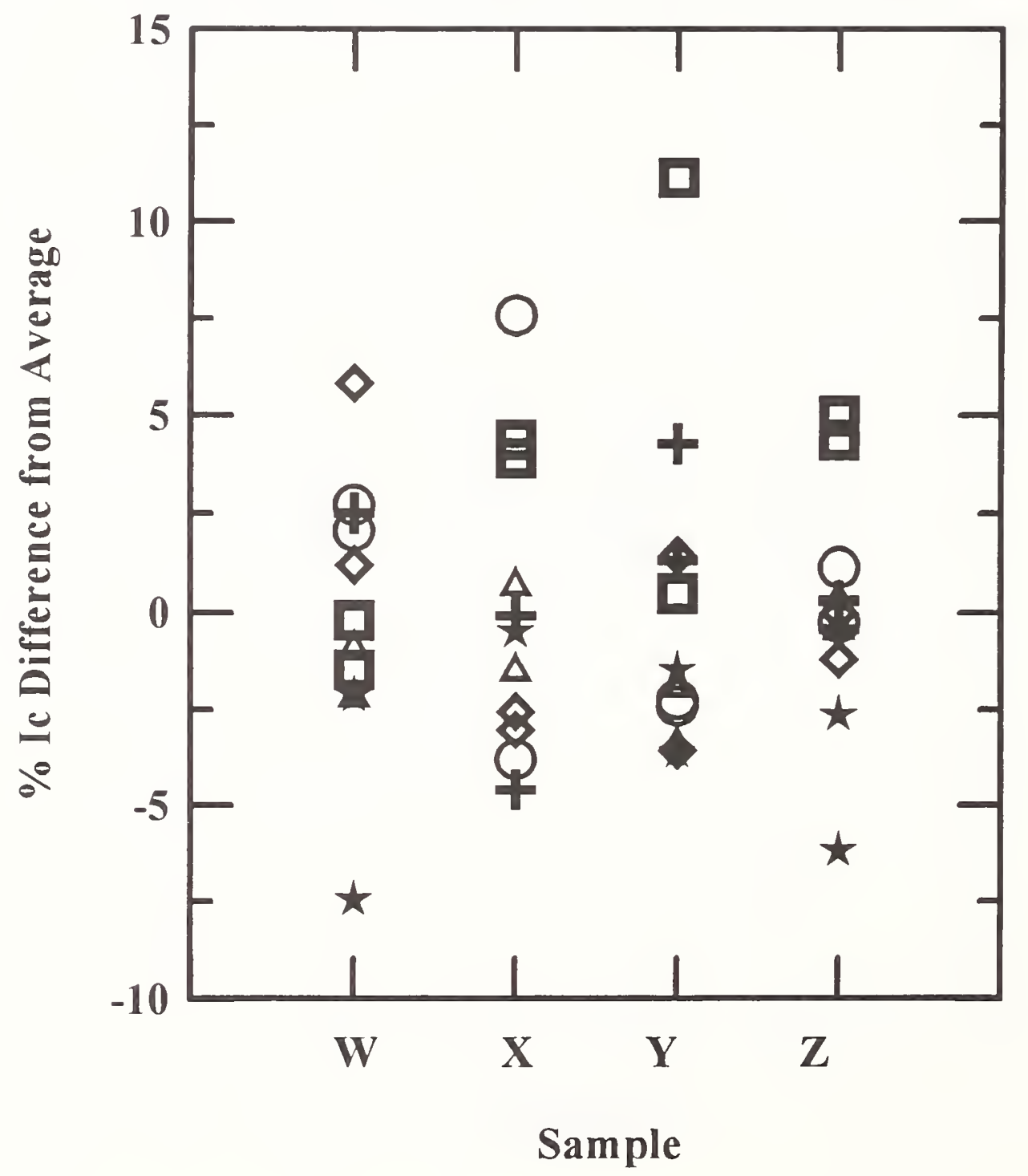

Figure 1-5. Percent difference of critical current versus sample for each laboratory. This plot is the same as Figure 1-4 except on a more sensitive scale excluding two outliers. 


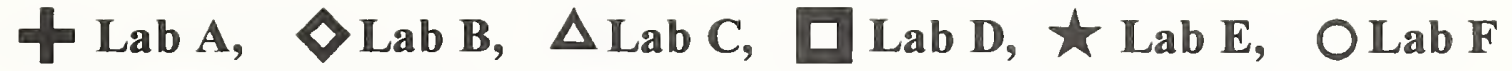

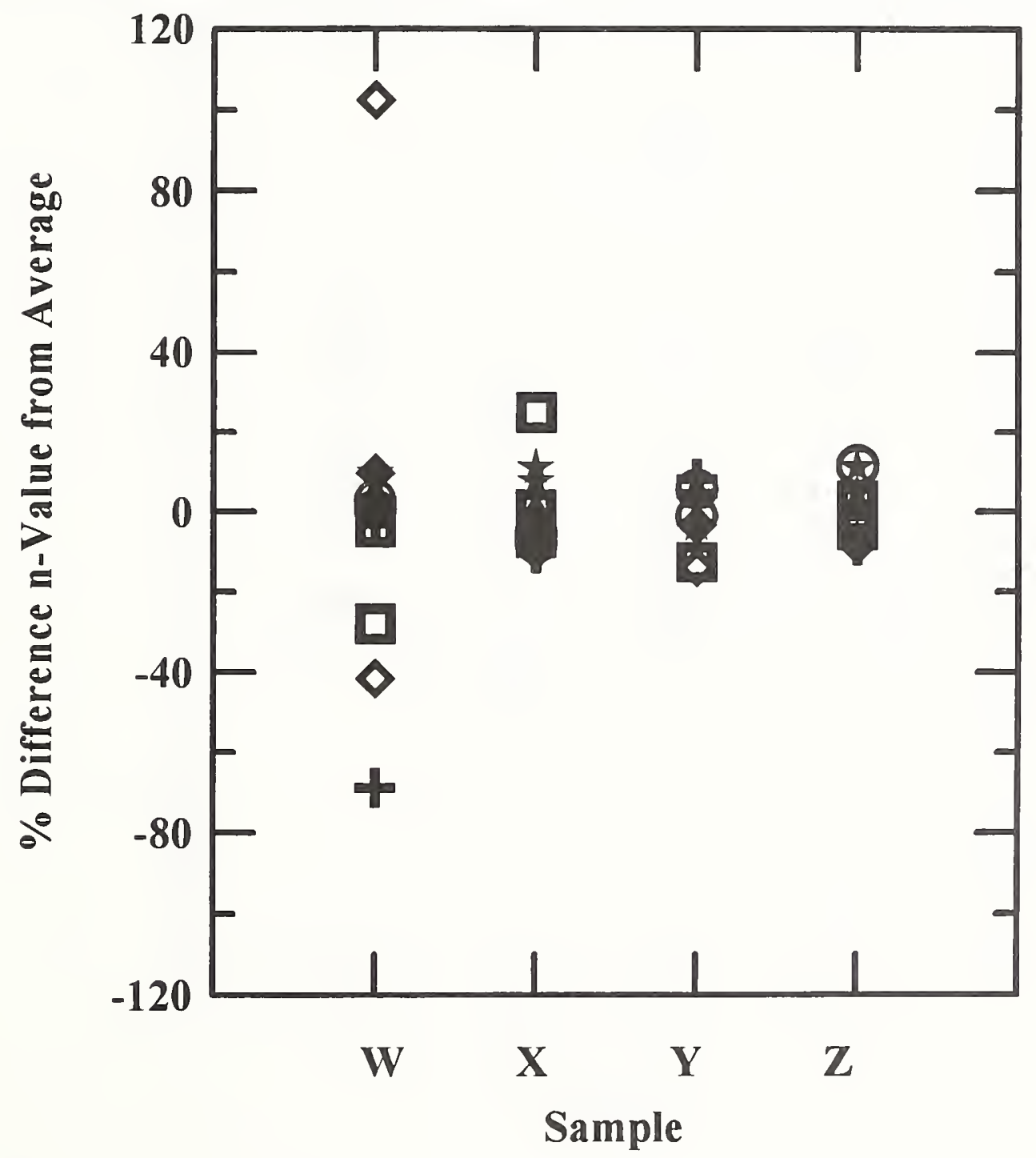

Figure 1-6. Percent difference of $n$-value versus sample for each laboratory. 


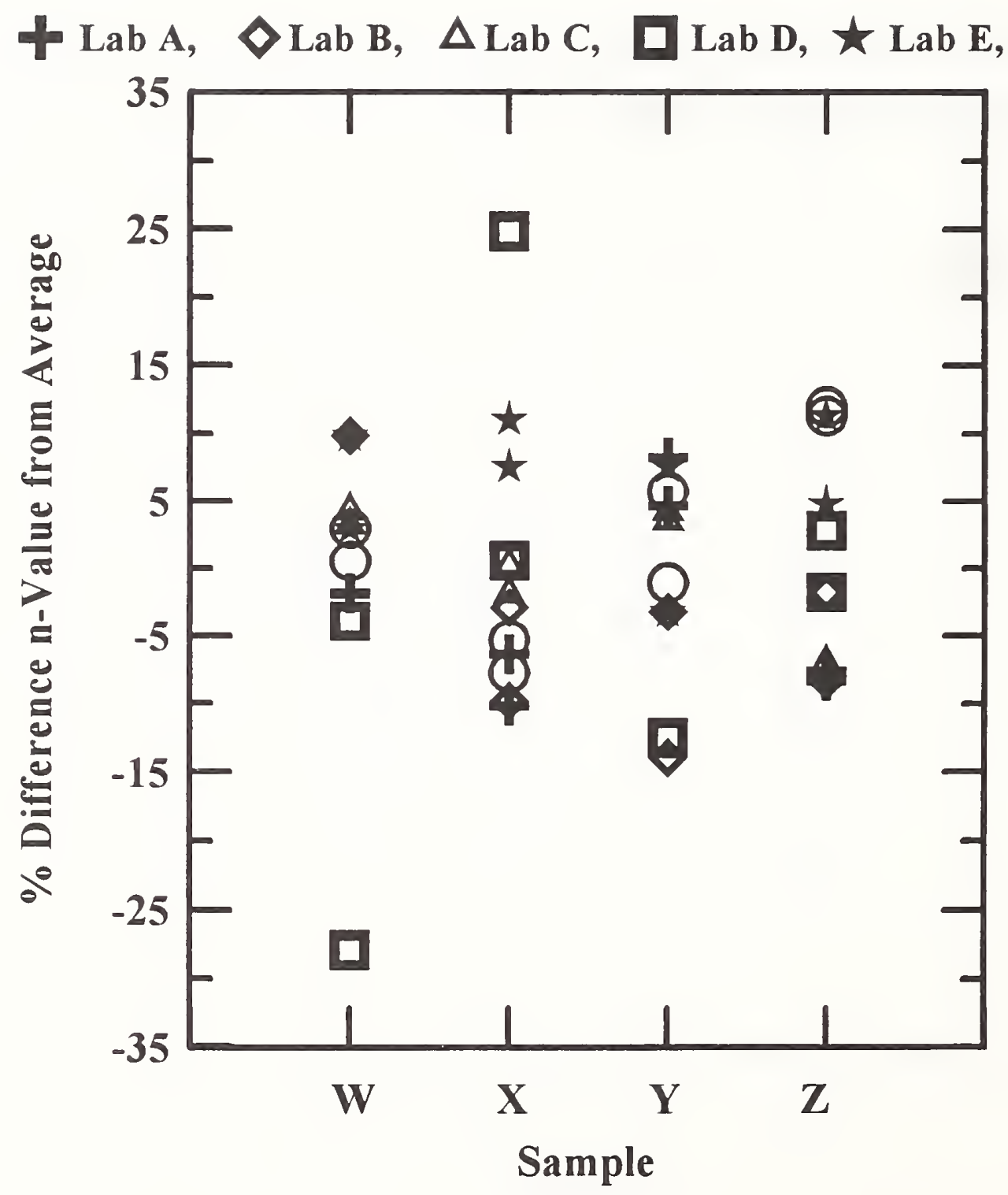

Figure 1-7. Percent difference of $n$-value versus sample for each laboratory. This plot is the same as Figure 1-6 except on a more sensitive scale excluding three outliers. 


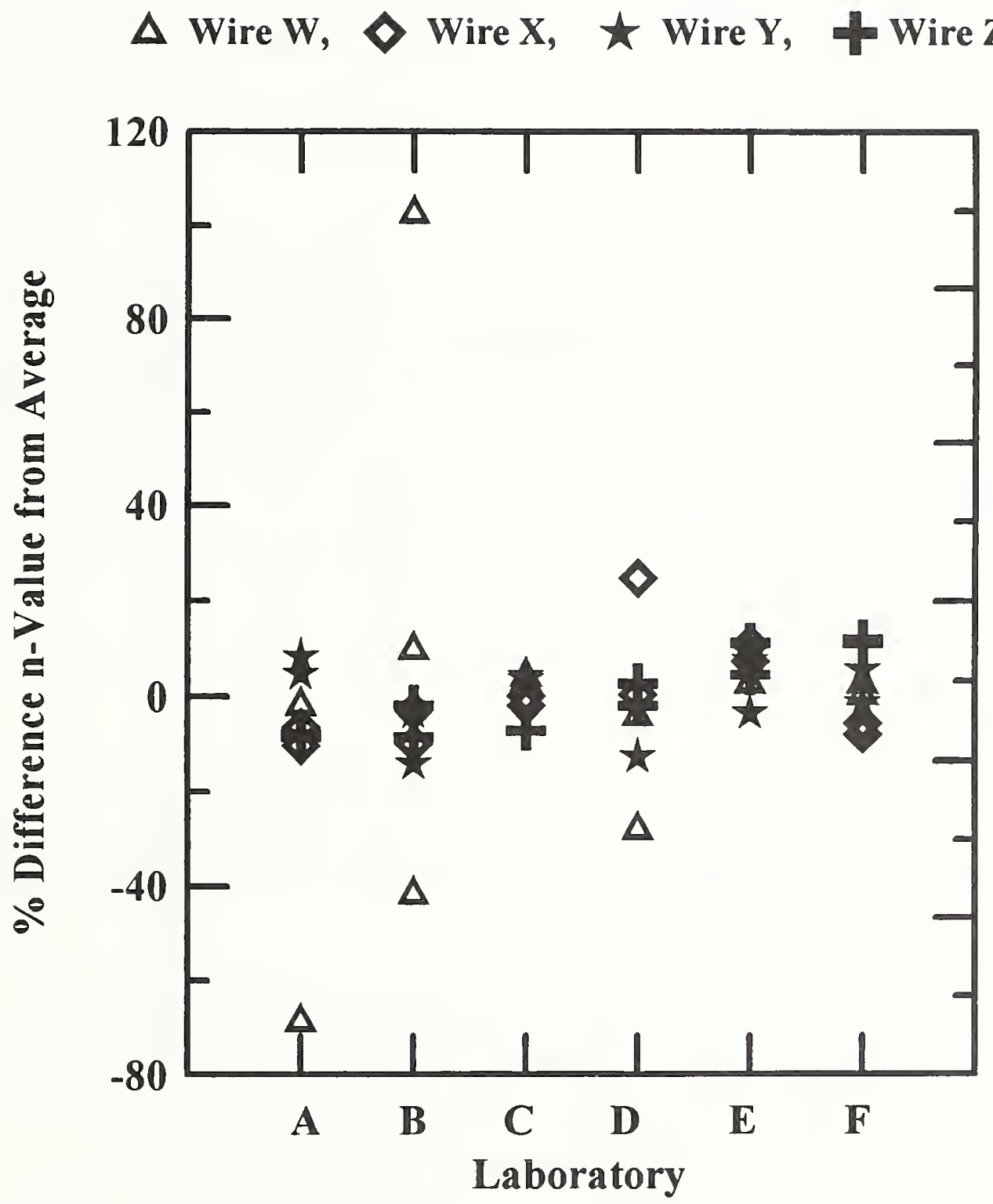

Figure 1-8. Percent difference of n-value versus laboratory for each sample measured. 


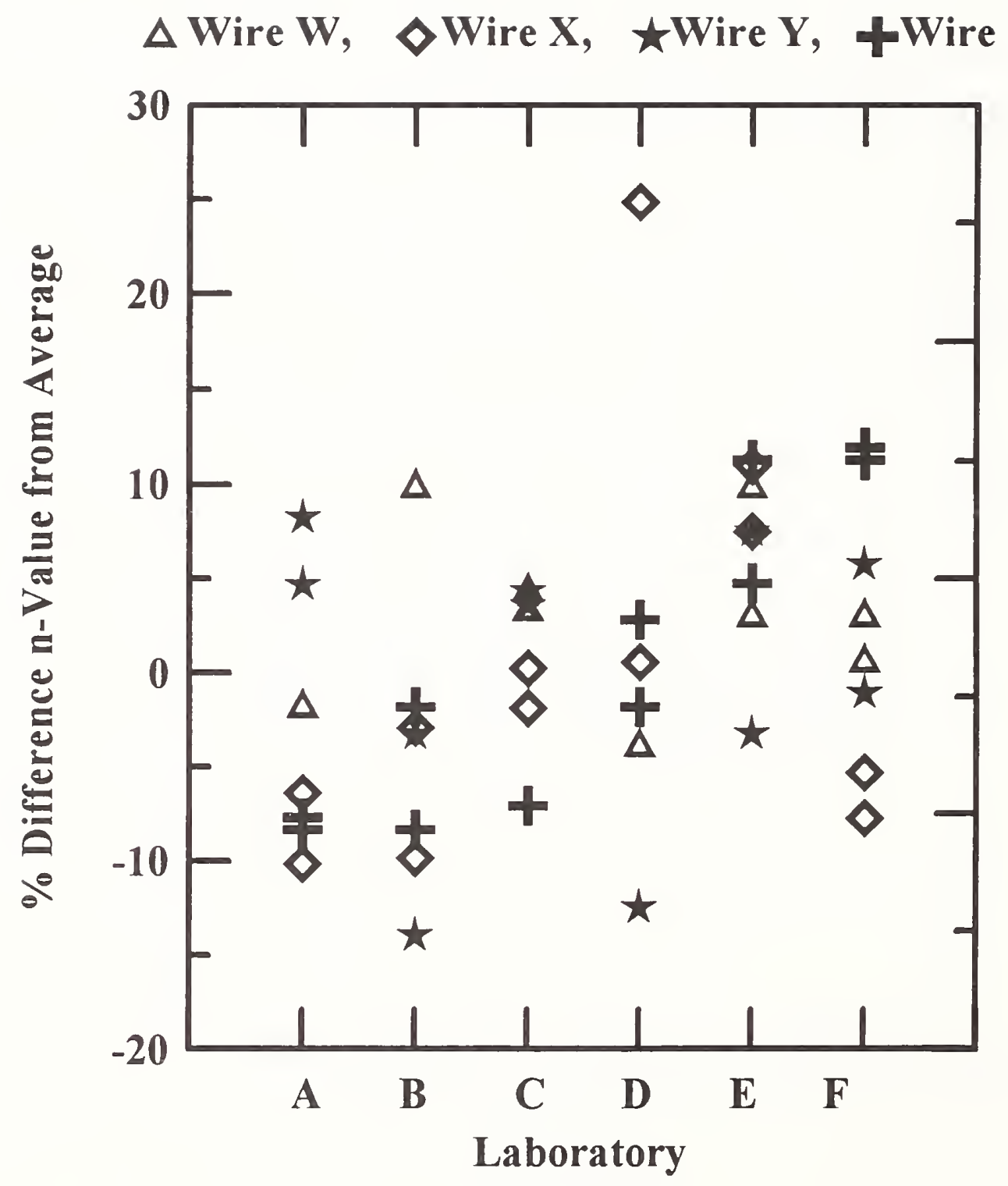

Figure 1-9. Percent difference of n-value versus laboratory for each sample measured. This plot is the same as Figure 1-8 except on a more sensitive scale excluding three outliers. 


\title{
2. COMPARISON OF CRITICAL CURRENT MEASUREMENTS FROM INTERNATIONAL LABORATORIES
}

\begin{abstract}
A second data comparison was compiled using data from five international laboratories to determine the present agreement among the international laboratories that make critical current measurements. A five laboratory subset, including one U.S. laboratory and all of the non-U.S. laboratories, was selected to represent a cross section of laboratories that did not use a standardized measurement procedure. These laboratories were labeled $C, G, H, J$, and $K$. The samples used are labeled $W, X, Y$, and $Z$. This is a brief presentation of these results.
\end{abstract}

\subsection{Introduction}

The analytical approach to comparing the results among these five laboratories was similar to the previous approach used for the six U.S. laboratories. Each laboratory contributed data for critical current and n-value measurements for each of four samples, labeled W, X, Y, and Z (Laboratory G did not measure Sample X and Laboratory H measured only Sample W). Because some of the laboratories contributed different numbers of measurements for each sample, a weighted average was calculated with equal weight given to each laboratory. Each laboratory's data was averaged for each sample, and these laboratory averages were used to compute an overall average for each sample which we define as the weighted average. The statistics shown in Tables II-1 to II-3 and Figures 2-1 to 2-5 are relative to this weighted average.

\subsection{Experimental Results}

Table 2-1 is a summary of each of the five laboratories' measurements of critical current and nvalues for each of four samples at $10 \mu \mathrm{V} / \mathrm{m}, 12 \mathrm{~T}$, and $4.2 \mathrm{~K}$. The weighted average for $\mathrm{I}_{c}$ and $\mathrm{n}$-value for each sample is given at the bottom of the table. Figure 2-1 illustrates the critical current measurements from each laboratory for each sample; the weighted average is shown by a horizontal line.

Table 2-2 gives the statistical summary of $I_{c}$ and $n$-value measurements for each sample using data from all five international laboratories. The coefficient of variation is the standard deviation divided by the weighted average, expressed in percent. The statistics for Sample W used 8 measurements, Sample X used 6 measurements, Sample Y used 12 measurements and Sample Z used 11 measurements. These statistics are illustrated in Figures 2-3 and 2-4. Figure 2-3 shows the percent difference of the measured critical current for each laboratory from the overall weighted average for each sample, as a function of sample. Figure 2-4 shows the percent difference in a similar manner for the n-values of each sample. 
Table 2-3 shows measurement statistics for each laboratory that participated in the intercomparison. These measurement statistics are relative to the weighted average value for each of the four samples. For this table, the percentage differences between the results of a laboratory's measurements on a given sample and the overall average for that sample are calculated. The range of these percent differences in $I_{c}$ for all samples is shown in the row of the table labeled $I_{c}$ Range (\%). The average of these percent differences for a given laboratory and all samples is shown in the row of the table labeled $I_{c}$ Average Bias (\%). These measurement statistics are best illustrated in Figure 2-2. This figure shows the variation in $I_{c}$ measurements made by a given laboratory for each sample. Thus, the average bias of $I_{c}$ indicates the average position of a laboratory's results relative to the overall weighted averages and the $I_{c}$ range indicated the variability of a laboratory's results for two specimens of each of four samples. The statistics on the n-value measurements were done in the same way and are illustrated in Figure 2-5. This analysis was used to attempt to quantify the results from each laboratory and it is not an independent evaluation because the overall weighted averages were used.

\subsection{Discussion}

It is informative to contrast the results from this international comparison to the comparison among U.S. laboratories. The average critical current values in the international comparison were lower than the U.S. laboratory comparison for all four samples. The coefficient of variations for the international comparison ranged from $9.6 \%$ to $14.2 \%$ compared to $2.9 \%$ to $4.3 \%$ for the U.S. laboratories. Also, the biases for each international laboratory were more pronounced than for the U.S. laboratories. The lack of a standard measurement mandrel material for all laboratories may have caused this increase in variation and bias. Another factor affecting variability may be that some laboratories transferred samples between reaction and measurement mandrels. 
Table 2-1. International laboratories and one U.S. laboratory: Summary of critical current and $\mathrm{n}$-value measurements on $\mathrm{Nb}_{3}$ Sn strand: $10 \mu \mathrm{V} / \mathrm{m}, 12 \mathrm{~T}$, and $4.2 \mathrm{~K}$.

\begin{tabular}{|c|c|c|c|c|c|c|c|c|}
\hline \multirow[t]{2}{*}{ Laboratory } & \multicolumn{2}{|c|}{ Wire W } & \multicolumn{2}{|c|}{ Wire $\mathrm{X}$} & \multicolumn{2}{|c|}{ Wire Y } & \multirow{2}{*}{\multicolumn{2}{|c|}{$\begin{array}{c}\text { Wire } \mathbf{Z} \\
\mathrm{I}_{c} \text { (A) n-value }\end{array}$}} \\
\hline & $\mathrm{I}_{c}(\mathrm{~A})$ & n-value & $I_{c}(A)$ & n-value & $I_{c}(A)$ & $\mathrm{n}$-value & & \\
\hline C & 117 & $\begin{array}{l}32 \\
32\end{array}$ & 210 & 29 & $\begin{array}{l}138 \\
136\end{array}$ & $\begin{array}{l}29 \\
20\end{array}$ & 84 & 11 \\
\hline G & $\begin{array}{l}95 \\
97\end{array}$ & $\begin{array}{l}27 \\
24\end{array}$ & & & $\begin{array}{l}105 \\
110 \\
106 \\
115 \\
120\end{array}$ & $\begin{array}{l}25 \\
26 \\
26 \\
31 \\
28\end{array}$ & $\begin{array}{l}86 \\
72 \\
77 \\
67 \\
68 \\
67\end{array}$ & $\begin{array}{l}26 \\
12 \\
20 \\
12 \\
12 \\
13\end{array}$ \\
\hline $\mathrm{H}$ & 110 & 37 & & & & & & \\
\hline $\mathrm{J}$ & 102 & 30 & 174 & 28 & 123 & 25 & 70 & 17 \\
\hline K & $\begin{array}{l}126 \\
127\end{array}$ & $\begin{array}{l}24 \\
26\end{array}$ & $\begin{array}{l}233 \\
232 \\
241\end{array}$ & $\begin{array}{l}33 \\
31 \\
31\end{array}$ & $\begin{array}{l}151 \\
151 \\
150 \\
150\end{array}$ & $\begin{array}{l}33 \\
32 \\
35 \\
34\end{array}$ & $\begin{array}{l}79 \\
80\end{array}$ & $\begin{array}{l}11 \\
12\end{array}$ \\
\hline $\begin{array}{l}\text { Weighted } \\
\text { average }\end{array}$ & 110.20 & 29.90 & 207.28 & 29.56 & 130.43 & 28.68 & 76.58 & 13.83 \\
\hline
\end{tabular}


Table 2-2. International laboratories and one U.S. laboratory: Summary statistics for each sample measured at $4.2 \mathrm{~K}$ and $12 \mathrm{~T}$.

\begin{tabular}{||c|c|c|c|c||}
\hline & Sample W & Sample X & Sample Y & Sample Z \\
\hline$I_{c}$ average (A) & 110.20 & 207.28 & 130.43 & 76.58 \\
\hline $\begin{array}{c}I_{c} \text { standard deviation } \\
\text { (A) }\end{array}$ & 12.5 & 26.8 & 18.5 & 7.3 \\
\hline $\begin{array}{c}I_{c} \text { coefficient of } \\
\text { variation (\%) }\end{array}$ & 11.3 & 12.9 & 14.2 & 9.6 \\
\hline \hline n-value average & 29.90 & 29.56 & 28.68 & 13.83 \\
\hline $\begin{array}{c}\text { n-value standard } \\
\text { deviation }\end{array}$ & 4.7 & 2.0 & 3.6 & 4.8 \\
\hline $\begin{array}{c}\text { n-value coefficient } \\
\text { of variation (\%) }\end{array}$ & 15.6 & 6.6 & 12.7 & 35.0 \\
\hline \hline
\end{tabular}

Table 2-3. International laboratories and one U.S. laboratory: Statistical summary of laboratory measurements of critical current and $n$-value at $4.2 \mathrm{~K}$ and $12 \mathrm{~T}$.

\begin{tabular}{||c|r|r|r|r|r||}
\hline \hline & \multicolumn{1}{|c|}{ Lab C } & \multicolumn{1}{c|}{ Lab G } & \multicolumn{1}{c|}{ Lab H } & \multicolumn{1}{c|}{ Lab J } & \multicolumn{1}{c|}{ Lab K } \\
\hline \hline $\begin{array}{c}\mathrm{I}_{c_{c} \text { average }} \\
\text { bias (\%) }\end{array}$ & 5.7 & -9.9 & -0.2 & -9.4 & 12.7 \\
\hline $\mathrm{I}_{c}$ range (\%) & 11.0 & 31.8 & $0.0^{\mathrm{a}}$ & 10.4 & 13.1 \\
\hline \hline $\begin{array}{c}\text { n-value average } \\
\text { bias (\%) }\end{array}$ & -3.5 & 2.4 & 23.7 & 1.3 & 2.0 \\
\hline$n$-value range (\%) & 27.5 & 107.7 & $0.0^{\mathrm{a}}$ & 35.7 & 42.5 \\
\hline
\end{tabular}

${ }^{a} \mathrm{Lab} \mathrm{H}$ only measured one specimen of one sample therefore their range was zero. 


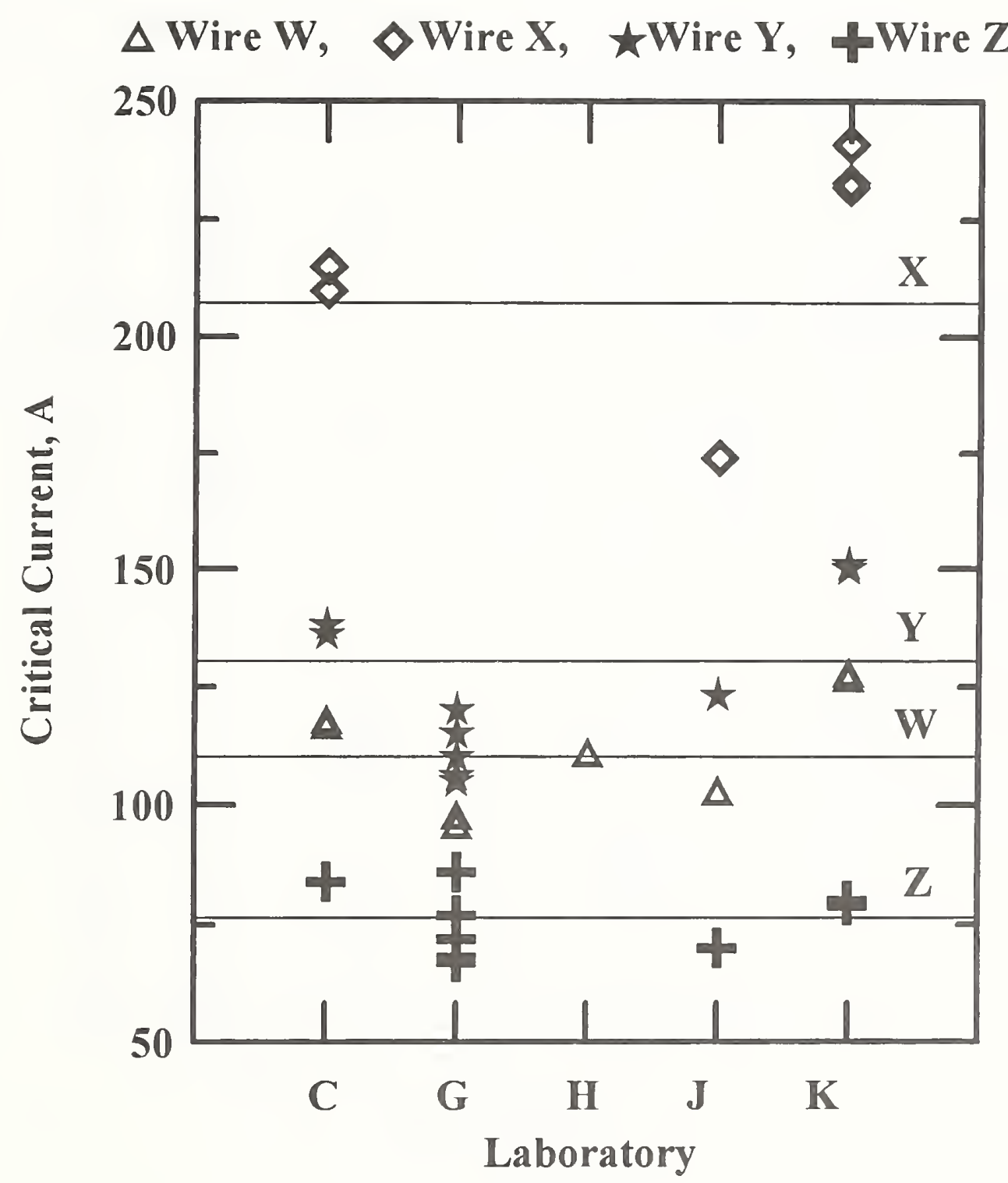

Figure 2-1. Critical current versus laboratory for each of the four samples. The horizontal lines show the weighted average $I_{c}$ for each sample. 


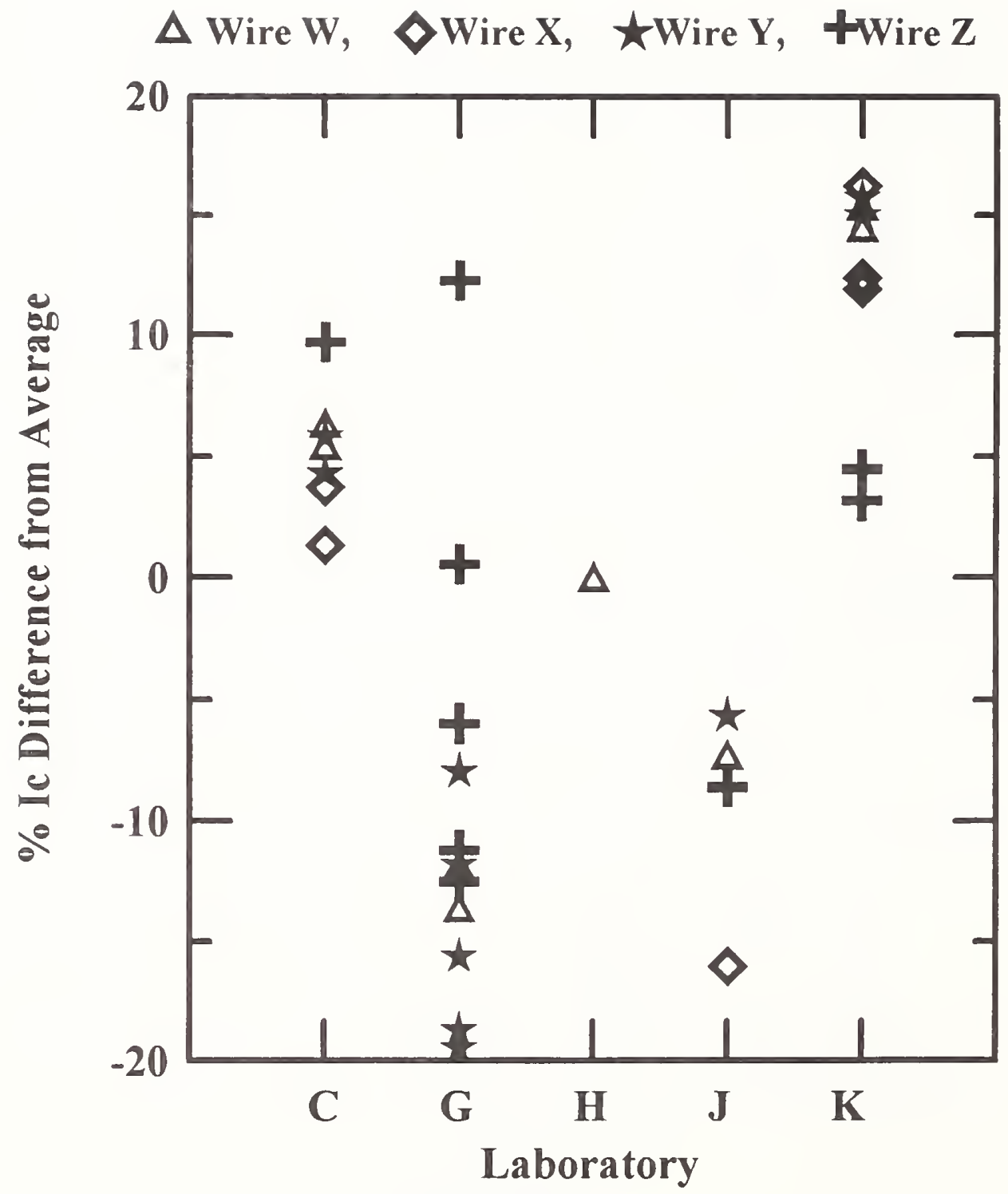

Figure 2-2. Percent difference of critical current versus laboratory for each sample measured. 


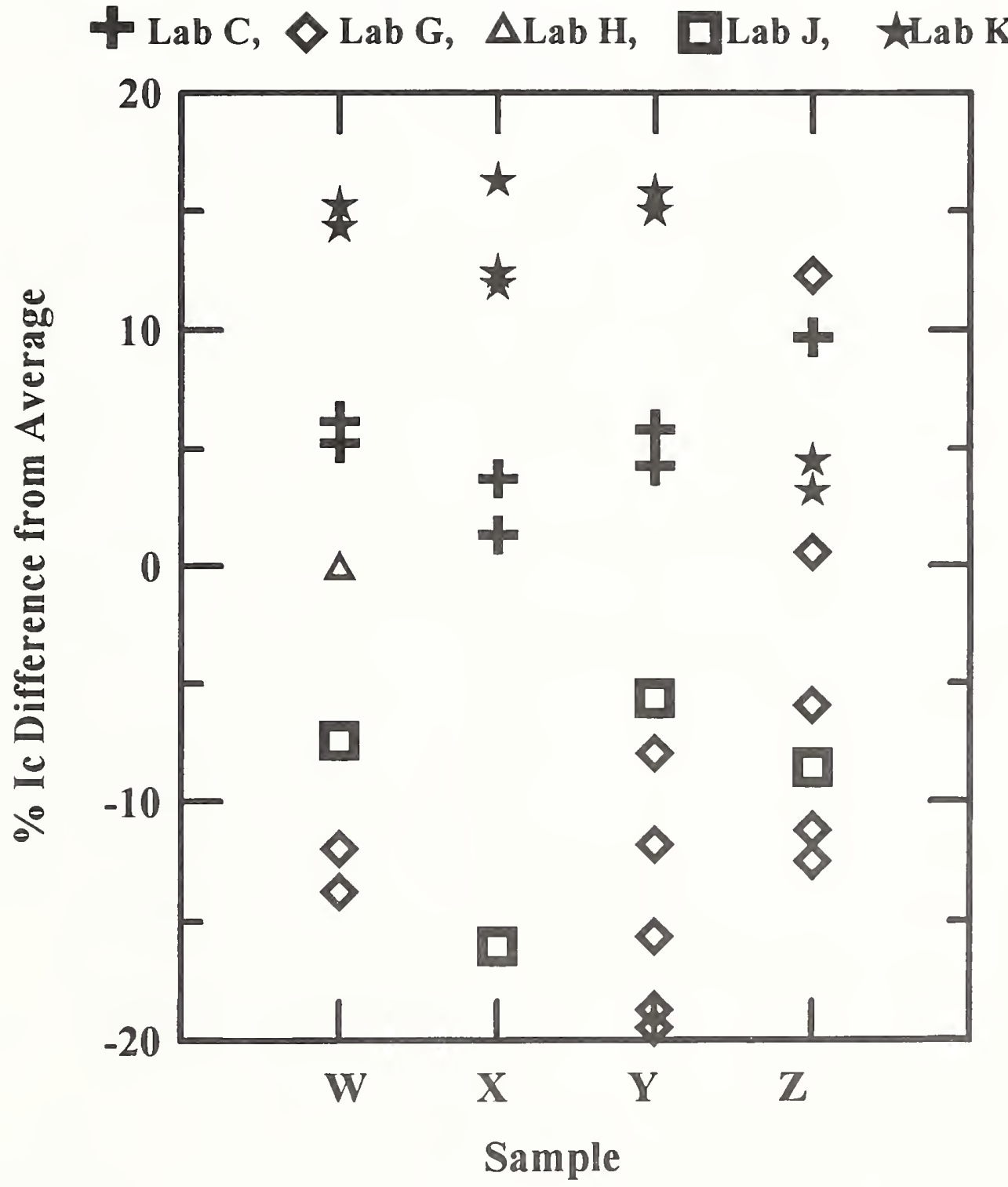

Figure 2-3. Percent difference of critical current versus sample for each laboratory. 


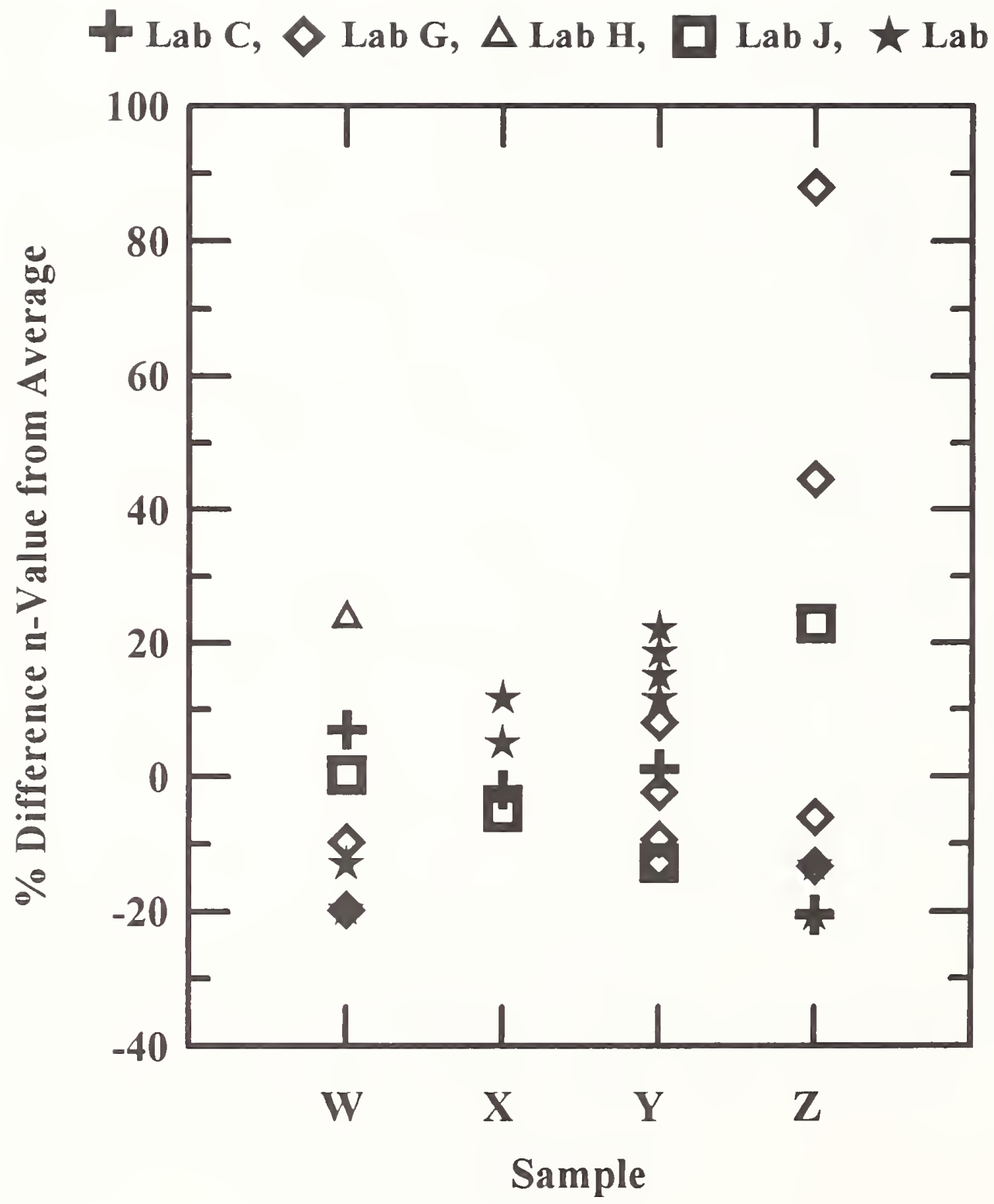

Figure 2-4. Percent difference of $n$-value versus sample for each laboratory. 


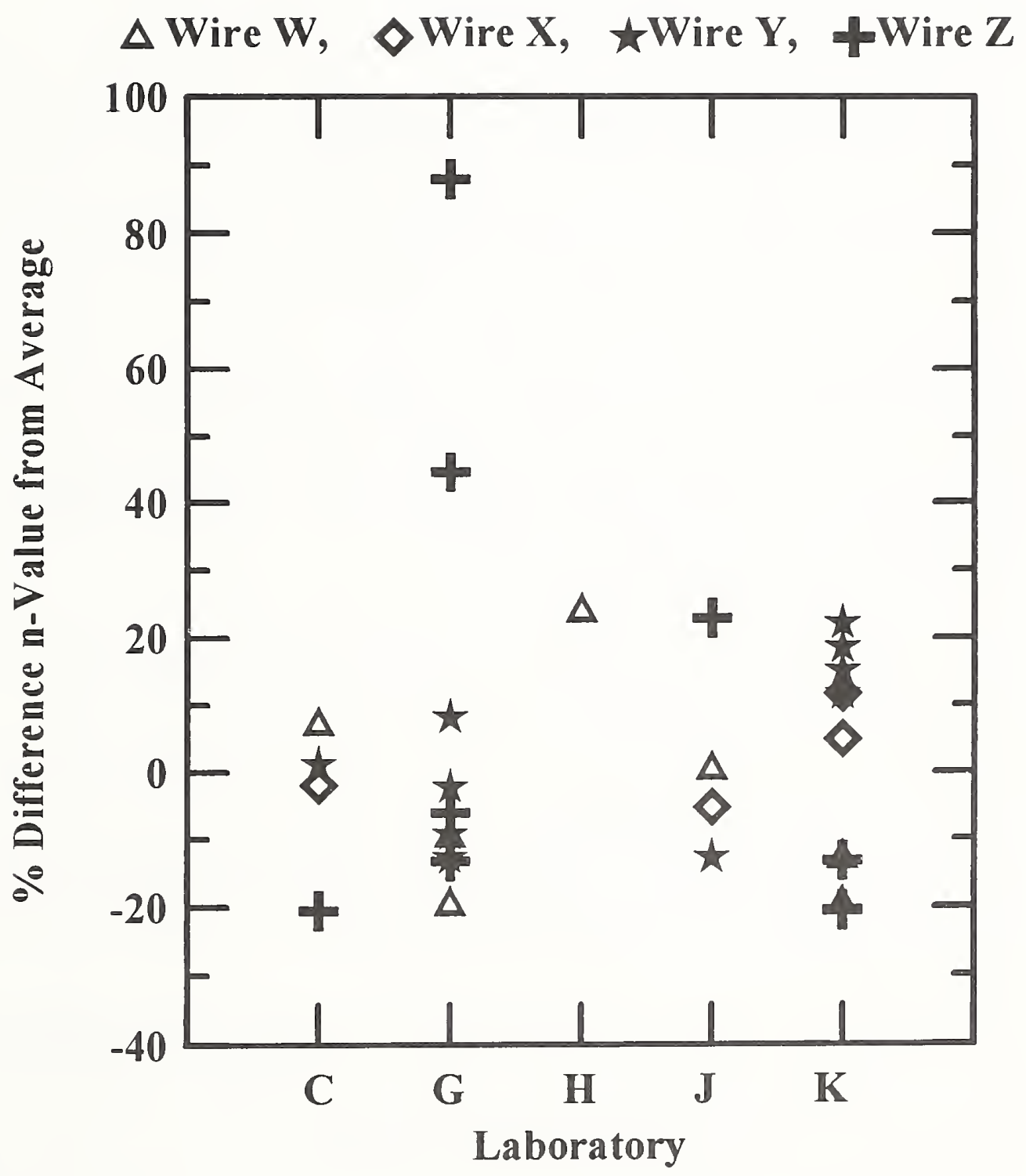

Figure 2-5. Percent difference of $n$-value versus laboratory for each sample measured. 


\title{
3. CRITICAL CURRENT HOMOGENEITY OF A Nb $\mathrm{N}_{3} \mathrm{Sn}$ WIRE
}

\begin{abstract}
This chapter discusses the results of critical current homogeneity studies that were carried out on one of the $\mathrm{Nb}_{3} \mathrm{Sn}$ wires that was used in an ITER interlaboratory comparison. The data included here are a summary of critical current measurements made at seven magnetic fields and two temperatures, and for three repeat determinations at each setting on ten specimens.
\end{abstract}

\subsection{Experimental Details of the Homogeneity Study}

This study was conducted to verify the critical current $I_{c}$ homogeneity of one of the $\mathrm{Nb}_{3} \mathrm{Sn}$ conductors used in the ITER Benchmarking Test (interlaboratory comparison). The part of the wire used in the interlaboratory comparison started as a continuous piece that was about $450 \mathrm{~m}$ long. This length was divided into nine pieces which were identified with codes that started with numbers 1 through 9 in the same sequence that they had in the continuous length. The pieces with odd number codes were $10 \mathrm{~m}$ long. Those with even number codes were $100 \mathrm{~m}$ long.

A number of specimens were cut from the $10 \mathrm{~m}$ pieces. These specimens were used to perform homogeneity studies on the following parameters: $\mathrm{I}_{c}$, ac losses, $\mathrm{Cu}$ to non- $\mathrm{Cu}$ ratio, and residual resistivity ratio. These parameters were studied in the interlaboratory comparison. The $100 \mathrm{~m}$ pieces were distributed to the four ITER parties to be measured by a number of laboratories. This sampling pattern allowed for testing of the homogeneity over the whole length including specimens on each side of the four $100 \mathrm{~m}$ lengths.

Two specimens from each of five $10 \mathrm{~m}$ lengths were used in the $I_{c}$ homogeneity study for a total of ten specimens. The two specimens within each $10 \mathrm{~m}$ length were identified either as a tail (t) or point (p) specimen, depending on the specimen's location within the $10 \mathrm{~m}$ length. Thus, the ten specimens in the $I_{c}$ homogeneity study were identified as: $1 \mathrm{t}, 1 \mathrm{p}, 3 \mathrm{t}, 3 \mathrm{p}, 5 \mathrm{t}, 5 \mathrm{p}, 7 \mathrm{t}, 7 \mathrm{p}, 9 \mathrm{t}$, and $9 \mathrm{p}$. Specimens $1 \mathrm{t}$ and $1 \mathrm{p}$ were separated by less than $10 \mathrm{~m}$ in the original continuous length of wire. Specimens $1 \mathrm{p}$ and $3 \mathrm{t}$ were separated by a little more than $100 \mathrm{~m}$. Each specimen was instrumented with three pairs of adjacent voltage taps, with each pair separated by $25 \mathrm{~cm}$. The voltage taps are identified as tap 1 (center), 2 (bottom), and 3 (top). The separation between the current contacts and the nearest voltage tap was more than $7 \mathrm{~cm}$.

The ten specimens were measured at magnetic fields of 6 to $12 \mathrm{~T}$ and at temperatures of approximately 4.02 and $4.2 \mathrm{~K}$. At each setting of field and temperature, the voltage-current (V-I) characteristics of the three voltage tap pairs were simultaneously measured. This was repeated three times, yielding a total of $126 \mathrm{~V}$-I curves on each specimen.

Each V-I curve was analyzed to determine the $\mathrm{I}_{c}$ at an electric field criterion of $10 \mu \mathrm{V} / \mathrm{m}$. Thus, we obtained three determinations of $I_{c}$ for each voltage tap pair at each setting. To correct for 
magnetic field profile in each tap region, we performed a first-order correction to the measured $\mathrm{I}_{c}$. This correction was about $0.4 \%$ at $12 \mathrm{~T}$ (maximal case).

Figure 3-1 shows the repeatability of the $I_{c}$ measurement as a function of temperature at a magnetic field of $12 \mathrm{~T}$. There were three determinations of $I_{c}$ on each tap at each of three temperatures. The extra data at the middle temperature were taken on this specimen to demonstrate the linearity of the temperature dependence of $I_{c}$ over this field and temperature range. This specimen was from the same $450 \mathrm{~m}$ sample as the homogeneity specimens. The dependence of $I_{c}$ on temperature is very nearly linear: typical standard deviations from the leastsquares fit line are less than $0.03 \%$. The temperature intercept of this fit is defined as $T_{c} *$ and its physical interpretation is the effective transition temperature at a given magnetic field. The $T_{c}$ * equations are:

$\mathrm{I}_{\mathrm{c}}(\mathrm{B}, \mathrm{T})=\mathrm{I}_{\mathrm{cr}}\left(\mathrm{B}, \mathrm{T}_{\mathrm{r}}\right)\left[\left(\mathrm{T}_{\mathrm{c}} *(\mathrm{~B})-\mathrm{T}\right) /\left(\mathrm{T}_{\mathrm{c}} *(\mathrm{~B})-\mathrm{T}_{\mathrm{r}}\right)\right]$, where

$\mathrm{T}_{\mathrm{c}}{ }^{*}$ is defined by $\mathrm{I}_{\mathrm{c}}(\mathrm{B}, \mathrm{T})=\mathrm{I}_{\mathrm{c} 0}(\mathrm{~B})\left[1-\mathrm{T} / \mathrm{T}_{\mathrm{c}}{ }^{*}(\mathrm{~B})\right]$

$\mathrm{T}_{\mathrm{c}}$ * is the effective transition temperature and $\mathrm{I}_{\mathrm{cr}}$ is the measured critical current at a reference temperature $T_{r}$. The first equation can be used to estimate $I_{c}$ at any temperature using $I_{c r}, T_{r}$, and $\mathrm{T}_{\mathrm{c}}{ }^{*}$.

The estimated uncertainty of these $\mathrm{I}_{\mathrm{c}}$ measurements is $\pm 2 \%$ for $\mathrm{Nb}_{3} \mathrm{Sn}$ wires. The estimated precision is $\pm 1 \%$. Extra digits are provided in data tables for precise interpolation. The estimated uncertainty of the $n$-value measurements is $\pm 10 \%$ with a precision of $\pm 2 \%$. The effective transition temperature, $\mathrm{T}_{\mathrm{c}} *$, is just an expression of the measured temperature dependence of $I_{c}$ at each magnetic field.

\subsection{Experimental Results}

Figures $3-2 \mathrm{a}$ and $3-3 \mathrm{a}$ show the critical current homogeneity of the $\mathrm{Nb}_{3} \mathrm{Sn}$ conductor at a temperature of $4.2 \mathrm{~K}$ and magnetic fields of 6 and $12 \mathrm{~T}$, respectively. Figures $3-2 \mathrm{~b}$ and $3-3 \mathrm{~b}$ show the corresponding n-values. The solid symbols indicate the measurements made on the tail, while the open symbols indicate measurements made on the point. The circle, square, and triangles correspond to voltage taps 1 (center), 2 (bottom), and 3 (top), respectively. A summary of the statistics for $I_{c}, n$-value, and $T_{c}{ }^{*}$ are given in Table 3-1.

The $I_{c}$ measurements at $6 \mathrm{~T}$ shown in Figure 3-2a have a 7.9\% range (maximum to minimum), although most of the data fall within half of this range. These data suggest that there may be an 'end effect' on this wire as indicated by the higher $I_{c}$ on specimens $1 t$ and $1 \mathrm{p}$ which originated on one end of the wire. This effect, however, is not as evident at $12 \mathrm{~T}$; therefore there may not be an end effect. 
The $I_{c}$ measurements at $12 \mathrm{~T}$ shown in Figure 3-3a have a $10.9 \%$ range. Although the 5t-tap-3 data point at $12 \mathrm{~T}$ might seem like an outlier, it is not inconsistent with the distribution of the rest of the data points. The $I_{c}$ 's of $3 p$ are less than $2 \%$ different from this point. Also, the $I_{c}$ of $5 t-$ tap-3 at $6 \mathrm{~T}$ was not an extreme data point.

The range of critical currents shown in Figures 3-2a and 3-3a shows that the critical current is somewhat inhomogeneous along the length of the conductor. By observing the range of values obtained on the three pairs of voltage taps on each specimen, we can get an indication of the local inhomogeneity of the wire. Six specimens had a small range of values (less than $1.3 \%$ ) for the three pairs. Four specimens had a large range: $3.4,3.5,3.6$, and $7.6 \%$. This suggests that the wire can exhibit significant local inhomogeneity, which may be of concern in the application of these wires. These results may give insight to the source of this inhomogeneity.

The coefficient of variation ( $\sigma$ /average) is about $2.6 \%$ at $12 \mathrm{~T}$, a temperature of $4.2 \mathrm{~K}$, and an electric field criterion of $10 \mu \mathrm{V} / \mathrm{m}$. For comparison to other $\mathrm{Nb}_{3} \mathrm{Sn}$ wires, the homogeneity of two wires used in the first VAMAS interlaboratory comparison are $2.4 \%$ at $10 \mathrm{~T}$ for Sample A and $1.3 \%$ at fields of 7 to $15 \mathrm{~T}$ for Sample B [1].

Figure $3-2 b$ shows a $24.5 \%$ range and $7.9 \%$ coefficient of variation in the measured values of $n$ at $6 \mathrm{~T}$. Figure $3-3 \mathrm{~b}$ shows a $31.2 \%$ range and $6.3 \%$ coefficient of variation at $12 \mathrm{~T}$. The lowest $\mathrm{n}$-value at $12 \mathrm{~T}$ was obtained on 5t-tap-3 which also had the lowest $\mathrm{I}_{\mathrm{c}}$. Variation in $\mathrm{n}$-value is not as critical an issue as variation in $I_{c}$, and the present variation in $n$ may be acceptable.

$I_{c}$ measurements at magnetic fields between 6 and $12 \mathrm{~T}$ and the systematic trends with magnetic field are illustrated in Figures 3-4 to 3-9 and Tables 3-2 to 3-5. Figure 3-4 shows $I_{c}$ as a function of magnetic field for ten samples with three taps at integer magnetic fields between 6 and $12 \mathrm{~T}$ at a temperature of $4.2 \mathrm{~K}$. Figure 3-5 shows the percent difference of the measured critical current from the average measurement at a given field. The lines connect the data points for a given tap on a given specimen. These lines are fairly smooth across magnetic field, which indicates a systematic trend with respect to the average and a self consistency of the measurements. Most of the lines diverge from the average with increasing magnetic field. The trend for 5t-tap-3 is somewhat exaggerated, which is consistent with the observations made on Figure 3-2a and Figure 3-3a. All measurements fell within $\pm 6 \%$ of the average, and the percentage range is relatively constant with magnetic field.

Figure 3-6 shows the $n$-value at $4.2 \mathrm{~K}$ for each $\mathrm{I}_{\mathrm{c}}$ measurement given above. Figure 3-7 shows the difference in the determined $n$-values from the average $n$-value at each field. Notice that the $y$-axis in Figure 3-7 is not in percent. Again, there are systematic trends with magnetic field for each tap and self consistency of the measurements. The curve with the lowest $n$-value at $12 \mathrm{~T}$ is from $5 \mathrm{t}$-tap-3.

Figure 3-8 shows the values of $T_{c}{ }^{*}$ for each critical current measurement given above. Figure 3-9 shows the difference in the determined $T_{c}{ }^{*}$ from the average $T_{c}{ }^{*}$ at each field. Notice that 
the $y$-axis in Figure 3-9 is not in percent. We analyzed the effect of using the values of $T_{c}{ }^{*}$ computed, including and excluding the outliers on Sample 7t. We suspect that these outliers were caused by a lack of thermal equilibrium between the liquid helium and the ullage pressure in the Dewar. Our measurement procedure for the elevated temperature is to: raise the pressure and heat the liquid helium to get it in equilibrium with a pressure higher than the target point, let it soak for a few minutes, then drop the pressure to the target point. This was apparently not done correctly in this case. The liquid will asymptotically approach equilibrium with the gas pressure. This fact and the sequence of $\mathrm{I}_{\mathrm{c}}$ measurements starting at $6 \mathrm{~T}$ and ending at $12 \mathrm{~T}$ explains the shape of the $7 \mathrm{t}$ curve with field, that is the largest error at $6 \mathrm{~T}$ and the smallest error at $12 \mathrm{~T}$. We calculated the error in $I_{c}$ that resulted from this error in $T_{c} *$ when the $I_{c}$ was corrected from 4.02 $\mathrm{K}$ to $4.2 \mathrm{~K}$. The maximum error was $0.45 \%$ at $6 \mathrm{~T}$, which is small compared to the observed inhomogeneity. The error in $\mathrm{I}_{c}$ was $0.14 \%$ at $12 \mathrm{~T}$. The errors in $\mathrm{I}_{c}$ without these outliers, using the data points furthest from the average $\mathrm{T}_{c} *$ were $-0.08 \%$ at $6 \mathrm{~T}$ and $-0.17 \%$ at $12 \mathrm{~T}$. The majority of the $\mathrm{T}_{\mathrm{c}}{ }^{*}$ determinations were within $\pm 0.2 \mathrm{~K}$, indicating high repeatability.

\subsection{Discussion of Experimental Results}

The variations seen in the critical current as a function of specimen indicate inhomogeneity along the length of the conductor. There are a number of possible sources of inhomogeneity; the following is a partial list of sources:

1. Intrinsic sample variations: The intrinsic properties may vary along the length of the conductor, thus leading to the nonuniform critical current measurements.

2. Variation due to nonuniform precompression: Nonuniform precompression along the length of the conductor could be another source of variation [2].

3. Variation in tension: The wire tension for each specimen and variation in wire tension along a specimen would cause a variation in the measured $I_{c}$. Variation in tension along the wire on a given specimen does not seem likely since both the wire and its holding groove are smooth. Moreover, the tension is applied uniformly along the wire. This, coupled with the fact that significant inhomogeneity was observed in some specimens suggests that variation in tension cannot explain all of the observed variation.

4. Variation in mechanical properties of the sample: The sample could have mechanical instabilities along its length. For example, a weak section in the conductor might focus all the strain, thus leading to nonuniform strain along the conductor and nonuniform critical currents. The differential contraction between the sample and the mandrel puts a mechanical load on the whole $1 \mathrm{~m}$ length of wire. This situation has not been studied before in the U.S.. A typical sample length for testing $I_{c}$ as a function of strain is $3 \mathrm{~cm}$. If mechanical variations are present in the conductor, they may be observed in this coil- $\mathrm{I}_{\mathrm{c}}$ measurement. If these variations cause problems in the test, they may also affect the magnet application. 
5. Accidental damage to the samples: This may be possible but unlikely because of the design of the sample mandrel. There is very little handling of the portion of the sample between the voltage taps.

This list is not exhaustive: there could be a host of other possibilities for the measured inhomogeneity. The most pronounced evidence of the problem is the observed variation among the three voltage taps.

\subsection{References}

[1] Tachikawa, K.; Itoh, K.; Wada, H.; Gould, D.; Jones, H.; Walters, C. R.; Goodrich, L.F.; et. al. "VAMAS intercomparison of critical current measurement in $\mathrm{Nb}_{3} \mathrm{Sn}$ Wires," IEEE Trans. Magn., Vol. 25, No. 3, p. 2368; 1989.

[2] Ekin, J.W. NIST/Boulder, Personal communication, 1994. 
Table 3-1. Summary statistics of $\mathrm{I}_{c}, \mathrm{n}$-values and $\mathrm{T}_{c} *$.

\begin{tabular}{|c|c|c|c|c|c|c|c|}
\hline \multicolumn{8}{|l|}{$I_{c} @ 4.2 \mathrm{~K}$} \\
\hline & $6 \mathrm{~T}$ & $7 \mathrm{~T}$ & $8 \mathrm{~T}$ & $9 \mathrm{~T}$ & $10 \mathrm{~T}$ & $11 \mathrm{~T}$ & $12 \mathrm{~T}$ \\
\hline \# pts. & 30 & 30 & 30 & 30 & 30 & 30 & 30 \\
\hline Average, $\mathrm{A}$ & 383.47 & 316.68 & 262.71 & 218.04 & 180.37 & 148.21 & 120.52 \\
\hline Std. dev., A & 7.85 & 6.60 & 5.62 & 4.84 & 4.19 & 3.65 & 3.19 \\
\hline Min, $\mathrm{A}$ & 370.08 & 305.37 & 253.08 & 209.80 & 172.79 & 141.02 & 113.72 \\
\hline $\operatorname{Max}, A$ & 400.52 & 330.93 & 274.74 & 228.24 & 189.04 & 155.60 & 126.81 \\
\hline Range, A & 30.44 & 25.56 & 21.66 & 18.44 & 16.25 & 14.58 & 13.09 \\
\hline Coeff., $\%$ & 2.05 & 2.09 & 1.99 & 2.22 & 2.32 & 2.46 & 2.65 \\
\hline \multicolumn{8}{|c|}{ n-value@4.2 K } \\
\hline & $6 \mathrm{~T}$ & $7 \mathrm{~T}$ & $8 \mathrm{~T}$ & $8 \mathrm{~T}$ & $10 \mathrm{~T}$ & $11 \mathrm{~T}$ & $12 \mathrm{~T}$ \\
\hline \# pts. & 30 & 30 & 30 & 30 & 30 & 30 & 30 \\
\hline Average & 43.24 & 41.44 & 39.80 & 38.10 & 36.25 & 34.29 & 32.13 \\
\hline Std. dev. & 3.40 & 2.97 & 2.72 & 2.46 & 2.30 & 2.17 & 2.03 \\
\hline Min & 37.56 & 36.55 & 34.61 & 32.37 & 30.30 & 27.95 & 25.53 \\
\hline Max & 48.16 & 46.33 & 44.91 & 41.94 & 41.00 & 38.58 & 35.54 \\
\hline Range & 10.60 & 9.78 & 10.30 & 9.56 & 10.70 & 10.63 & 10.01 \\
\hline Coeff., \% & 7.87 & 7.16 & 6.83 & 6.47 & 6.35 & 6.33 & 6.33 \\
\hline \multicolumn{8}{|c|}{$\mathrm{T}_{c} *$ with outliers } \\
\hline & $6 \mathrm{~T}$ & $7 \mathrm{~T}$ & $8 \mathrm{~T}$ & $9 \mathrm{~T}$ & $10 \mathrm{~T}$ & $11 \mathrm{~T}$ & $12 \mathrm{~T}$ \\
\hline \# pts. & 30 & 30 & 30 & 30 & 30 & 30 & 30 \\
\hline Average, $\mathrm{K}$ & 13.596 & 12.772 & 12.013 & 11.369 & 10.727 & 10.101 & 9.498 \\
\hline Std. dev., K & 0.665 & 0.333 & 0.127 & 0.115 & 0.096 & 0.097 & 0.093 \\
\hline Min, $\mathrm{K}$ & 13.041 & 12.464 & 11.803 & 11.156 & 10.499 & 9.838 & 9.254 \\
\hline $\operatorname{Max}, \mathrm{K}$ & 15.791 & 13.820 & 12.384 & 11.698 & 10.988 & 10.339 & 9.686 \\
\hline Range, $\mathrm{K}$ & 2.751 & 1.356 & 0.581 & 0.541 & 0.489 & 0.501 & 0.432 \\
\hline Coeff., \% & 4.891 & 2.606 & 1.058 & 1.009 & 0.892 & 0.962 & 0.984 \\
\hline \multicolumn{8}{|c|}{$\mathrm{T}_{\mathcal{C}} *$ w/o outliers } \\
\hline & $6 \mathrm{~T}$ & $7 \mathrm{~T}$ & $8 \mathrm{~T}$ & $8 \mathrm{~T}$ & $10 \mathrm{~T}$ & $11 \mathrm{~T}$ & $12 \mathrm{~T}$ \\
\hline \# pts. & 27 & 27 & 27 & 27 & 27 & 27 & 27 \\
\hline Average, $\mathrm{K}$ & 13.382 & 12.666 & 11.980 & 11.342 & 10.704 & 10.080 & 9.484 \\
\hline Std. dev., $\mathrm{K}$ & 0.118 & 0.079 & 0.080 & 0.079 & 0.068 & 0.078 & 0.086 \\
\hline Min, $\mathrm{K}$ & 13.041 & 12.464 & 11.803 & 11.156 & 10.499 & 9.839 & 9.254 \\
\hline Max, K & 13.568 & 12.800 & 12.086 & 11.461 & 10.787 & 10.175 & 9.604 \\
\hline Range, $\mathrm{K}$ & 0.527 & 0.336 & 0.283 & 0.305 & 0.288 & 0.337 & 0.350 \\
\hline Coeff., $\%$ & 0.878 & 0.613 & 0.665 & 0.698 & 0.634 & 0.747 & 0.904 \\
\hline
\end{tabular}


Table 3-2. Summary of $I_{c}$ measurements at $10 \mu \mathrm{V} / \mathrm{m}, 4.20 \mathrm{~K}$, and $6 \mathrm{~T}$ to $12 \mathrm{~T}$.

\begin{tabular}{||c|c|c|c|c|c|c|c|c|c|c|c||}
\hline Field & Tap\# & $1 \mathrm{t}$ & $1 \mathrm{p}$ & $3 \mathrm{t}$ & $3 \mathrm{p}$ & $5 \mathrm{t}$ & $5 \mathrm{p}$ & $7 \mathrm{t}$ & $7 \mathrm{p}$ & $9 \mathrm{t}$ & $9 \mathrm{p}$ \\
\hline \hline 6 & 1 & 397.70 & 392.00 & 381.33 & 370.99 & 384.42 & 379.94 & 382.87 & 385.27 & 384.49 & 376.00 \\
\hline 6 & 2 & 396.68 & 393.07 & 382.18 & 373.52 & 388.56 & 379.50 & 388.31 & 377.01 & 386.27 & 381.01 \\
\hline 6 & 3 & 400.52 & 394.30 & 379.92 & 370.08 & 373.65 & 375.36 & 378.38 & 383.30 & 384.08 & 383.44 \\
\hline \hline 7 & 1 & 328.45 & 323.46 & 314.81 & 306.07 & 317.27 & 313.80 & 316.56 & 318.27 & 317.66 & 310.01 \\
\hline 7 & 2 & 327.93 & 324.46 & 315.76 & 308.26 & 320.98 & 313.40 & 321.15 & 311.02 & 319.25 & 314.83 \\
\hline 7 & 3 & 330.93 & 325.45 & 313.78 & 305.37 & 307.54 & 310.20 & 312.77 & 316.82 & 317.30 & 316.75 \\
\hline \hline 8 & 1 & 272.54 & 268.21 & 261.08 & 253.59 & 263.05 & 260.40 & 262.86 & 264.06 & 263.65 & 256.70 \\
\hline 8 & 2 & 272.34 & 269.08 & 262.06 & 255.52 & 266.46 & 259.99 & 266.84 & 257.68 & 265.10 & 261.32 \\
\hline 8 & 3 & 274.74 & 269.90 & 260.35 & 253.08 & 254.19 & 257.60 & 259.66 & 263.09 & 263.35 & 262.86 \\
\hline \hline 9 & 1 & 226.24 & 222.55 & 216.63 & 210.13 & 218.13 & 216.14 & 218.36 & 219.22 & 218.95 & 212.58 \\
\hline 9 & 2 & 226.30 & 223.28 & 217.59 & 211.86 & 221.35 & 215.70 & 221.87 & 213.51 & 220.29 & 217.02 \\
\hline 9 & 3 & 228.24 & 224.01 & 216.08 & 209.80 & 210.02 & 214.00 & 215.69 & 218.59 & 218.68 & 218.27 \\
\hline \hline 10 & 1 & 187.22 & 184.11 & 179.13 & 173.48 & 180.27 & 178.84 & 180.79 & 181.43 & 181.25 & 175.41 \\
\hline 10 & 2 & 187.49 & 184.71 & 180.06 & 175.06 & 183.31 & 178.37 & 183.92 & 176.28 & 182.52 & 179.66 \\
\hline 10 & 3 & 189.04 & 185.35 & 178.74 & 173.30 & 172.79 & 177.23 & 178.56 & 181.08 & 180.99 & 180.72 \\
\hline \hline 11 & 1 & 153.87 & 151.31 & 147.14 & 142.16 & 147.95 & 147.00 & 148.70 & 149.21 & 149.07 & 143.68 \\
\hline 11 & 2 & 154.33 & 151.78 & 148.01 & 143.59 & 150.86 & 146.49 & 151.54 & 144.51 & 150.25 & 147.77 \\
\hline 11 & 3 & 155.60 & 152.37 & 146.85 & 142.09 & 141.02 & 145.82 & 146.87 & 149.08 & 148.84 & 148.64 \\
\hline \hline 12 & 1 & 125.18 & 123.09 & 119.61 & 115.21 & 120.10 & 119.58 & 121.02 & 121.34 & 121.39 & 116.37 \\
\hline 12 & 2 & 125.78 & 123.44 & 120.45 & 116.54 & 122.91 & 119.03 & 123.61 & 117.05 & 122.49 & 120.27 \\
\hline 12 & 3 & 126.81 & 123.97 & 119.40 & 115.23 & 113.72 & 118.75 & 119.54 & 121.38 & 121.18 & 121.03 \\
\hline \hline
\end{tabular}


Table 3-3. Summary of $I_{c}$ measurements at $10 \mu \mathrm{V} / \mathrm{m}, 4.02 \mathrm{~K}$, and $6 \mathrm{~T}$ to $12 \mathrm{~T}$.

\begin{tabular}{|c|c|c|c|c|c|c|c|c|c|c|c|}
\hline Field & Tap\# & $1 \mathrm{t}$ & $1 p$ & $3 \mathrm{t}$ & $3 p$ & $5 \mathrm{t}$ & $5 p$ & $7 \mathrm{t}$ & $7 p$ & $9 \mathrm{t}$ & $9 p$ \\
\hline 6 & 1 & 405.50 & 399.64 & 388.68 & 378.36 & 391.98 & 387.37 & 388.82 & 392.83 & 392.04 & 383.45 \\
\hline 6 & 2 & 404.52 & 400.80 & 389.56 & 380.89 & 396.12 & 386.97 & 394.48 & 384.45 & 393.79 & 388.34 \\
\hline 6 & 3 & 408.36 & 402.01 & 387.27 & 377.54 & 381.26 & 382.69 & 384.55 & 390.76 & 391.59 & 390.84 \\
\hline 7 & 1 & 335.44 & 330.33 & 321.43 & 312.66 & 324.08 & 320.45 & 322.48 & 324.99 & 324.39 & 316.68 \\
\hline 7 & 2 & 334.87 & 331.38 & 322.41 & 314.87 & 327.82 & 320.08 & 327.20 & 317.69 & 326.01 & 321.46 \\
\hline 7 & 3 & 337.94 & 332.36 & 320.41 & 311.97 & 314.24 & 316.78 & 318.77 & 323.45 & 324.04 & 323.42 \\
\hline 8 & 1 & 278.86 & 274.42 & 267.04 & 259.54 & 269.16 & 266.37 & 268.71 & 270.15 & 269.74 & 262.74 \\
\hline 8 & 2 & 278.60 & 275.35 & 268.05 & 261.50 & 272.61 & 265.99 & 272.71 & 263.70 & 271.22 & 267.32 \\
\hline 8 & 3 & 281.07 & 276.16 & 266.29 & 259.04 & 260.21 & 263.51 & 265.45 & 269.10 & 269.44 & 268.89 \\
\hline 9 & 1 & 231.93 & 228.18 & 222.02 & 215.52 & 223.65 & 221.56 & 223.67 & 224.70 & 224.44 & 218.03 \\
\hline 9 & 2 & 231.96 & 228.96 & 223.01 & 217.27 & 226.90 & 221.18 & 227.20 & 218.95 & 225.80 & 222.44 \\
\hline 9 & 3 & 233.94 & 229.66 & 221.44 & 215.18 & 215.45 & 219.36 & 220.96 & 224.04 & 224.16 & 223.73 \\
\hline 10 & 1 & 192.38 & 189.19 & 184.07 & 178.36 & 185.29 & 183.75 & 185.63 & 186.43 & 186.23 & 180.35 \\
\hline 10 & 2 & 192.63 & 189.84 & 185.03 & 179.94 & 188.38 & 183.33 & 188.80 & 181.21 & 187.50 & 184.59 \\
\hline 10 & 3 & 194.24 & 190.46 & 183.66 & 178.17 & 177.73 & 182.09 & 183.37 & 186.05 & 185.99 & 185.67 \\
\hline 11 & 1 & 158.58 & 155.92 & 151.63 & 146.58 & 152.50 & 151.46 & 153.11 & 153.73 & 153.61 & 148.18 \\
\hline 11 & 2 & 159.02 & 156.45 & 152.52 & 148.04 & 155.44 & 150.96 & 155.98 & 149.00 & 154.81 & 152.27 \\
\hline 11 & 3 & 160.31 & 157.00 & 151.32 & 146.52 & 145.53 & 150.22 & 151.24 & 153.58 & 153.39 & 153.15 \\
\hline 12 & 1 & 129.41 & 127.27 & 123.65 & 119.19 & 124.23 & 123.63 & 125.05 & 125.52 & 125.46 & 120.46 \\
\hline 12 & 2 & 130.00 & 127.63 & 124.51 & 120.54 & 127.05 & 123.10 & 127.67 & 121.17 & 126.57 & 124.38 \\
\hline 12 & 3 & 131.06 & 128.16 & 123.44 & 119.22 & 117.77 & 122.75 & 123.53 & 125.54 & 125.24 & 125.14 \\
\hline
\end{tabular}


Table 3-4. Summary of n-value measurements at $4.20 \mathrm{~K}$ at magnetic fields of 6 to $12 \mathrm{~T}$.

\begin{tabular}{|c|c|c|c|c|c|c|c|c|c|c|c|}
\hline Field & ap\# & $1 \mathrm{t}$ & $1 \mathrm{p}$ & $3 \mathrm{t}$ & $3 p$ & $5 \mathrm{t}$ & $5 p$ & $7 \mathrm{t}$ & $7 p$ & $9 \mathrm{t}$ & $9 p$ \\
\hline 6 & 1 & 44.68 & 48.02 & 42.33 & 40.01 & 47.05 & 46.33 & 41.85 & 47.58 & 4.62 & 43.22 \\
\hline 6 & 2 & 41.81 & 45.68 & 40.12 & 39.14 & 45.02 & 45.71 & 48.16 & 40.42 & 46.78 & 45.20 \\
\hline 6 & 3 & 45.07 & 46.40 & 40.43 & 37.97 & 38.84 & 37.57 & 37.56 & 38.95 & 45.02 & 45.68 \\
\hline 7 & 1 & 41.57 & 44.80 & 40.68 & 38.81 & 44.58 & 44.39 & 41.05 & 46.33 & 43.08 & 41.86 \\
\hline 7 & 2 & 40.32 & 43.23 & 38.86 & 37.75 & 42.98 & 43.15 & 45.90 & 38.65 & 43.81 & 43.20 \\
\hline 7 & 3 & 42.75 & 45.03 & 39.02 & 36.86 & 36.64 & 36.55 & 36.97 & 38.25 & 42.72 & 43.54 \\
\hline 8 & 1 & 40.27 & 43.27 & 39.01 & 37.39 & 43.20 & 42.50 & 39.76 & 44.91 & 41.12 & 39.92 \\
\hline 8 & 2 & 38.78 & 41.06 & 37.65 & 36.20 & 40.78 & 41.11 & 43.39 & 37.03 & 41.60 & 41.39 \\
\hline 8 & 3 & 41.16 & 42.30 & 37.67 & 35.42 & 34.61 & 35.71 & 35.85 & 38.10 & 41.13 & 41.66 \\
\hline 9 & 1 & 38.32 & 41.35 & 37.35 & 35.95 & 40.76 & 40.27 & 38.62 & 41.94 & 39.41 & 38.49 \\
\hline 9 & 2 & 37.25 & 38.95 & 36.39 & 34.88 & 39.05 & 38.64 & 41.49 & 35.17 & 39.82 & 40.01 \\
\hline 9 & 3 & 39.75 & 40.47 & 36.29 & 34.24 & 32.37 & 34.38 & 34.95 & 37.08 & 39.55 & 39.81 \\
\hline 10 & 1 & 36.24 & 38.73 & 35.75 & 34 & 37.85 & 39 & 36.78 & 41.00 & 37.26 & 36.52 \\
\hline 10 & 2 & 35.42 & 37.65 & 35.15 & 33.29 & 37.11 & 37.07 & 39.07 & 33.32 & 37.74 & 37.35 \\
\hline 10 & 3 & 37.02 & 38.19 & 35.04 & 32.49 & 30.30 & 33.34 & 33.63 & 35.99 & 37.01 & 37.89 \\
\hline 11 & 1 & 33.85 & 36.23 & 34.25 & 32.31 & 35.35 & 36.63 & 34.82 & 38.58 & 35.37 & 34.19 \\
\hline 11 & 2 & 33.79 & 35.13 & 33.46 & 31 & 35.06 & 34 & 37.29 & 31.17 & 35.81 & 35.54 \\
\hline 11 & 3 & 35.12 & 36.01 & 33.43 & 31.12 & 27.95 & 31.90 & 32.23 & 34.81 & 35.20 & 36.05 \\
\hline 12 & 1 & 31.86 & 33.57 & 32.36 & 30.31 & 32.48 & 34.87 & 32.61 & 35.54 & 33.24 & 32.10 \\
\hline 12 & 2 & 31.68 & 32.76 & 31.73 & 29.26 & 32.80 & 32.33 & 34.84 & 29.04 & 33.74 & 33.3 \\
\hline 12 & 3 & 33.4 & 33. & 31.7 & 29.3 & 25 & 30 & 30.6 & 32.74 & 33 & 33 \\
\hline
\end{tabular}


Table 3-5. Summary of $\mathrm{T}_{c}{ }^{*} \mathrm{~s}$ at each magnetic field from $6 \mathrm{~T}$ to $12 \mathrm{~T}$.

\begin{tabular}{|c|c|c|c|c|c|c|c|c|c|c|c|}
\hline Field & Tap\# & $1 \mathrm{t}$ & $1 \mathrm{p}$ & $3 \mathrm{t}$ & $3 \mathrm{p}$ & $5 \mathrm{t}$ & $5 \mathrm{p}$ & $7 \mathrm{t}$ & $7 \mathrm{p}$ & $9 \mathrm{t}$ & $9 \mathrm{p}$ \\
\hline \hline 6 & 1 & 13.381 & 13.435 & 13.535 & 13.257 & 13.355 & 13.403 & 15.791 & 13.373 & 13.370 & 13.282 \\
\hline 6 & 2 & 13.308 & 13.350 & 13.533 & 13.316 & 13.453 & 13.338 & 15.523 & 13.327 & 13.452 & 13.568 \\
\hline 6 & 3 & 13.405 & 13.403 & 13.505 & 13.132 & 13.041 & 13.422 & 15.239 & 13.448 & 13.404 & 13.527 \\
\hline \hline 7 & 1 & 12.666 & 12.672 & 12.762 & 12.566 & 12.587 & 12.688 & 13.820 & 12.734 & 12.687 & 12.573 \\
\hline 7 & 2 & 12.708 & 12.647 & 12.745 & 12.596 & 12.646 & 12.645 & 13.761 & 12.598 & 12.691 & 12.751 \\
\hline 7 & 3 & 12.703 & 12.681 & 12.731 & 12.528 & 12.464 & 12.690 & 13.593 & 12.800 & 12.677 & 12.745 \\
\hline \hline 8 & 1 & 11.972 & 11.972 & 12.085 & 11.866 & 11.945 & 12.045 & 12.282 & 12.014 & 11.986 & 11.854 \\
\hline 8 & 2 & 12.034 & 11.917 & 12.075 & 11.887 & 11.991 & 12.000 & 12.384 & 11.906 & 12.006 & 12.029 \\
\hline 8 & 3 & 12.014 & 11.969 & 12.084 & 11.838 & 11.803 & 12.052 & 12.267 & 12.086 & 11.985 & 12.048 \\
\hline \hline 9 & 1 & 11.364 & 11.320 & 11.432 & 11.224 & 11.311 & 11.373 & 11.605 & 11.395 & 11.387 & 11.225 \\
\hline 9 & 2 & 11.402 & 11.278 & 11.424 & 11.239 & 11.370 & 11.283 & 11.698 & 11.264 & 11.386 & 11.405 \\
\hline 9 & 3 & 11.405 & 11.346 & 11.461 & 11.216 & 11.156 & 11.382 & 11.556 & 11.408 & 11.375 & 11.394 \\
\hline \hline 10 & 1 & 10.729 & 10.719 & 10.726 & 10.603 & 10.661 & 10.751 & 10.923 & 10.734 & 10.743 & 10.599 \\
\hline 10 & 2 & 10.774 & 10.684 & 10.729 & 10.646 & 10.714 & 10.679 & 10.988 & 10.634 & 10.787 & 10.767 \\
\hline 10 & 3 & 10.741 & 10.739 & 10.741 & 10.610 & 10.499 & 10.757 & 10.885 & 10.755 & 10.723 & 10.773 \\
\hline \hline 11 & 1 & 10.082 & 10.105 & 10.092 & 9.985 & 10.051 & 10.135 & 10.267 & 10.150 & 10.111 & 9.947 \\
\hline 11 & 2 & 10.112 & 10.057 & 10.102 & 10.011 & 10.127 & 10.088 & 10.339 & 10.000 & 10.139 & 10.116 \\
\hline 11 & 3 & 10.149 & 10.121 & 10.114 & 9.964 & 9.839 & 10.175 & 10.246 & 10.171 & 10.096 & 10.126 \\
\hline \hline 12 & 1 & 9.531 & 9.508 & 9.538 & 9.405 & 9.440 & 9.508 & 9.607 & 9.422 & 9.567 & 9.322 \\
\hline 12 & 2 & 9.568 & 9.502 & 9.549 & 9.443 & 9.538 & 9.467 & 9.686 & 9.323 & 9.604 & 9.476 \\
\hline 12 & 3 & 9.568 & 9.533 & 9.525 & 9.403 & 9.254 & 9.548 & 9.594 & 9.450 & 9.565 & 9.499 \\
\hline
\end{tabular}




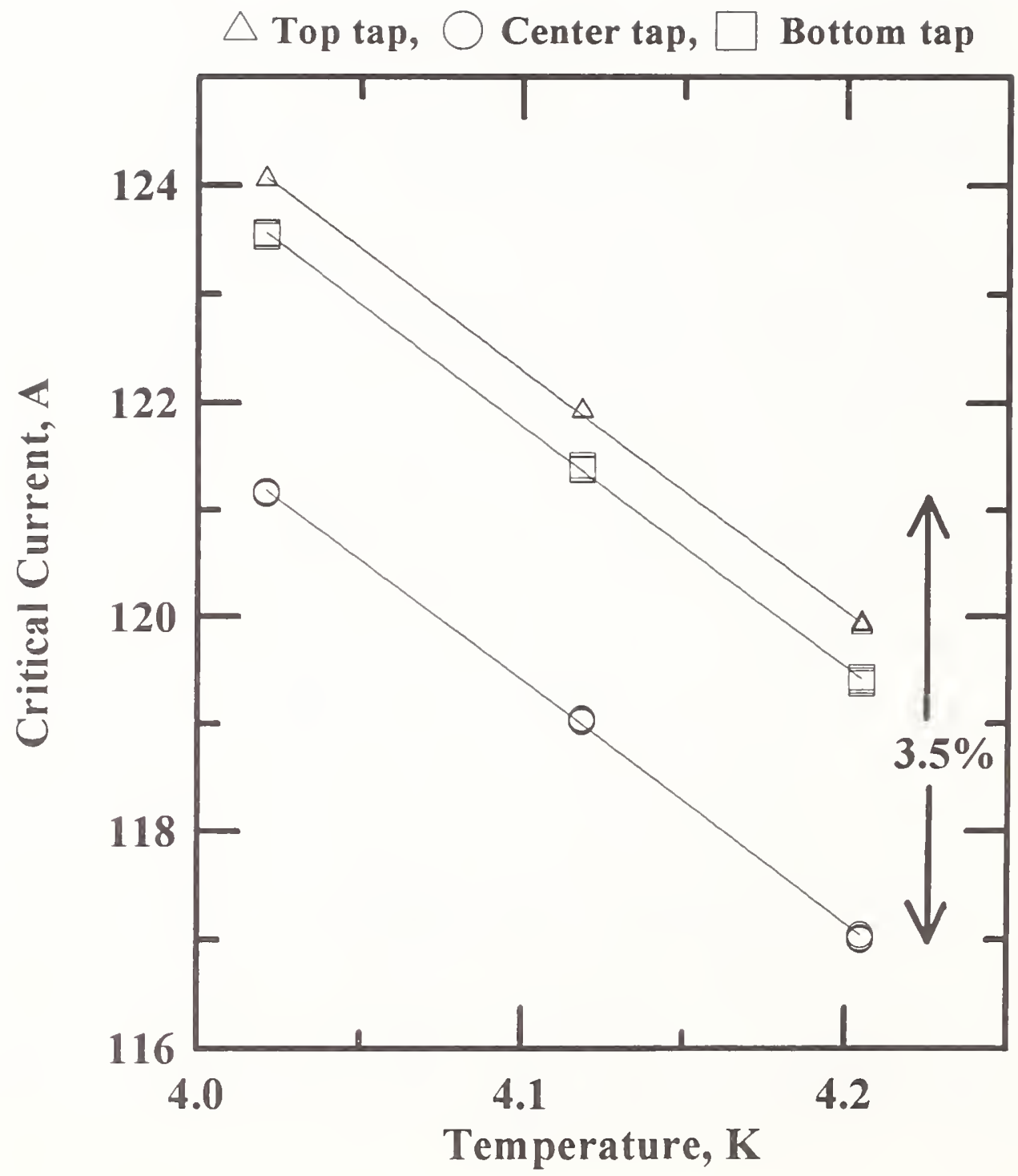

Figure 3-1. Critical current at $12 \mathrm{~T}$ versus temperature for three pairs of voltage taps. There are three determinations for each tap at each temperature; however, the three determinations are almost indistinguishable. 


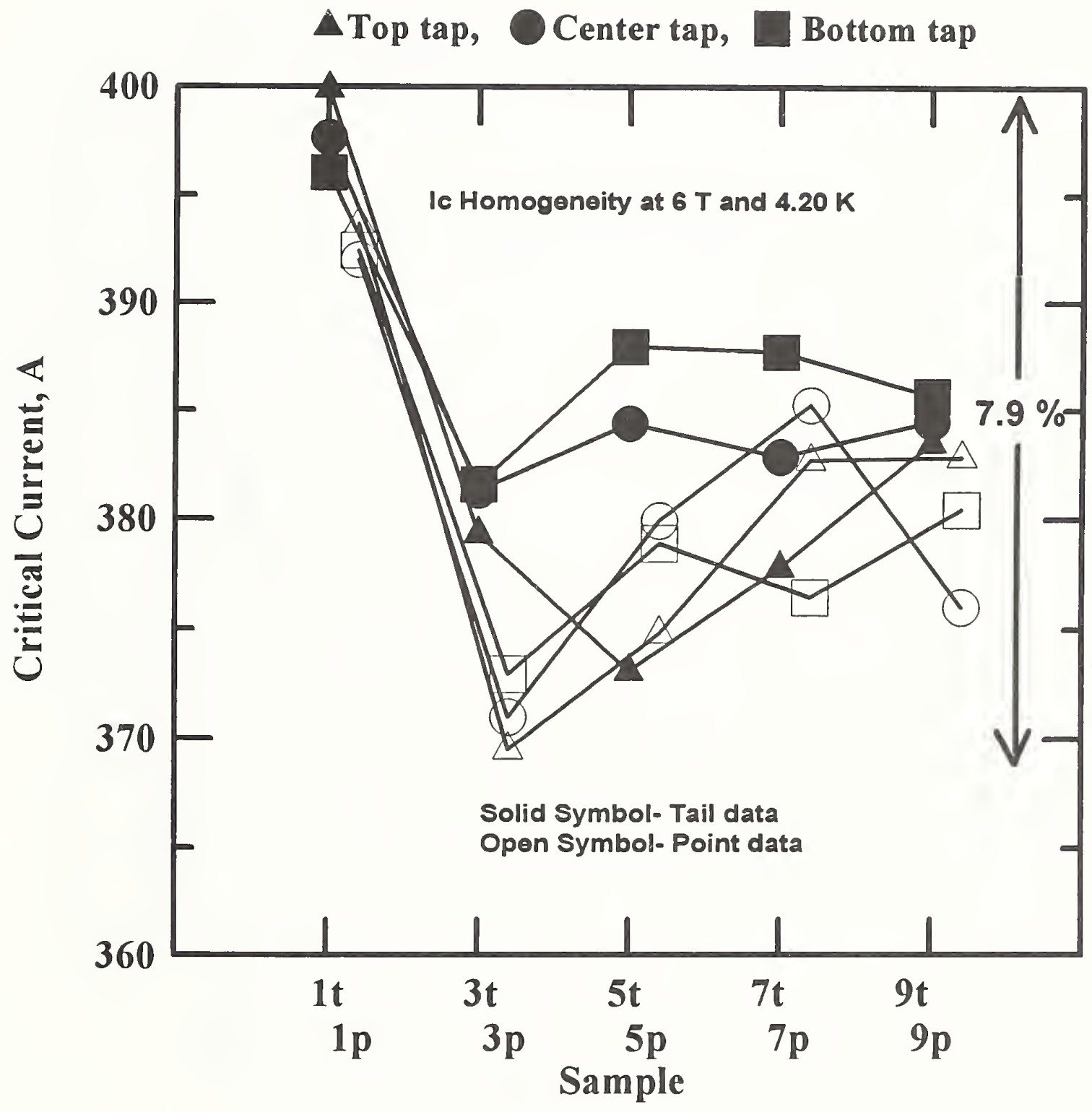

Figure 3-2a. Critical current at $6 \mathrm{~T}, 4.2 \mathrm{~K}$, and $10 \mu \mathrm{V} / \mathrm{m}$ versus sample. Each sample had three pairs of voltage taps. 


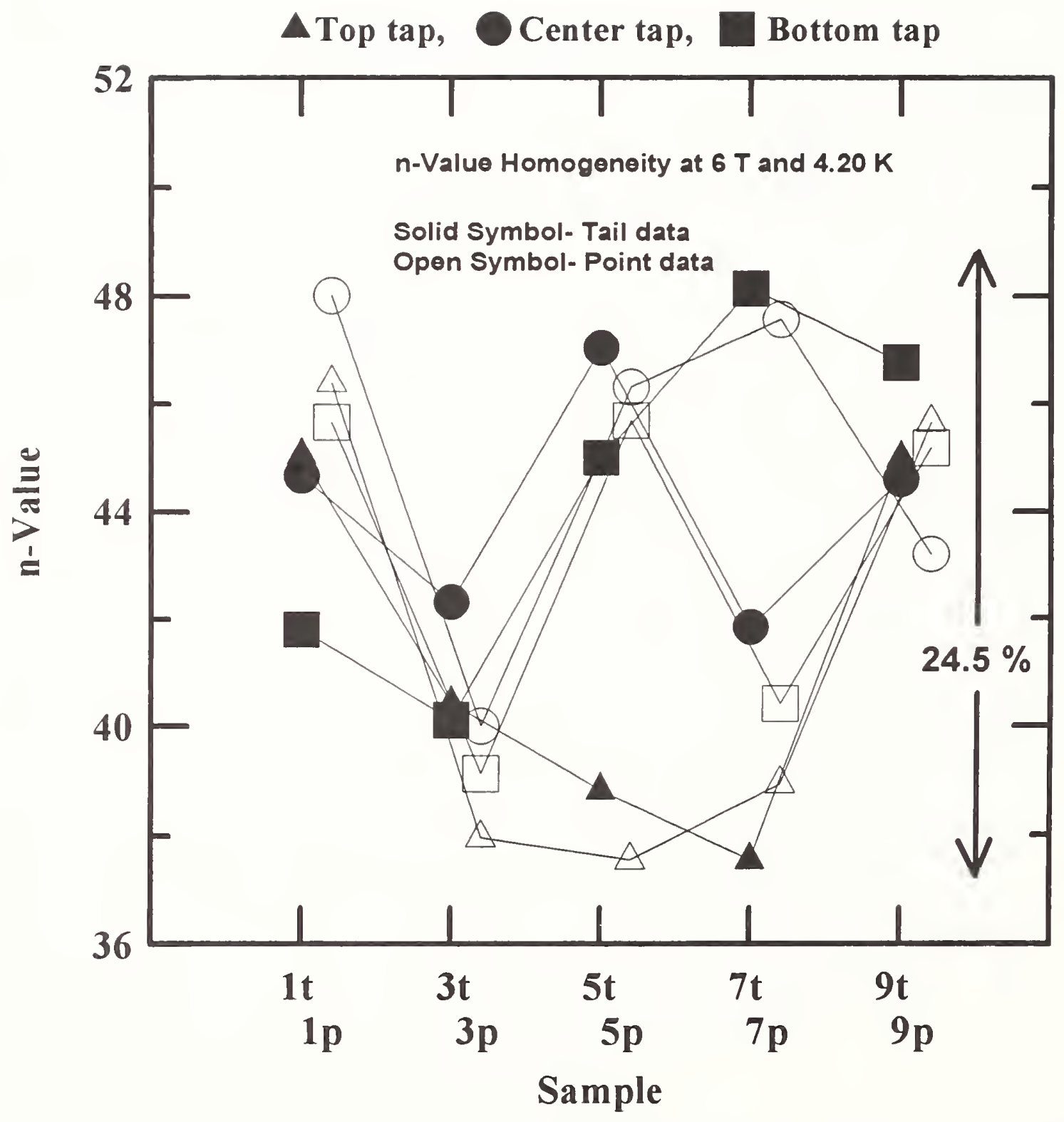

Figure 3-2b. n-values at $6 \mathrm{~T}, 4.2 \mathrm{~K}$, and $10 \mu \mathrm{V} / \mathrm{m}$ versus sample. Each sample had three pairs of voltage taps. 


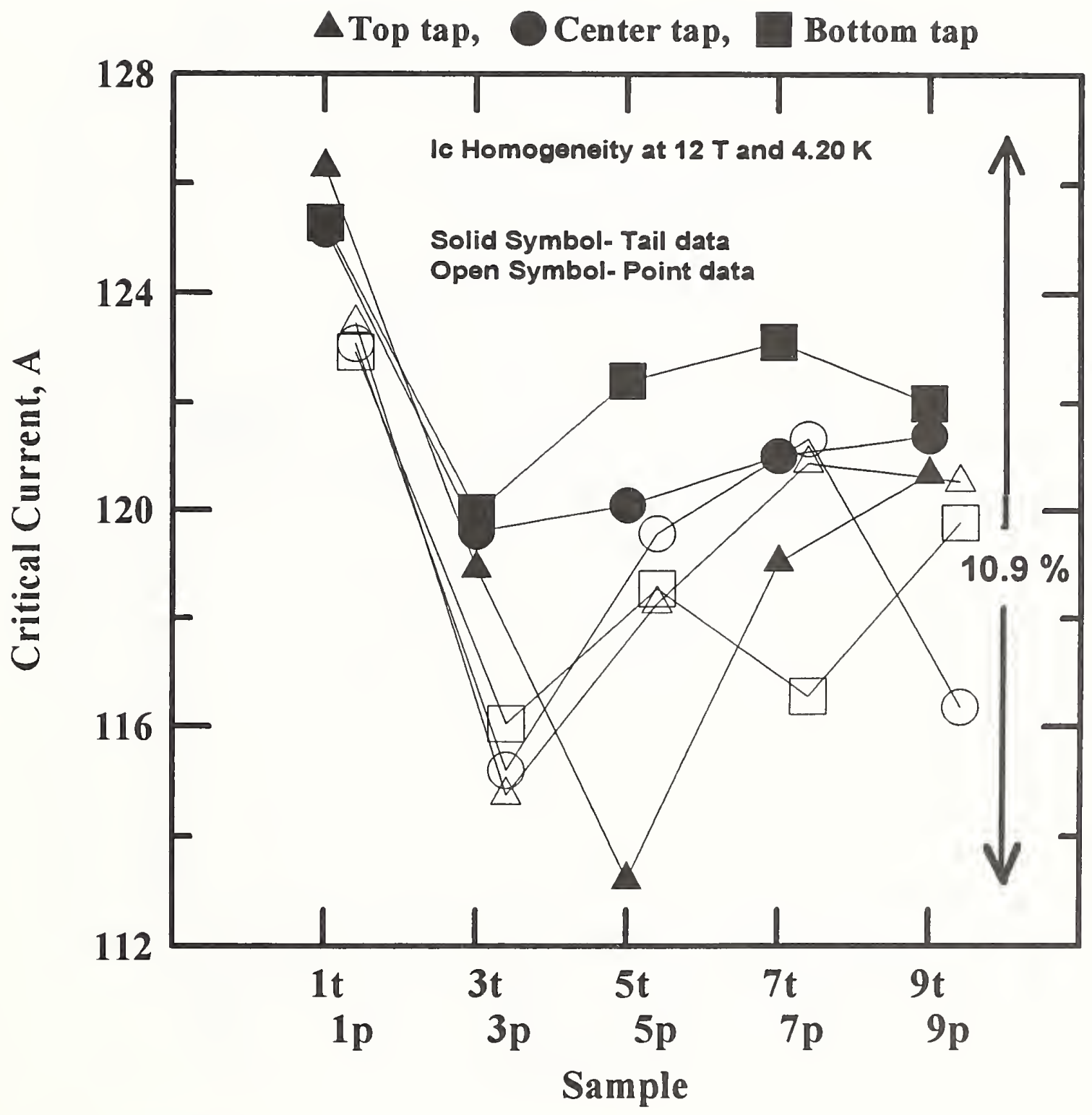

Figure 3-3a. Critical current at $12 \mathrm{~T}, 4.2 \mathrm{~K}$, and $10 \mu \mathrm{V} / \mathrm{m}$ versus sample. Each sample had three pairs of voltage taps. 


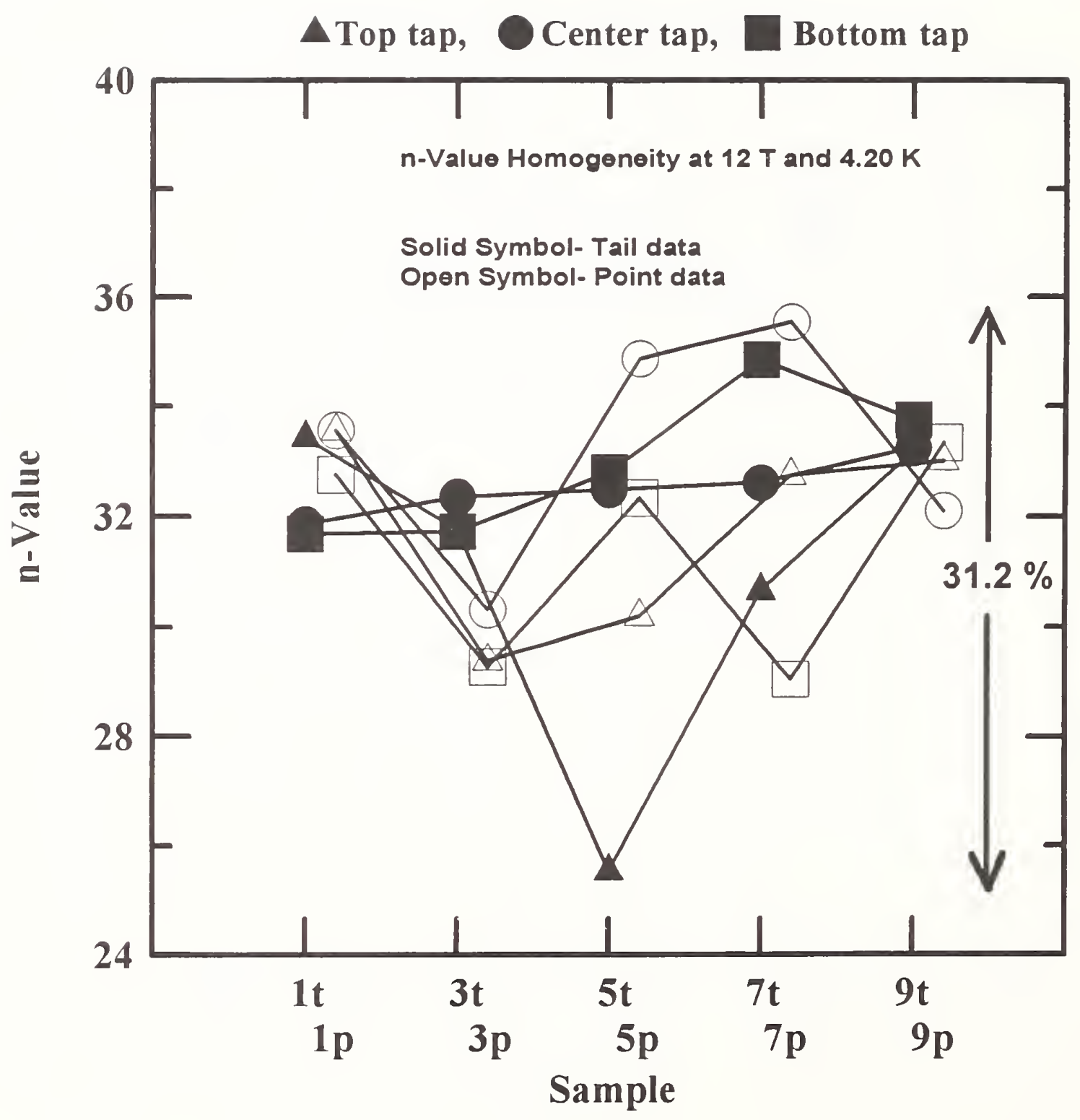

Figure 3-3b. n-values at $12 \mathrm{~T}, 4.2 \mathrm{~K}$, and $10 \mu \mathrm{V} / \mathrm{m}$ versus sample. Each sample had three pairs of voltage taps. 


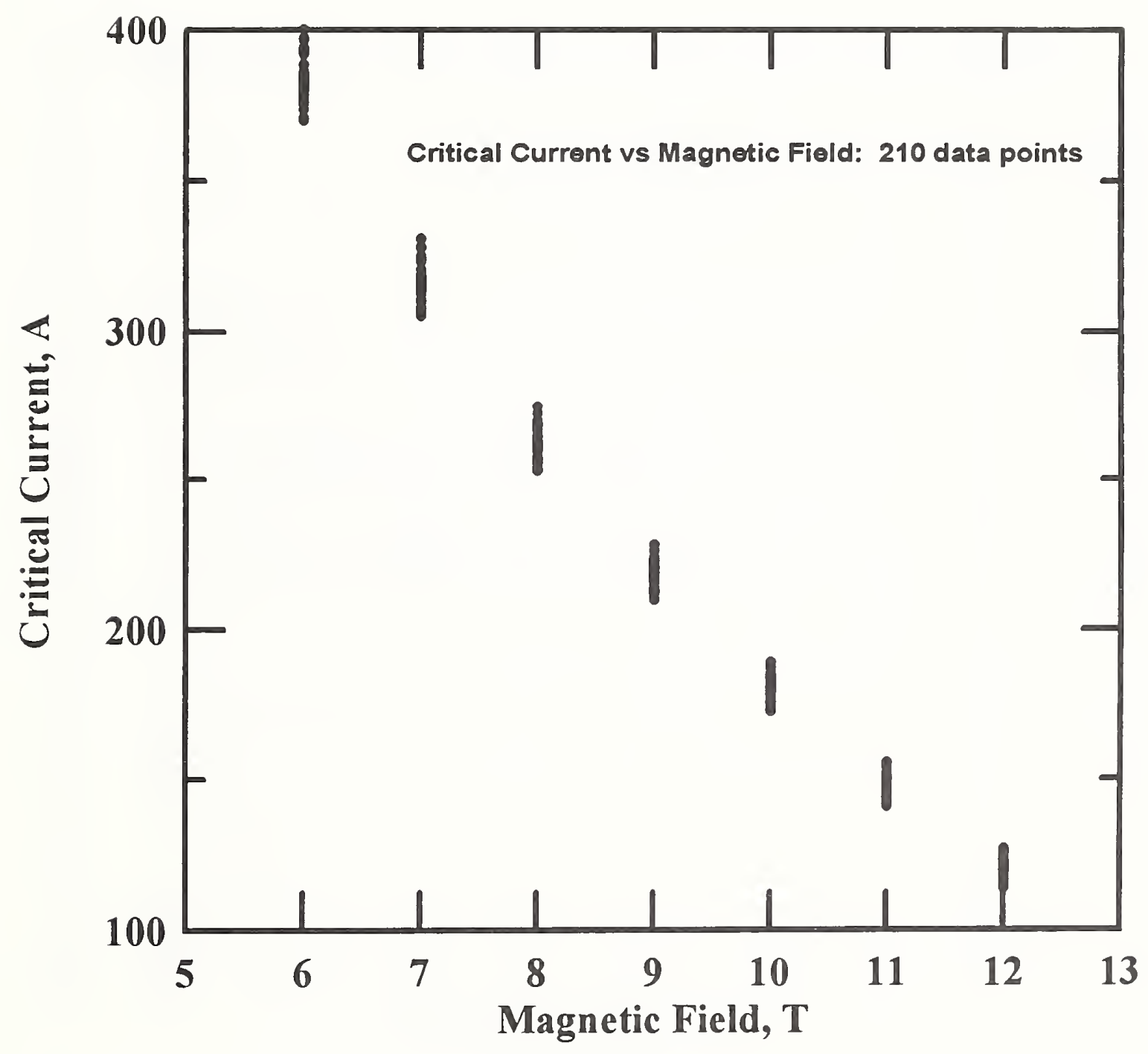

Figure 3-4. Critical current at $4.2 \mathrm{~K}$ versus magnetic field for three pairs of voltage taps on each of the ten samples. 


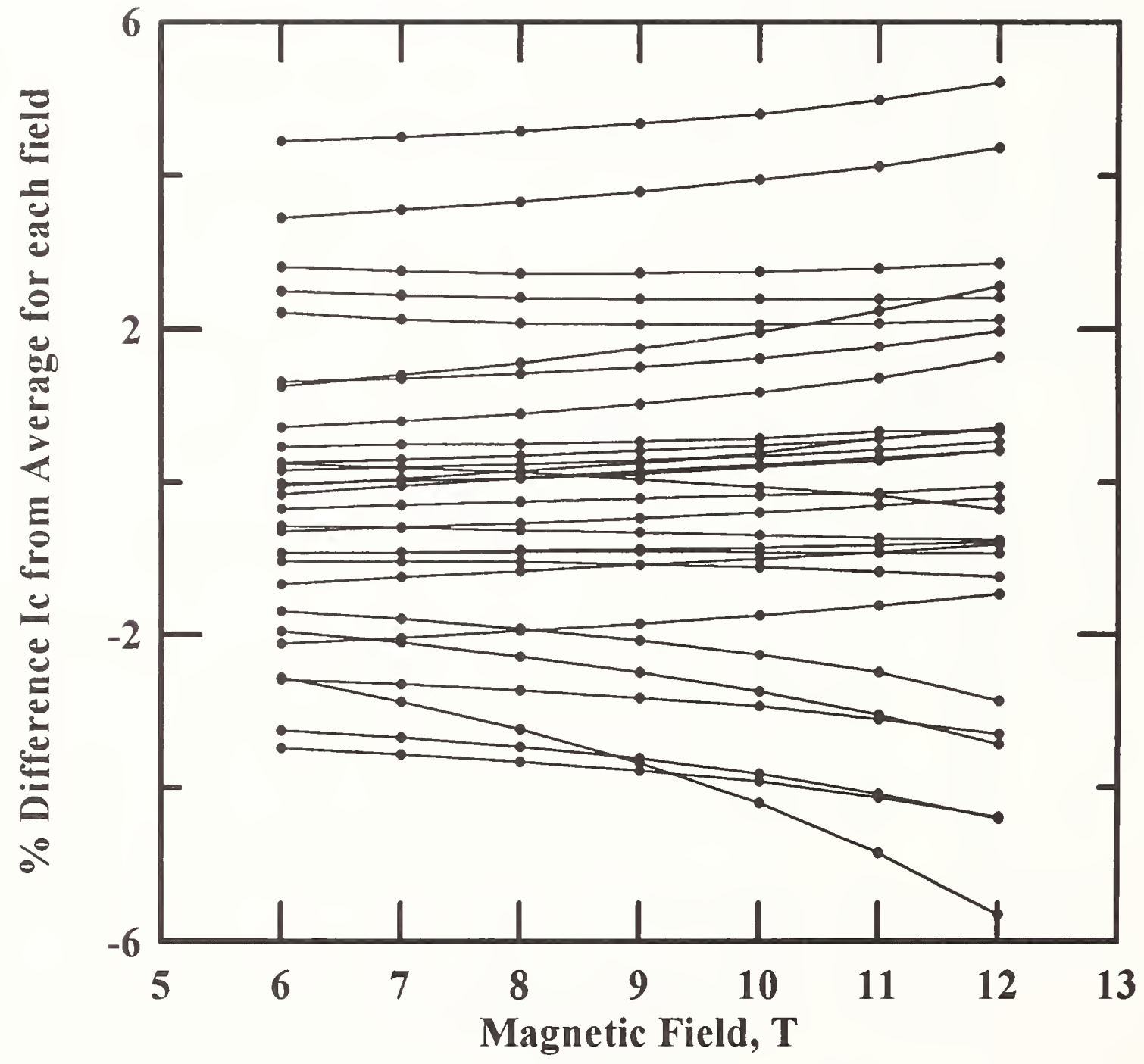

Figure 3-5. Percent difference of critical current at $4.2 \mathrm{~K}$ from the average critical current at each field versus magnetic field. The lines connect data points for a given tap on each specimen. 


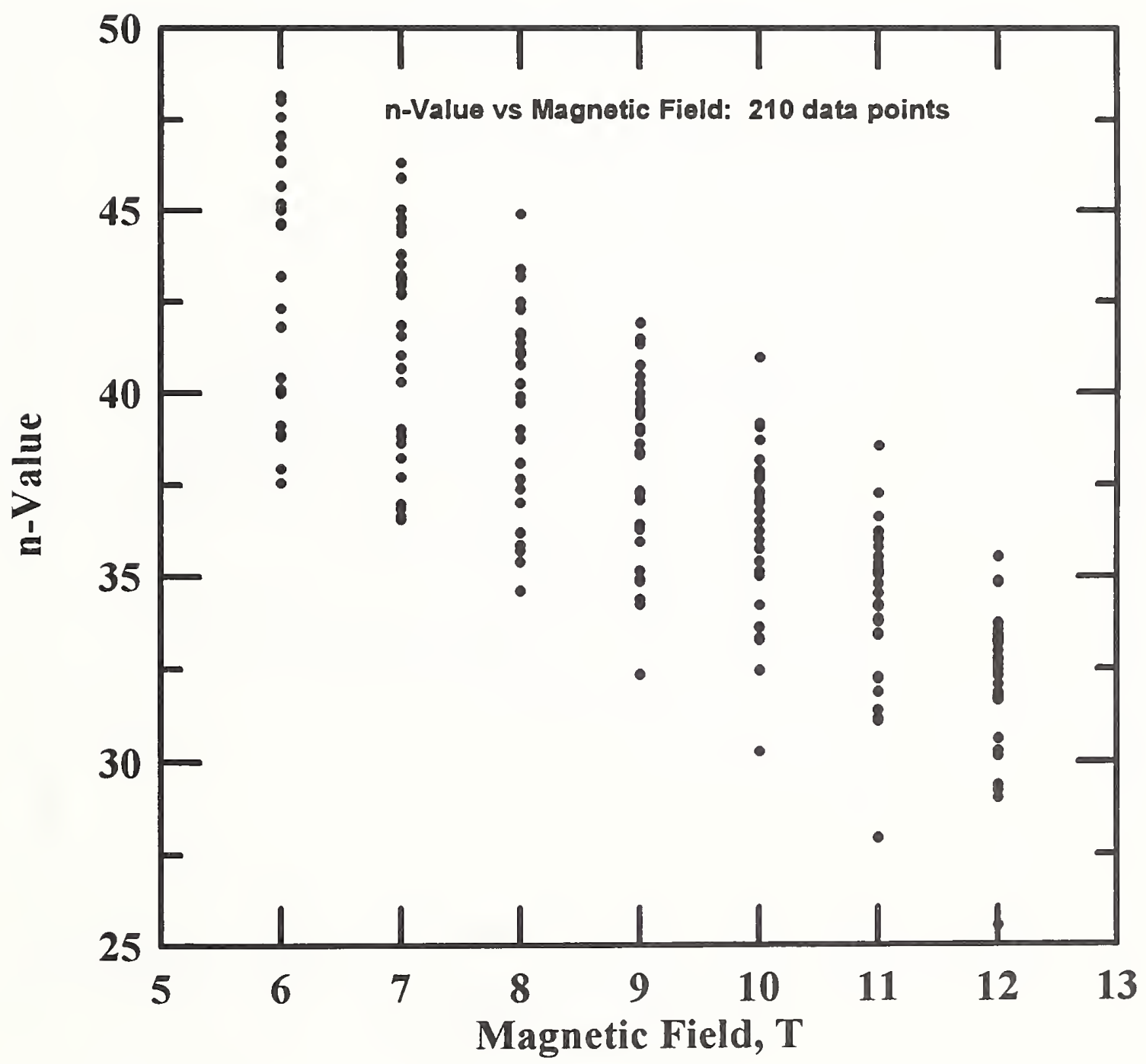

Figure 3-6. n-values at $4.2 \mathrm{~K}$ versus magnetic field for three pairs of voltage taps on each of the ten samples. 


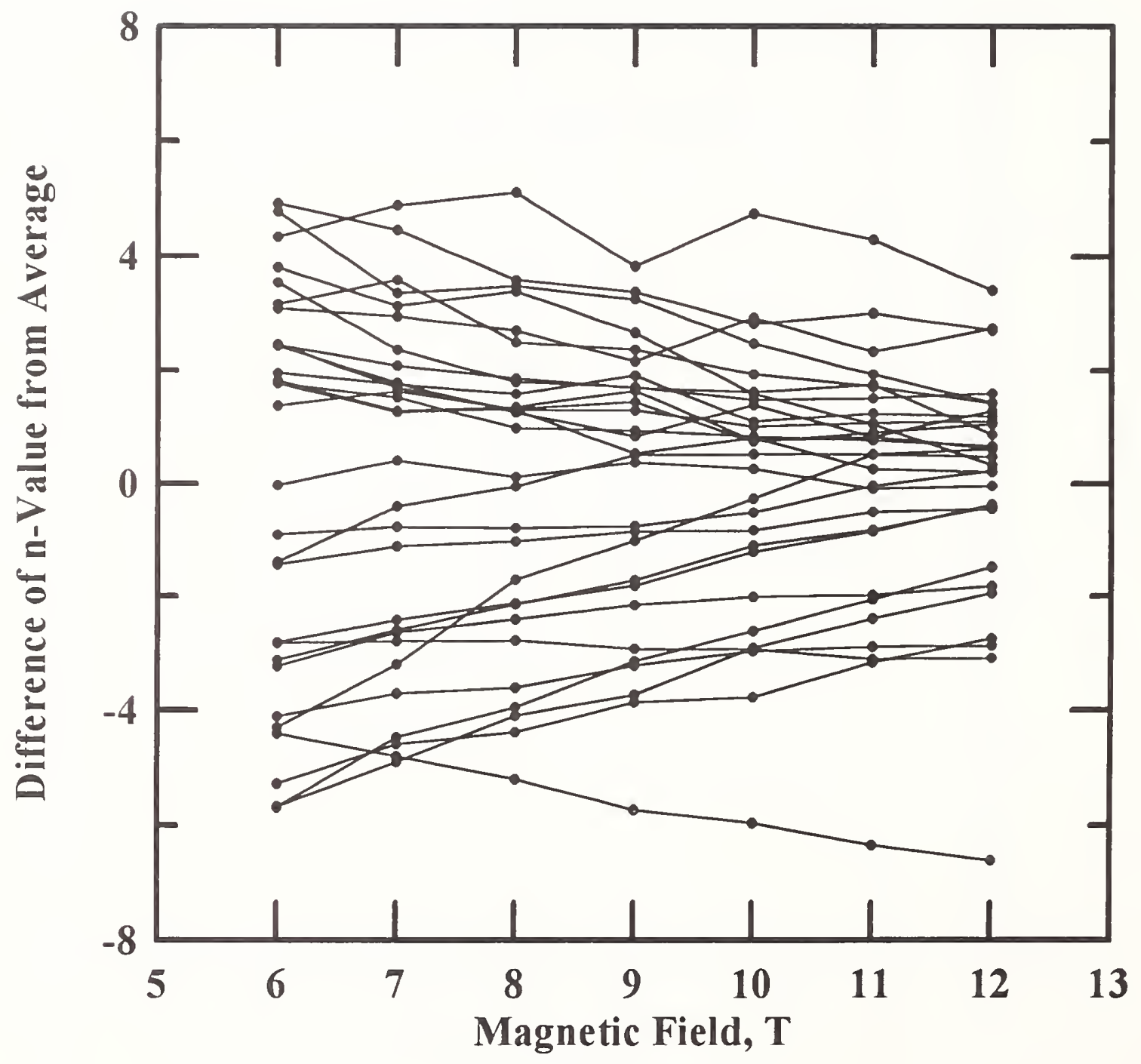

Figure 3-7. Difference of $\mathrm{n}$-value at $4.2 \mathrm{~K}$ from the average $\mathrm{n}$-value at each field versus magnetic field. The lines connect data points for a given tap on each specimen. 


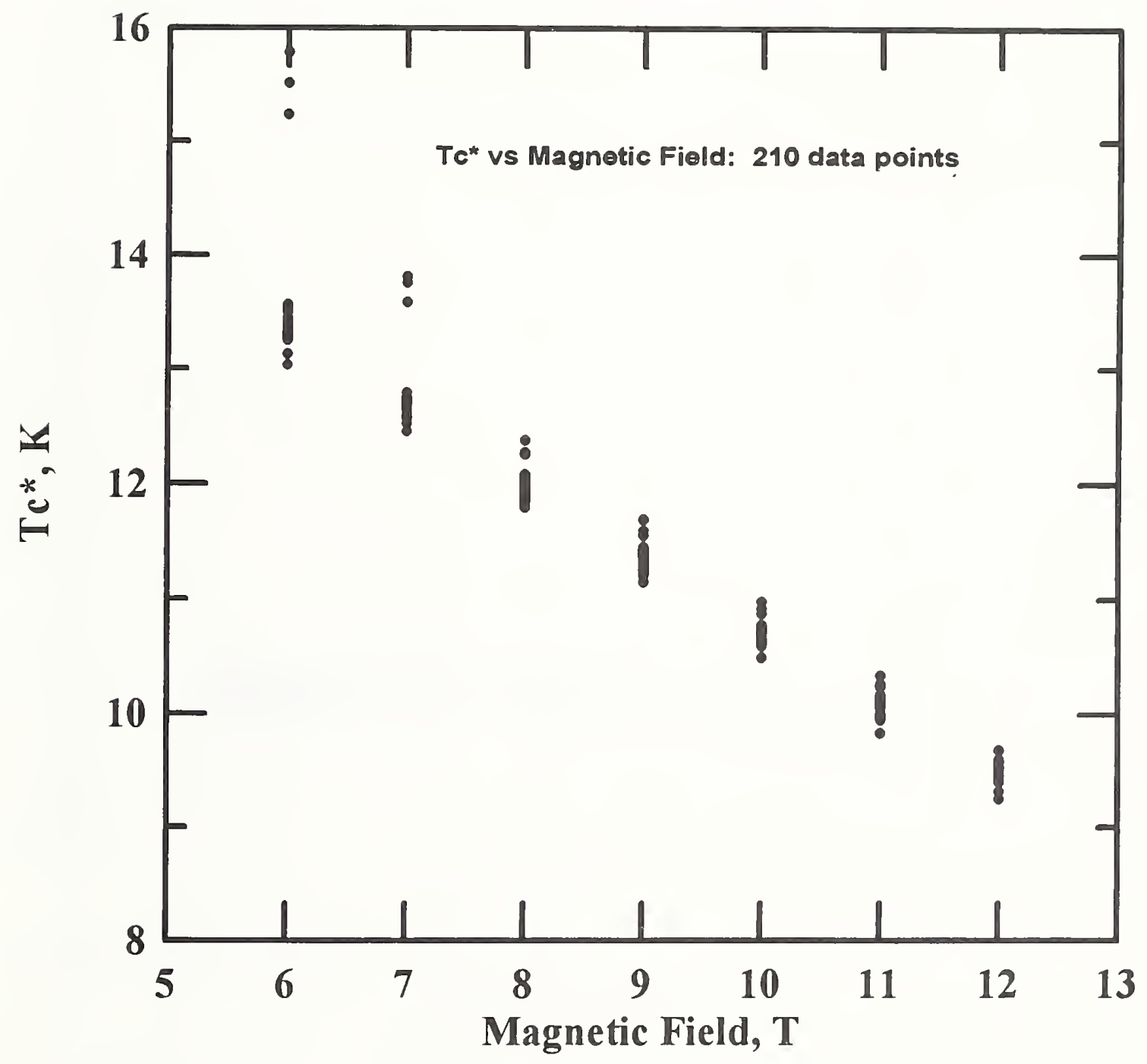

Figure 3-8. $T_{c} *$ versus magnetic field for three pairs of voltage taps on each of the ten samples. 


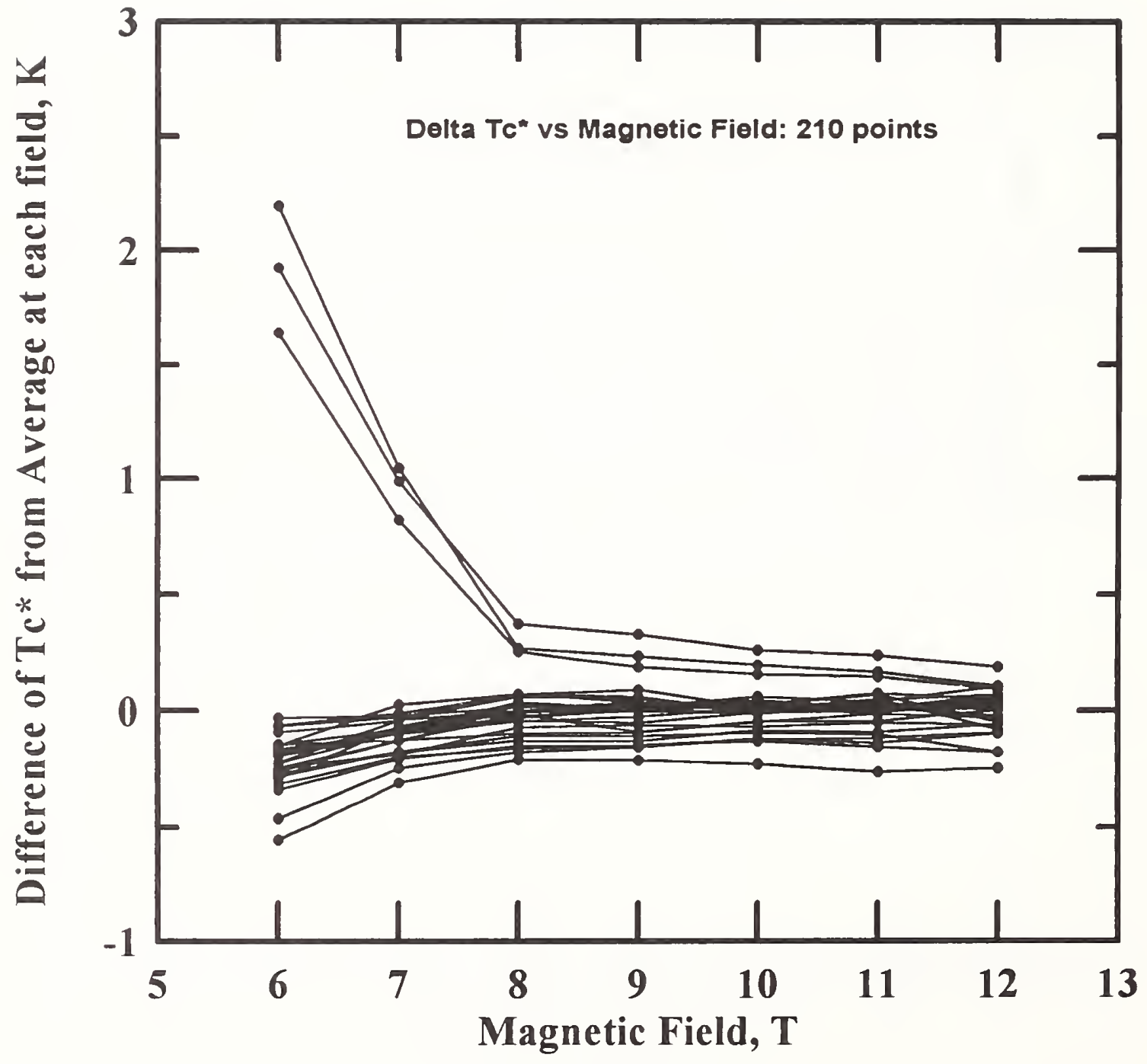

Figure 3-9. Difference of $T_{c}{ }^{*}$ from the average $T_{c}{ }^{*}$ at each field versus magnetic field. The lines connect data points for a given tap on each specimen. The $T_{c}{ }^{*}$ data for three taps on $7 t$ are outliers, possibly due to lack of thermal equilibrium. 


\section{OBSERVATIONS AND RECOMMENDATIONS ON THE CRITICAL CURRENT MEASUREMENT PROCEDURE}

This chapter is a collection of observations and recommendations that we made in our experience using the ITER Standard Critical Current test sample mandrel. This mandrel, adopted by the U.S. ITER Home Team, evolved from the designs used at the University of Wisconsin[1], MIT PFC [2], and Brookhaven National Lab and discussions at U.S. Home Team meetings. The details of the mandrel design and machining drawings were made by Makoto Takayasu (MIT-PFC). A detailed procedure entitled "ITER Critical Current Barrel Assembling" was written by M. Takayasu and R. N. Randall (MIT-PFC). This describes the preparation of the mandrel and sample for reaction and measurement.

\subsection{Critical Current Measurement Apparatus}

Our measurement apparatus consists of the following parts: G-10 structural tube, $19 \mathrm{~mm}(3 / 4 \mathrm{in})$ brass draw bolt, upper current contact lug, measurement mandrel with copper ring current contacts, lower current contact lug, and a brass nut (see Figure 4-1). The draw bolt is threaded into the G-10 tube and is keyed firmly in position. The G-10 tube also serves as a mounting position for the upper current contact lug and electrically isolates the two current contacts. The brass draw bolt extends through the center of the upper current contact lug, measurement mandrel, and lower current contact lug. An insulating sleeve is placed around the brass draw bolt to keep the stainless steel retaining wire from shorting to the draw bolt. The lower current contact lug is keyed to reduce its rotation about the draw bolt, thus minimizing the transfer of torsional strain to the mandrel or sample when pressure is applied to the system by the brass nut. The lower current contact lug is preloaded by hand with torque in the tight direction to take out the lash in the keyway and reduce the relative motion of the lug and ring when the brass nut is tightened. The lower current contact lug is also held in the tight direction when the brass nut is loosened after the measurements, to again reduce the relative motion of the lug and ring. Using a textbook expression we determined that a $19 \mathrm{~mm}(3 / 4 \mathrm{in})$ diameter bolt torqued to $10.2 \mathrm{~N} \cdot \mathrm{m}(7 \mathrm{ft}-\mathrm{lb})$ produces approximately $2500 \mathrm{~N}(560 \mathrm{lb})$ force. We estimate that the differential thermal contraction of the system would produce an additional $156 \mathrm{~N}(35 \mathrm{lb})$ of tightening force. The applied force aids in reducing the contact resistance.

Our measurement apparatus also employs two laminated $\mathrm{Nb}_{3} \mathrm{Sn}$ and $\mathrm{NbTi}$ current leads. One lead is soldered directly to the upper current contact lug of the apparatus. The other lead goes through the center of the draw bolt, the upper current contact lug, measurement mandrel, and lower current contact lug, and is connected to the lower current contact lug with a soldered splice. The splice is necessary for the placement and removal of the lower current contact lug and mounted specimen. 


\subsection{Current Contacts}

Before reaction, the specimen is wound onto the Ti mandrel with approximately 1.5 to 2.5 extra turns around a stainless steel spacer ring on either end of the mandrel. After reaction, in preparation for measurement, the turns at each end are cut so that approximately $3 / 4$ turn of the wire can be soldered with $\mathrm{Pb}-\mathrm{Sn}$ solder to the $\mathrm{Cu}$ current contact ring. This $3 / 4$ turn starts where the wire leaves the end of the grooved mandrel. We use only $3 / 4$ turn to reduce the possibility of persistent current flow in the contact ring.

The total resistance $\mathrm{R}_{\mathrm{c}}$ of the current contact needs to be kept low to reduce the ohmic heating of the specimen ends. A significant and variable part of this total resistance is the resistance of the pressure contact between the current lug and the $\mathrm{Cu}$ ring. It is important to monitor the total contact resistance as part of the measurement procedure. We used two different techniques for making the pressure contacts.

In one technique, the current contact lugs are tinned with a thin layer of pure In solder; a thick layer of In is soldered onto the specimen's current contact rings and then textured by rolling a knurled tool over it, thus creating a number of well defined ridges. Since the local pressure on these ridges is high, cold welding is promoted. Texturing results in a relatively constant solder thickness. Texturing also breaks up any surface oxide and allows for deformation to accommodate any slight misalignment of the pressure fixture.

The specimen mandrel is then placed onto the measurement apparatus and the draw bolt and nut sandwiches the mandrel with its current contact rings between the current contact lugs of the apparatus. After tightening the mandrel, we allow the In solder to creep for approximately $5 \mathrm{~min}$ and then we tighten the nut a second time. Every tightening of this nut is performed with a breakaway torque wrench set at $10.2 \mathrm{~N} \cdot \mathrm{m}(7 \mathrm{ft}-\mathrm{lb})$. Voltage leads from the specimen are then attached to the measurement apparatus. In addition to the three pairs of voltage taps on the specimen, we have a pair with one voltage tap on each $\mathrm{Cu}$ ring and a pair with one voltage tap on each lug. Measurements on the lug pair gives the total contact resistance, $R_{c}$. Typical values of $R_{c}$ are 0.5 to $1.5 \mu \Omega$ (total for both contacts). The power dissipation at $400 \mathrm{~A}$ and $1.5 \mu \Omega$ is $240 \mathrm{~mW}$ which is significant; however, this power is not right at the end of the sample, and the copper components will reduce the temperature rise. Typically, the resistance measured on the $\mathrm{Cu}$ ring pair is about $0.1 \mu \Omega$.

In the second technique, the current contact lugs are tinned with a thin layer of pure In solder and the specimen's current contact rings are sanded to a clean $\mathrm{Cu}$ surface. This reduces specimen preparation time. The $\mathrm{Cu}$ ring is carefully held and the end surface is lapped in a manner to reduce the force and torque on the specimen. This is done with fine-grit paper after the specimen is soldered on. After sanding, the ends of the $\mathrm{Cu}$ rings are cleaned with alcohol. Typical values of $R_{c}$ are 0.5 to $4 \mu \Omega$. This larger range of values may limit the measurement current to values less than $400 \mathrm{~A}$. Periodic reflowing and cleaning of the In solder on the current lugs may lower 
the contact resistance. We did this after every fourth specimen and we observed a trend of increasing $R_{c}$ with the aging of the In.

The first technique requires careful soldering of the pure In on the end of the $\mathrm{Cu}$ ring without unsoldering the $\mathrm{Pb}-\mathrm{Sn}$ joint that would result in a loss of specimen tension on the mandrel. Reusing the $\mathrm{Cu}$ rings can also require that the solders be cleaned off to avoid mixing of the two solders. These complications are avoided in the second technique.

\subsection{Electrolytic Method for Removing Cr Plating from Reacted $\mathrm{Nb}_{3} \mathrm{Sn}$ Wires}

We used an electrolytic oxalic acid bath [3] to etch the Cr coating off of the $3 / 4$ turn current contact region of each end of the wire. The bath was constructed using a stainless steel bath assembly, stainless-steel painted end cap, and a power supply limited at $6 \mathrm{~V}$ and $1 \mathrm{~A}$ (see Fig. 4$3)$. The cathode for the electrolytic etch consisted of the bath assembly in electrical contact with the end cap. The anode was the specimen itself; the positive terminal of the power supply was soldered to a small filed spot on the conductor. Lacquer was used to electrically isolate the mandrel from the stainless-steel end cap (cathode) as well as isolating the specimen (anode) from the end cap. The oxalic acid solution was composed of $10 \mathrm{~g}$ of oxalic acid and $100 \mathrm{ml}$ of distilled water. The oxalic acid solution was placed in the bath using an eye-dropper to a level that would safely etch the current contact region of the specimen without coming in contact with the Ti mandrel. The mandrel is placed into the end cap, thus allowing the sample to be immersed in the oxalic acid solution. There is no sign of chemical activity until the current is turned on. When the current is applied, a violent fizzing ensues for about $2 \mathrm{~min}$, after which the current drops, indicating that the $\mathrm{Cr}$ is fully etched. We think that the acid does not etch the $\mathrm{Cu}$ sample appreciably. This process is repeated for the other end of the specimen. The entire specimen and the mandrel are then immersed into a soap bath in an ultrasonic cleaner to remove the $\mathrm{Cr}$ etch waste material. In some cases, we etched the specimen again after the cleaning. The sample is then ready for soldering onto the $\mathrm{Cu}$ current contact rings.

We have not performed conclusive tests on this process nor studied the relative merits of this process compared to mechanical abrasion or $\mathrm{HCl}$ etching. The electrolytic oxalic acid etch removes the $\mathrm{Cr}$ effectively with little risk of sample damage and yields a low contact resistance joint.

\subsection{Superconductivity of the Ti-6Al-4V Measurement Mandrel}

We discovered in this study that the Ti-6Al-4V measurement mandrel itself is superconducting at $4.2 \mathrm{~K}$ and at magnetic fields below $2 \mathrm{~T}$. Therefore, reliable $\mathrm{I}_{\mathrm{c}}$ measurements can be obtained only at magnetic fields higher than $2 \mathrm{~T}$ at $4.2 \mathrm{~K}$ with this mandrel material. Each element of this alloy is superconducting at some temperature according to the textbooks (Ti:0.4 K, Al:1.2 K, and V:5.3 $\mathrm{K})$. Vanadium is the element of concern, but it is a minority component of the alloy which makes 
the transition temperature of the alloy hard to predict. We ran experiments on annealed and unannealed mandrels to determine the critical current and resistance at magnetic fields of up to $12 \mathrm{~T}$.

Our measurements of critical current and resistance were made on actual machined mandrels that were thought to be more direct than a calculation based on measurements on a more nearly ideal specimen geometry. The more nearly ideal specimen geometry would neglect to account for the deep spiral groove and machining effects. The short cylinder geometry of the mandrel and the fact that contacts could not be soldered to the mandrel severely limited the accuracy of the measured resistance values due to uncertainty in the distribution of the current density. An alternative approach to measuring the resistance may be to take a slice of the mandrel material that is more suitable for resistivity measurements instead of measuring the entire mandrel. This may yield more accurate measurements.

We normalized the measured values of resistance in order to compare the two materials and their transitions. The normalized resistance $\mathrm{R}_{\mathrm{n}}$ is the measured resistance divided by the normal state resistance, expressed in percent. The values that we obtained for the normal state resistance of voltage taps separated by $1.27 \mathrm{~cm}$ were: $160 \mu \Omega$ for annealed at $4.0 \mathrm{~K}$ and $4.2 \mathrm{~K}$ and $95 \mu \Omega$ for the unannealed at $4.2 \mathrm{~K}$. The difference between these two normal state resistance values is likely due to systematic differences in the current distribution in these two measurements. Tables 4-1 and 4-2 give the critical current and normalized resistance values for an annealed mandrel in fields of 0 to $8 \mathrm{~T}$ at $4.0 \mathrm{~K}$ and in fields of 0 to $4 \mathrm{~T}$ at $4.2 \mathrm{~K}$ respectively. Table $4-3$ gives the $I_{c}$ and $R_{n}$ values for the unannealed mandrel material in fields of 0 to $12 \mathrm{~T}$ at $4.2 \mathrm{~K}$. $\mathrm{I}_{\mathrm{c}}$ values are listed at two criteria, 1 and $10 \mu \mathrm{V} / \mathrm{cm}$. $\mathrm{R}_{\mathrm{n}}$ values are listed at three current levels: 1,10 , and $50 \mathrm{~A}$. There was negligible change in resistance above $4 \mathrm{~T}$.

Annealing the alloy could change the morphology of the alloy and/or reduce the pinning force; thus lowering the measured critical current significantly. For example, in zero field at $4.2 \mathrm{~K}$, the annealed mandrel had a critical current of $0.56 \mathrm{~A}$ while the unannealed mandrel had a critical current of greater than $112 \mathrm{~A}$. The shunt path through the mandrel is much shorter than the spiral path of the superconducting wire, which is why the high criteria of 1 and $10 \mu \mathrm{V} / \mathrm{cm}$ were selected for these measurements. The $n$-value of the mandrel is very low, which makes the $I_{c}$ at $10 \mu \mathrm{V} / \mathrm{cm}$ much higher than at $1 \mu \mathrm{V} / \mathrm{cm}$.

Another factor in considering how much current will flow through the mandrel during a measurement of superconductor wire is the contact resistance between the $\mathrm{Cu}$ ring and the mandrel. This contact resistance was observed to be as high as $300 \mu \Omega$ even when the surfaces of the mandrel were cleaned. If superconducting wire was diffusion bonded to the mandrel during the heat treatment, this contact resistance would be much lower.

One possible alternative material is Ti-5Al-2.5Sn. The $\mathrm{T}_{\mathrm{c}}$ of $\mathrm{Sn}$ is $3.7 \mathrm{~K}$; thus this alloy should not be superconducting at temperatures above $3.7 \mathrm{~K}$. The thermal contraction of this alloy is 
about $0.15 \%$ from 293 to $4 \mathrm{~K}$. The availability, machinability, oxidation, and high temperature properties would need to be determined.

\subsection{Critical Current Measurements on the Nb-Ti Wire SRM-1457}

We made $I_{c}$ measurements on the Nb-Ti wire Standard Reference Material (SRM-1457) which we mounted on the Ti alloy mandrel to compare to previous measurements on a G-10 mandrel. A summary of a number of $I_{c}$ measurements is given in Table 4-4 and percentage differences from the reference data are plotted in Figure 4-4. The reference data in column 2 of the table are NIST measurement on SRM-1457 mounted on the G-10 mandrel used in the 1990-91 Versailles Project on Advanced Materials and Standards (VAMAS) interlaboratory comparison [4]. The average results of 12 laboratories in VAMAS comparison are within $0.5 \%$ of the reference data. The two runs of one specimen on a Ti alloy mandrel are systematically higher, within about $0.6 \%$. The difference between the two runs was less than $0.05 \%$ showing the repeatability of the $I_{c}$ measurements on the $\mathrm{Ti}$ mandrel and the potential use of such specimens for precise interlaboratory comparisons. The results on the second specimen on the Ti mandrel were slightly higher, about $0.2 \%$, than the first and had a similar systematic trend with magnetic field. The G10 mandrel, on which the reference data was taken, had a smaller diameter $(25 \mathrm{~mm})$ than the Ti alloy mandrel $(32 \mathrm{~mm})$, which could contribute to the observed differences. All of these differences are well within the uncertainty of the measurements and the variability of the SRM.

A summary of the measured $n$-values corresponding to the above $I_{c} s$ is given in Table 4-5 and the $\mathrm{n}$-value differences relative to the reference data are shown in Figure 4-5. The n-values measured on the Ti alloy were somewhat lower than the reference data which was obtained on a G-10 mandrel. The significance of this difference is not known because of systematic differences in the data acquisition and the determination of the $n$-value.

An $\mathrm{I}_{\mathrm{c}}$ measurement was made on the SRM at $12 \mathrm{~T}$ to determine the possible effect of current sharing between the $\mathrm{Nb}$-Ti sample and the Ti alloy mandrel. The measured $\mathrm{I}_{\mathrm{c}}$ was approximately $13 \mathrm{~mA}$ at $10 \mu \mathrm{V} / \mathrm{m}$, which indicates that there is very little current sharing.

\subsection{Observations on the Standard Specimen Mandrel}

Some observations were made concerning the design and use of the Ti alloy specimen mandrels. The design of a mandrel that will be used for sample reaction and subsequently for measurement is challenging. Furthermore, there is a trade off between the complexity of the design and the ease of use and fabrication.

The quality of the fit of the current contact ring onto the barrel (main tube) is critical to preventing specimen damage. A stainless steel retaining pin is used to hold the Ti spacer rings in place on 
the barrel during reaction as well as holding the copper terminals on the barrel for measurement. The retaining pin goes across the diameter of the barrel and pins the spacer or copper rings at points $180^{\circ}$ apart from each other. This pin is shaped like the capital Greek letter omega $(\Omega)$. Since the pin cannot be absolutely tight in the pinholes, there is room for the rings to move, either in a rocking motion or a slight rotation. Three situations were observed in which the specimen was damaged because the current contact ring was not fitted correctly.

There was a random phase relation between the pinhole locations and the region where the specimen leaves the barrel and goes onto the contact. If the two are out of phase with each other, a rocking motion might damage the specimen; this situation would be extreme when the phase difference is $90^{\circ}$. We observed specimen damage on a mandrel that had a large rocking latitude on one current contact ring. The damage was between this ring and the nearest voltage tap and this damage limited the measurement current through the specimen. Also, if care is not taken in winding the specimen onto the mandrel before reaction, the rocking motion may cause a small diameter specimen to fall between the end of the grooved barrel and the spacer ring, changing its shape. This has happened, and the reshaping of the specimen may have caused damage.

Another situation arose with a specimen in which the retaining wire had missed the pinhole in the barrel, before the reaction, and only went through the pin hole in the spacer ring. As a result, the spacer ring was tilted, and there was a large gap between the ring and the barrel. The specimen fell into this gap when it was wrapped onto the mandrel and it was reacted to that shape. The current contact could not be put on without moving the specimen from its reacted position to conform to the current contact, which resulted in damage to the specimen.

Another situation occured because there was a slight rotation between the barrel and copper ring which caused the specimen to loosen itself on the barrel. To counter this effect the copper ring can be preloaded, before soldering, in a manner to remove the rotational slack that otherwise would release specimen tension.

A modification that would reduce the effect of all three of these situations would be to add a second omega-shaped pin $90^{\circ}$ out of phase with the first. This may or may not be easy to implement now.

Several specimens bonded to the mandrel during instrumentation. In these cases the specimen was slightly uncoiled to break the bonds to the mandrel. Although great care was taken in breaking the specimen away from the mandrel, the specimen may have experienced some damage. As the mandrels are used repeatedly, their oxidation may become more complete, resulting in less bonding. 


\subsection{References}

[1] Meingast, C; Larbalestier, D.C. J. Appl. Phys. 66, p 5971; 1989.

[2] Takayasu, M.; Gung, C.Y.; Steeves, M.M.; Hoenig, M. O.; Hale, J. R.; Smathers, D. B. IEEE Trans. Mag., 27, No. 2, p. 1767; 1991.

[3] Petzow, G. "Metallographic Etching," American Society for Metals, p. 57; 1978.

[4] Wada, H.; Itoh, K. Cryogenics ICMC Supplement 32, p. 557; 1992. 
Table 4-1. Critical current and resistance values of annealed/oxidized Ti-6Al-4V measurement mandrel material@4.0 K.

\begin{tabular}{||c|r|r|r|r|r||}
\hline \hline$\mu_{0} \mathrm{H}, \mathrm{T}$ & $\mathrm{I}_{c}(1 \mu \mathrm{V} / \mathrm{cm})$ & $\mathrm{I}_{c}(10 \mu \mathrm{V} / \mathrm{cm})$ & $\mathrm{R} / \mathrm{R}_{\mathrm{n}} @ 1 \mathrm{~A}$ & $\mathrm{R} / \mathrm{R}_{\mathrm{n}} @ 10 \mathrm{~A}$ & $\mathrm{R} / \mathrm{R}_{\mathrm{n}} @ 50 \mathrm{~A}$ \\
\hline 0 & $0.56 \mathrm{~A}$ & $1.91 \mathrm{~A}$ & $2.5 \%$ & $8.8 \%$ & $14 \%$ \\
\hline 0.5 & $0.27 \mathrm{~A}$ & $1.17 \mathrm{~A}$ & $6.3 \%$ & $14 \%$ & $26 \%$ \\
\hline 1 & $0.18 \mathrm{~A}$ & $0.89 \mathrm{~A}$ & $8.8 \%$ & $20 \%$ & $35 \%$ \\
\hline 1.5 & $0.13 \mathrm{~A}$ & $0.69 \mathrm{~A}$ & $13 \%$ & $26 \%$ & $47 \%$ \\
\hline 2 & $0.08 \mathrm{~A}$ & $0.52 \mathrm{~A}$ & $18 \%$ & $33 \%$ & $70 \%$ \\
\hline 2.5 & $0.028 \mathrm{~A}$ & $0.26 \mathrm{~A}$ & $34 \%$ & $52 \%$ & $93 \%$ \\
\hline 3 & $0.011 \mathrm{~A}$ & $0.11 \mathrm{~A}$ & $74 \%$ & $83 \%$ & $99 \%$ \\
\hline 4 & & $0.08 \mathrm{~A}$ & $100 \%$ & $100 \%$ & \\
\hline 8 & & & $100 \%$ & $100 \%$ & \\
\hline
\end{tabular}

Table 4-2. Critical current and resistance values of annealed/oxidized Ti-6Al-4V measurement mandrel material@ @ $4.2 \mathrm{~K}$.

\begin{tabular}{||c|r|r|r|r|r||}
\hline$\mu_{0} \mathrm{H}, \mathrm{T}$ & $\mathrm{I}_{c}(1 \mu \mathrm{V} / \mathrm{cm})$ & $\mathrm{I}_{c}(10 \mu \mathrm{V} / \mathrm{cm})$ & $\mathrm{R}_{\mathrm{R}} @ 1 \mathrm{~A}$ & $\mathrm{R} / \mathrm{R}_{\mathrm{n}} @ 10 \mathrm{~A}$ & $\mathrm{R} / \mathrm{R}_{\mathrm{n}} @ 50 \mathrm{~A}$ \\
\hline 0 & $0.35 \mathrm{~A}$ & $1.64 \mathrm{~A}$ & $3.1 \%$ & $10 \%$ & $16 \%$ \\
\hline 0.5 & $0.21 \mathrm{~A}$ & $1.01 \mathrm{~A}$ & $7.5 \%$ & $17 \%$ & $31 \%$ \\
\hline 1 & $0.13 \mathrm{~A}$ & $0.74 \mathrm{~A}$ & $12 \%$ & $24 \%$ & $46 \%$ \\
\hline 1.5 & $0.083 \mathrm{~A}$ & $0.52 \mathrm{~A}$ & $18 \%$ & $34 \%$ & $71 \%$ \\
\hline 2 & $0.024 \mathrm{~A}$ & $0.24 \mathrm{~A}$ & $38 \%$ & $54 \%$ & $93 \%$ \\
\hline 2.5 & $0.010 \mathrm{~A}$ & $0.10 \mathrm{~A}$ & $77 \%$ & $86 \%$ & $99 \%$ \\
\hline 3 & $0.0082 \mathrm{~A}$ & $0.081 \mathrm{~A}$ & $98 \%$ & $99 \%$ & $99 \%$ \\
\hline 4 & $0.0079 \mathrm{~A}$ & $0.079 \mathrm{~A}$ & $100 \%$ & $100 \%$ & $99 \%$ \\
\hline
\end{tabular}

Table 4-3. Critical current and resistance values of unannealed Ti-6Al-4V measurement mandrel material @4.2 K.

\begin{tabular}{|c|c|c|c|c|c|c|}
\hline$\mu_{0} \mathrm{H}, \mathrm{T}$ & $\mathrm{I}_{c}(1 \mu \mathrm{V} / \mathrm{cm})$ & $\mathrm{I}_{c}(10 \mu \mathrm{V} / \mathrm{cm})$ & $\mathrm{R} / \mathrm{R}_{\mathrm{n}} @ 1 \mathrm{~A}$ & $\mathrm{R} / \mathrm{R}_{\mathrm{n}} @ 10 \mathrm{~A}$ & & R/R $@ 50 \mathrm{~A}$ \\
\hline 0 & $>112 \quad \mathrm{~A}$ & & & & & $0.0002 \%$ \\
\hline 0.5 & $>80$ & $>80 \quad A$ & & & & $0.0002 \%$ \\
\hline 1 & $\mathrm{~A}$ & $56 \quad \mathrm{~A}$ & & $<0.0005$ & & $0.11 \%$ \\
\hline 1.5 & $3.6 \quad \mathrm{~A}$ & $9.8 \mathrm{~A}$ & $<1.1 \%$ & 1.1 & & 74 \\
\hline 2 & $0.072 \mathrm{~A}$ & $0.67 \mathrm{~A}$ & $20 \%$ & $8 ?$ & & 96 \\
\hline 2.5 & $0.017 \mathrm{~A}$ & $0.17 \mathrm{~A}$ & $80 \%$ & 89 & & 99 \\
\hline 3 & $0.013 \mathrm{~A}$ & $0.13 \mathrm{~A}$ & $97 \%$ & 89 & & 100 \\
\hline 3 & $0.012 \mathrm{~A}$ & $0.13 \mathrm{~A}$ & $100 \%$ & 100 & & 100 \\
\hline 8 & $0.015 \mathrm{~A}$ & $0.13 \mathrm{~A}$ & $100 \%$ & 100 & & 100 \\
\hline 12 & $0.015 \mathrm{~A}$ & $0.13 \mathrm{~A}$ & $100 \%$ & 100 & & 100 \\
\hline
\end{tabular}


Table 4-4. Critical current measurements on SRM-1457.

\begin{tabular}{||c|r|r|r|r|r|}
\hline Field & \multicolumn{1}{|c|}{$\begin{array}{c}\text { Reference } \\
\text { data }\end{array}$} & $\begin{array}{c}\text { VAMAS } \\
\text { average }\end{array}$ & $\begin{array}{c}\text { Specimen 1 } \\
\text { run A on Ti }\end{array}$ & $\begin{array}{c}\text { Specimen 1 } \\
\text { run B on Ti }\end{array}$ & $\begin{array}{c}\text { Specimen 2 } \\
\text { run A on Ti }\end{array}$ \\
\hline 2 & 295.84 & & 296.415 & 296.453 & 297.123 \\
\hline 3 & 229.8 & & 230.144 & 230.197 & 230.491 \\
\hline 3 & 186.88 & & 187.068 & 187.063 & 187.335 \\
\hline 5 & 153.17 & & 153.343 & 153.343 & 153.579 \\
\hline 6 & 123.34 & 122.691 & 123.703 & 123.721 & 123.926 \\
\hline 7 & 95.46 & 95.255 & 95.857 & 95.899 & 96.089 \\
\hline 6 & 68.16 & 68.107 & 68.528 & 68.521 & 68.741 \\
\hline 9 & 40.9 & 40.83 & 41.156 & 41.171 & 41.356 \\
\hline \hline
\end{tabular}

Table 4-5. n-Value measurement on SRM-1457.

\begin{tabular}{|c|c|c|c|c|c|}
\hline Field & $\begin{array}{c}\text { Reference } \\
\text { Data }\end{array}$ & $\begin{array}{c}\text { VAMAS } \\
\text { average }\end{array}$ & $\begin{array}{c}\text { Specimen 1 } \\
\text { run A on Ti }\end{array}$ & $\begin{array}{c}\text { Specimen 1 } \\
\text { run B on Ti }\end{array}$ & $\begin{array}{c}\text { Specimen 2 } \\
\text { run A on Ti }\end{array}$ \\
\hline 2 & 58 & & 55.95 & 56.72 & 55.77 \\
\hline 3 & 58 & & 55.03 & 55.95 & 54.63 \\
\hline 3 & 58 & & 53.97 & 54.65 & 53.4 \\
\hline 5 & 57 & & 51.85 & 52.41 & 51.49 \\
\hline 6 & 53 & 54.28 & 48.75 & 49.37 & 48.58 \\
\hline 7 & 49 & 45.62 & 44.19 & 43.91 & 43.64 \\
\hline 6 & 42 & 40.06 & 36.78 & 36.91 & 36.31 \\
\hline 9 & 30 & 28.39 & 26.83 & 26.32 & 26.32 \\
\hline \hline
\end{tabular}




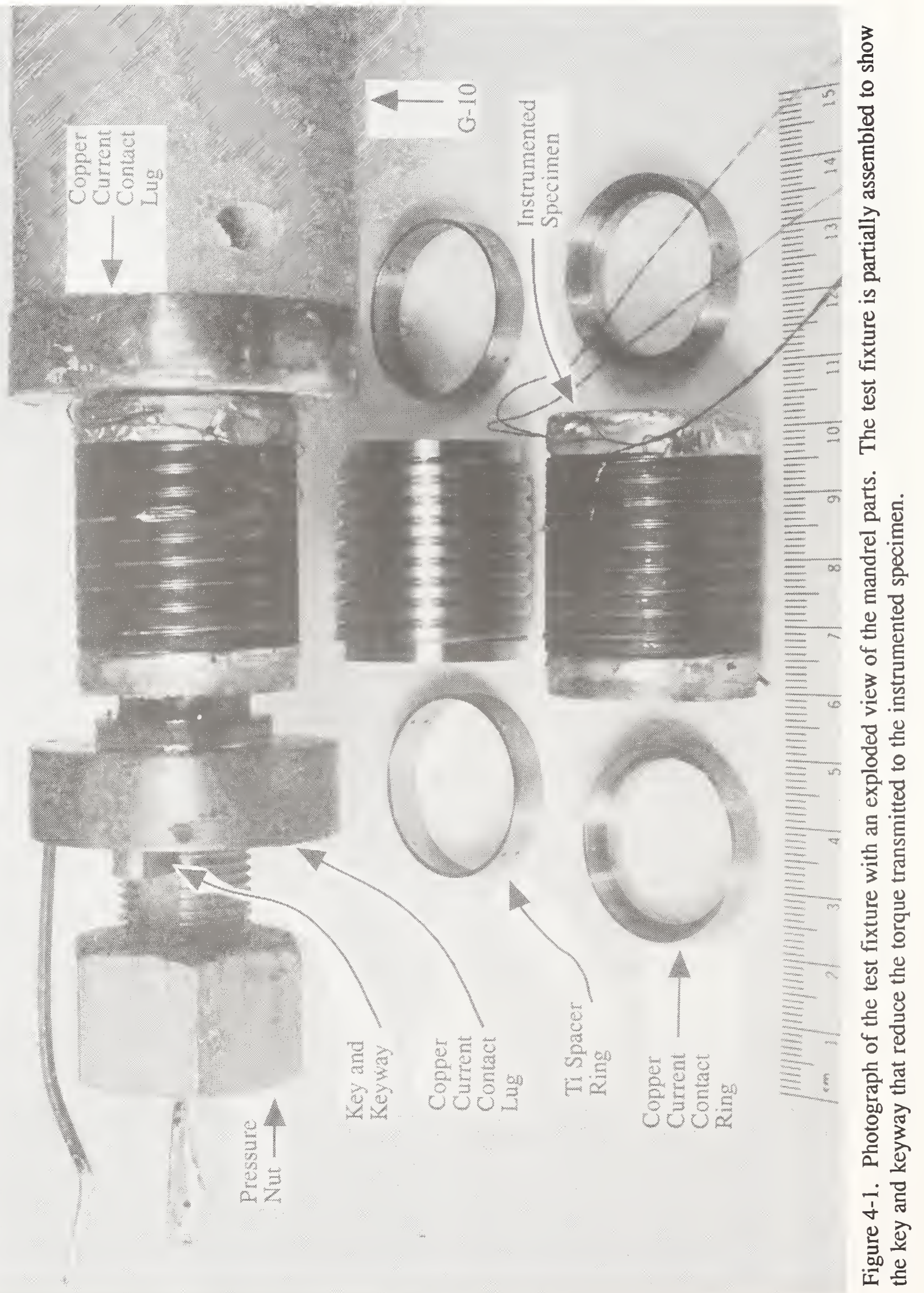




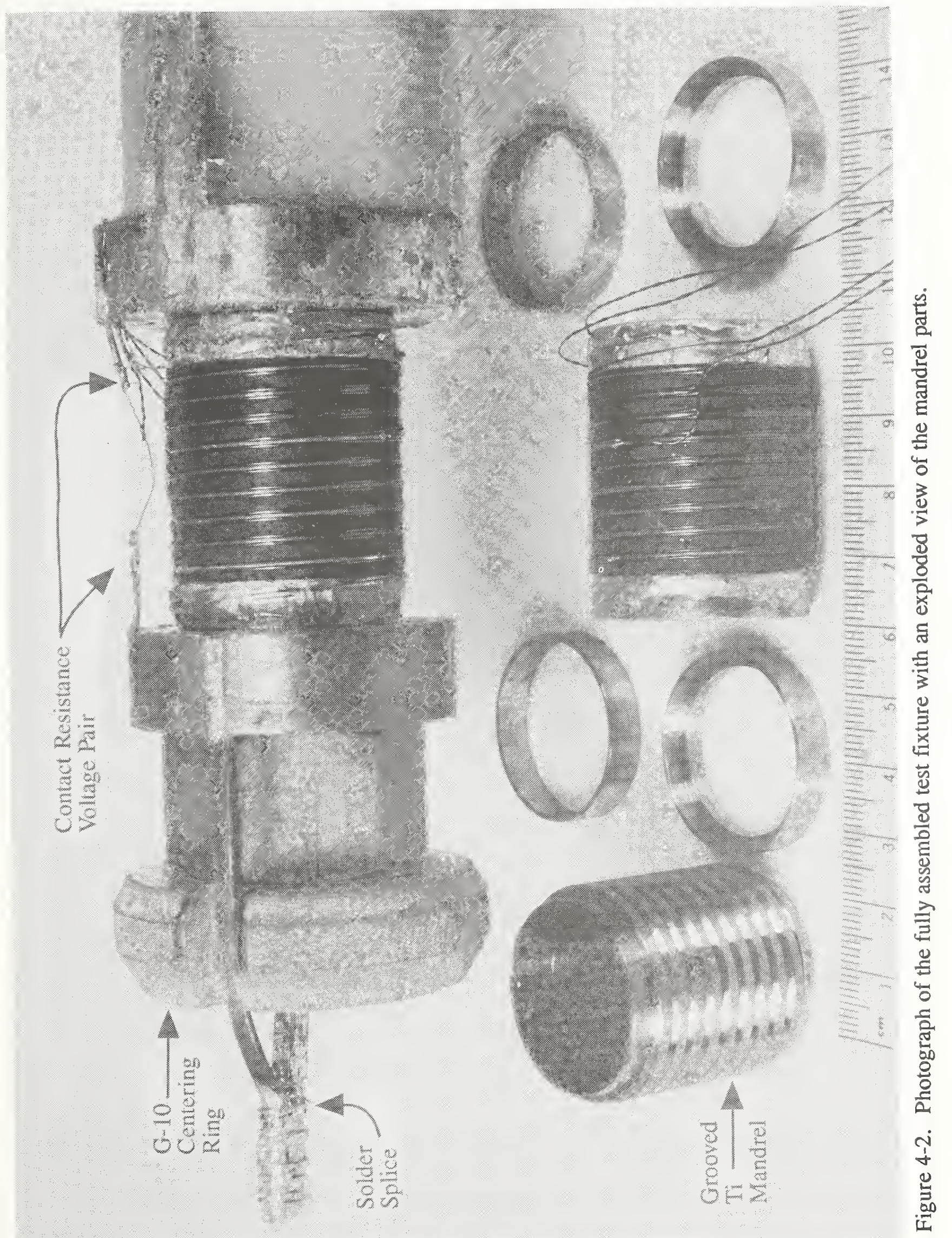




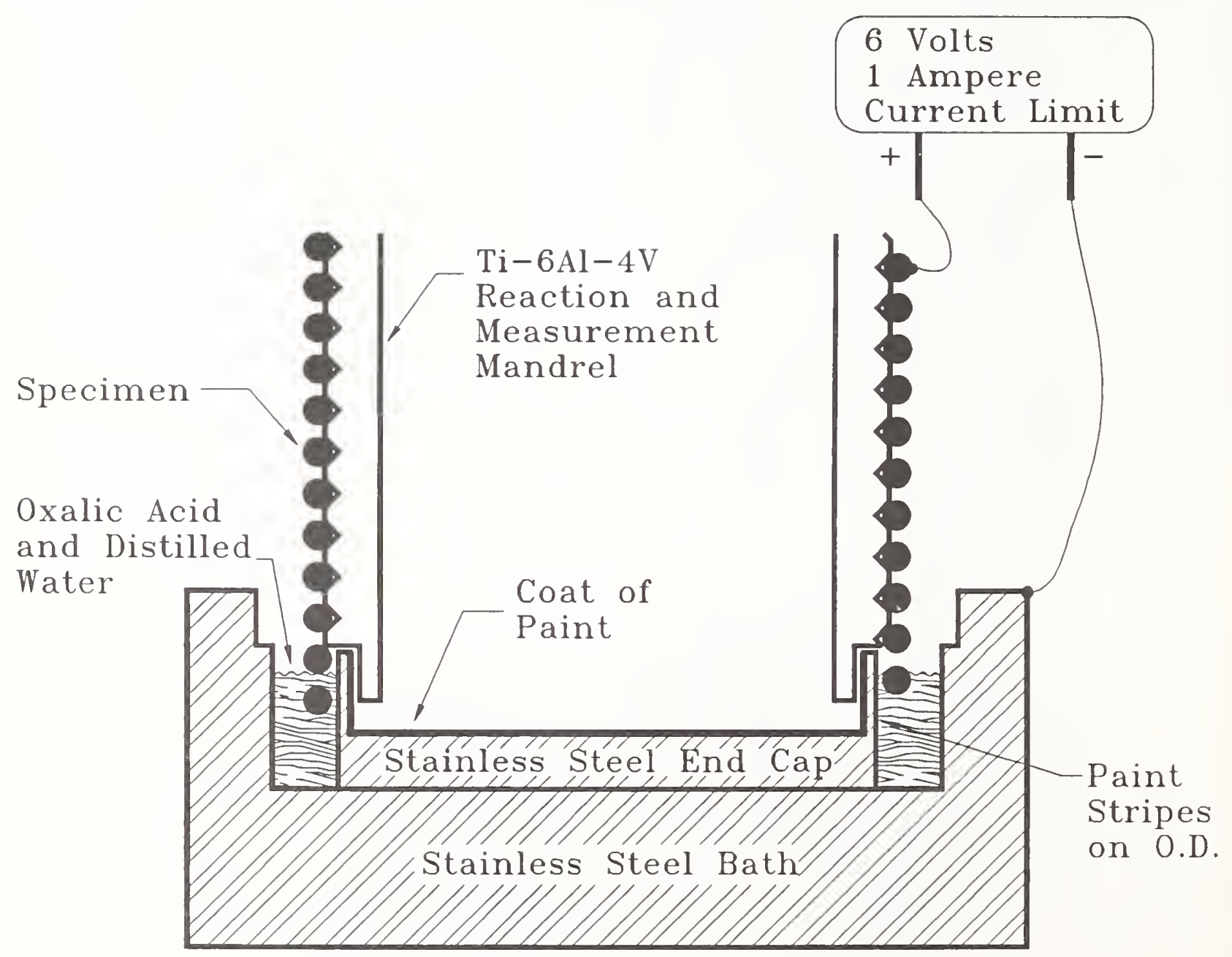

Figure 4-3. Illustration of the electrolytic etch used to remove the chrome plating from the current contact region of the $\mathrm{Nb}_{3} \mathrm{Sn}$ wire. 


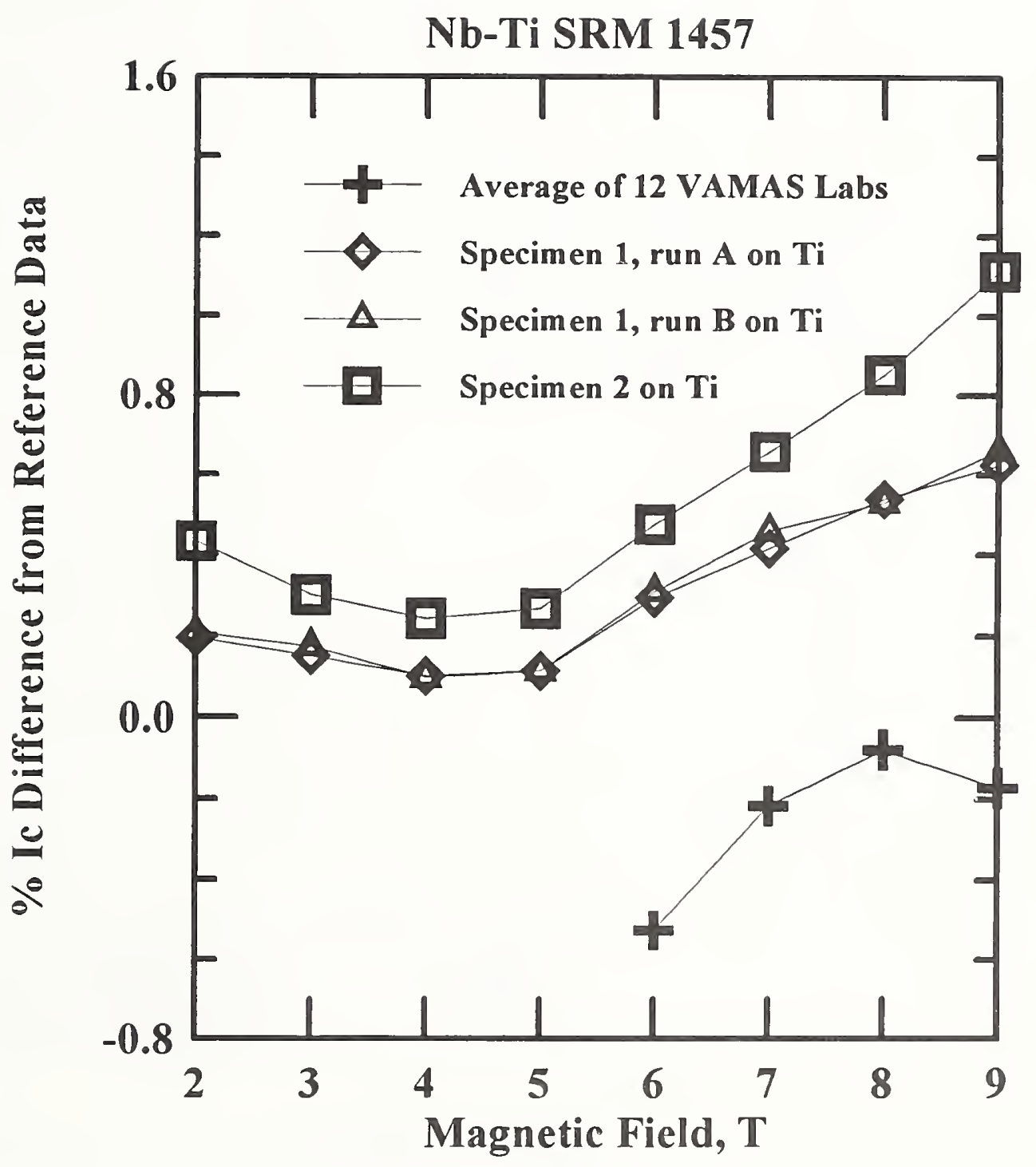

Figure 4-4. Percent difference of critical current from the reference data versus magnetic field for a number of measurements on the Nb-Ti SRM- 1457. 


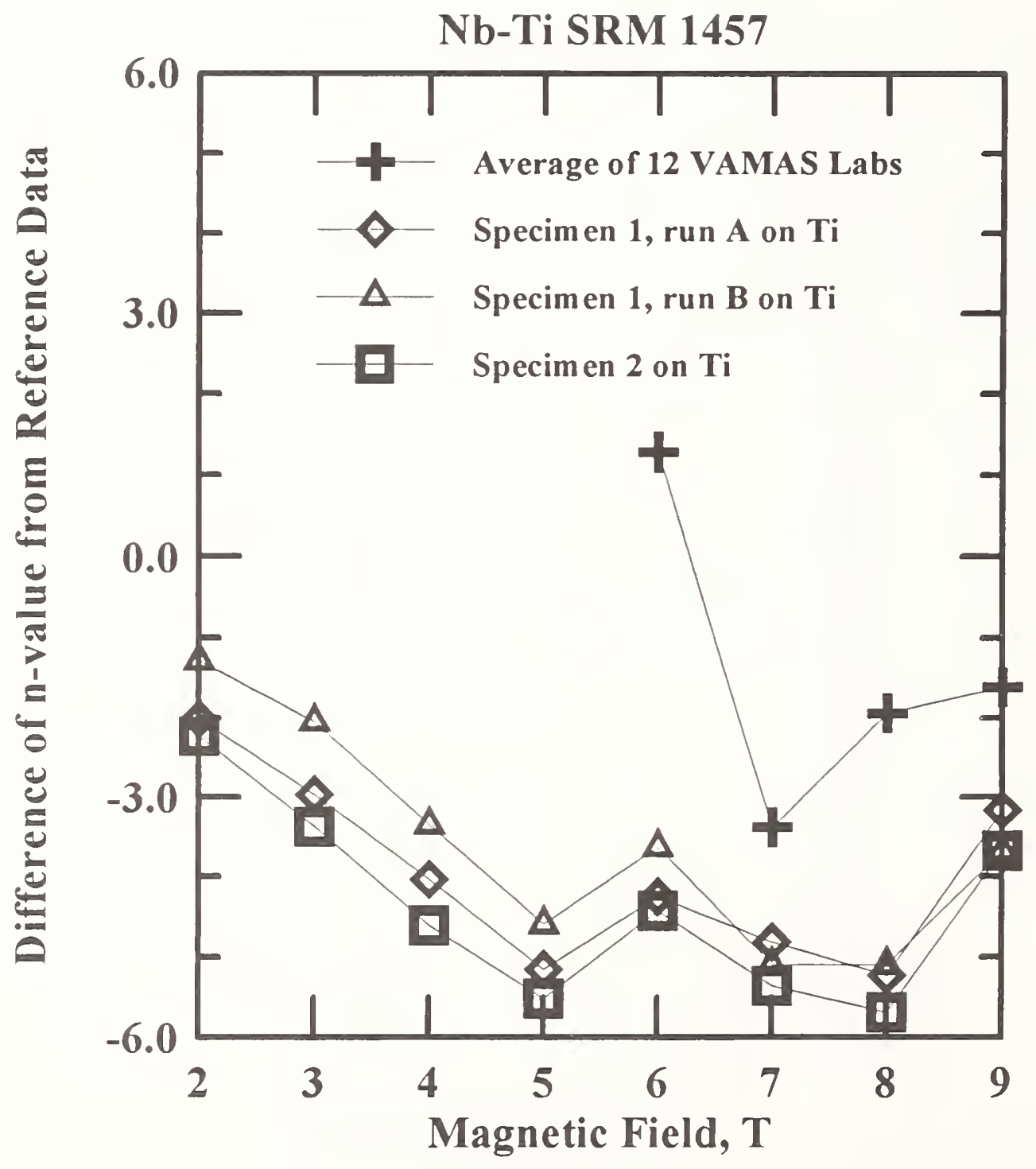

Figure 4-5. Difference of $n$-value from the reference data versus magnetic field for a number of measurements on the Nb-Ti SRM-1457. 


\section{COMMENTARY ON A $\mathrm{Nb}_{3}$ Sn REFERENCE WIRE}

\subsection{Introduction}

This is a requested commentary on the advantages and disadvantages of creating a $\mathrm{Nb}_{3} \mathrm{Sn}$ Reference Wire (RW) and a recommendation. The timely development of a standardized $\mathrm{I}_{c}$ measurement methodology for $\mathrm{Nb}_{3} \mathrm{Sn}$ superconducting wire is essential for acceptance testing and quality assurance of the strand procurement program. The question is, does this include the creation of a $\mathrm{Nb}_{3} \mathrm{Sn} \mathrm{RW}$ or not? A Nb-Ti Standard Reference Material (SRM) for the measurement of critical current $\left(\mathrm{I}_{\mathrm{c}}\right)$ exists already; however, there are significant differences between $\mathrm{Nb}$ - $\mathrm{Ti}$ and $\mathrm{Nb}_{3} \mathrm{Sn}$ conductors in sample preparation, performance, and strain sensitivity.

The existing Nb-Ti I I $_{c}$ SRM (SRM-1457) was created at NIST and made available in 1984. This SRM has been well accepted by the superconductivity community: over 200 units have been sold, approximately half to foreign laboratories. It has been used in a number of interlaboratory comparison of $I_{c}$ measurements. It was used as a control sample in the latest Versailles Project on Advanced Materials and Standards (VAMAS) interlaboratory comparison of $\mathrm{I}_{\mathrm{c}}$ on $\mathrm{Nb}_{3} \mathrm{Sn}$ wires.

It is helpful to compare the possible use of a $\mathrm{Nb}_{3} \mathrm{Sn} \mathrm{RW}$ to the present use of the $\mathrm{Nb}-\mathrm{Ti} \mathrm{SRM}$. The existing $\mathrm{Nb}$-Ti SRM is used to ensure the integrity of the measurement system. For example, one U.S. superconducting wire manufacturer measures a Nb-Ti SRM sample after every 20 measured test samples. A single Nb-Ti SRM unit can be used repeatedly and provides a fairly complete evaluation of the measurement system. In contrast, multiple use of a mounted $\mathrm{Nb}_{3} \mathrm{Sn} \mathrm{RW}$ would only address a portion of the $\mathrm{Nb}_{3} \mathrm{Sn}$ measurement variables. This necessitates an evaluation schedule that includes some re-testing of old units and the incorporation of new units. The envisioned strand test plan for ITER will require testing from several hundred to a thousand samples each year. If a $\mathrm{Nb}_{3} \mathrm{Sn} \mathrm{RW}$ is used at the same rate as the Nb-Ti SRM, this would consume nearly 50 units per year. A repeatability study of the RW should be performed in order to determine the total number of units and estimated cost.

Although a SRM is the ultimate physical standard, a $\mathrm{Nb}_{3} \mathrm{Sn} \mathrm{I}_{\mathrm{c}} \mathrm{RW}$ may be more appropriate for this application and the cost of development would be lower. The additional complications and sensitivities of the $\mathrm{I}_{\mathrm{c}}$ of a $\mathrm{Nb}_{3} \mathrm{Sn}$ wire do not favor an attempt to make a fully certified SRM. There is also a lingering question about the ultimate homogeneity of a $\mathrm{Nb}_{3} \mathrm{Sn}$ wire.

\subsection{Advantages}

- The significant differences between $\mathrm{Nb}_{3} \mathrm{Sn}$ and $\mathrm{Nb}$-Ti wires require that a new $\mathrm{RW}$ for $\mathrm{Nb}_{3} \mathrm{Sn}$ $\mathrm{I}_{c}$ measurements be developed in order to verify the precision and accuracy of $\mathrm{Nb}_{3} \mathrm{Sn} \mathrm{I}_{c}$ measurement systems. Unlike $\mathrm{Nb}-\mathrm{Ti}, \mathrm{Nb}_{3} \mathrm{Sn}$ superconducting wire requires heat treatment on a reaction mandrel and is extremely sensitive to mechanical strain. Thus the choice of reaction 
and measurement mandrels, as well as the measurement technique, is an important factor in reducing measurement variability for the $\mathrm{Nb}_{3} \mathrm{Sn} \mathrm{RW}$.

- $\quad \mathrm{A} \mathrm{Nb}_{3} \mathrm{Sn} \mathrm{RW}$ would provide a means for periodic checks of the detailed measurement procedure without conducting a full-scale interlaboratory comparison. $\mathrm{A} \mathrm{Nb}_{3} \mathrm{Sn} \mathrm{RW}$ could also provide a more precise check. During the second VAMAS international interlaboratory comparison of critical-current measurements on $\mathrm{Nb}_{3} \mathrm{Sn}$ conductors, a standardized test procedure which specifies the sample geometry, reaction and measurement mandrel geometry, and other details of the measurement yielded results with significantly lower variability than the first comparison. The results of the second study do not preclude other procedures that would yield sufficiently consistent results. A general result of these interlaboratory comparisons was the strong need for a detailed procedure. The results from the first ITER Benchmarking Test on $\mathrm{I}_{c}$ were consistent with this need. The largest difference in the average $I_{c}$ measurements of two ITER laboratories that did not use a common procedure was $23 \%$. The largest difference in the average $I_{c}$ measurements of two ITER laboratories that did use a common procedure was $6.5 \%$. There is still room and perhaps a need for improvement in the consistency of $I_{c}$ measurements.

- The research conducted during the development of a $\mathrm{Nb}_{3} \mathrm{Sn} \mathrm{RW}$ would also provide an indepth analysis of the state-of-the-art materials. This could include: short- and long-range inhomogeneity, dependence on magnetic field from 6 to $14 \mathrm{~T}$, dependence on temperature from 4.0 to $4.4 \mathrm{~K}$, dependence on criteria (1 to $10 \mu \mathrm{V} / \mathrm{m}$ ), dependence on voltage tap separation $(5$ to $75 \mathrm{~cm})$, dependence on reaction parameters, dependence on reaction and measurement mandrel materials, dependence on mounting procedure and the level of measurement variability. This would offer insight into reducing the variability and developing a standard measurement methodology for improving the repeatability of the critical-current measurement on $\mathrm{Nb}_{3} \mathrm{Sn}$ superconducting wires.

\subsection{Disadvantages}

- The present state-of-the-art materials may not provide a suitably low variability to serve as a RW.

- If the resources are not available to complete the creation of a $\mathrm{Nb}_{3} \mathrm{Sn} \mathrm{RW}$, it should not be started. This will be a fairly large project, so there may be better projects to invest in.

- If the NIST Office of Measurement Services (formerly Office of Standard Reference Materials) is involved in the creation of this RW, they will set the unit price. The cost is the same to everyone; an agency that helped create them pays the same as a foreign laboratory. 


\subsection{Recommendation}

If there is a need for higher accuracy and reliability in $\mathrm{Nb}_{3} \mathrm{Sn} \mathrm{I}_{\mathrm{c}}$ measurements, then invest in a $\mathrm{Nb}_{3} \mathrm{Sn}$ $I_{c}$ Reference Wire. If this need is less than the benefit of using the limited resources on other projects, then do not start on $\mathrm{Nb}_{3} \mathrm{Sn} \mathrm{RW}$. 


\section{Appendix A.}

\section{STANDARDIZED LABORATORY REPORTING SHEETS}

By request, we drafted a standard reporting sheet, distributed it to a total of nine U.S. measurement laboratories for comments and completion, and compiled the information received from seven laboratories as they were provided to us. This serves to document the present procedures that are being used for $\mathrm{Nb}_{3} \mathrm{Sn} \mathrm{I}$ measurements. This reporting sheet included measurement conditions, calibration method, ${ }^{1}$ sample heat treatment, measurement mandrel and mounting details, and measurement results. Possible changes to this sheet were suggested by some of the labs and included are two possible new versions of the last page of the reporting sheet, $4 \mathrm{a}$ and $4 \mathrm{~b}$. Sheet $4 \mathrm{a}$ is designed for reporting measurement results on a number of samples at one magnetic field. Sheet $4 \mathrm{~b}$ is designed for reporting measurement results on one sample at magnetic fields of 6 to $14 \mathrm{~T}$.

${ }^{1}$ Certain commercial products are identified by the participants to adequately describe their experimental procedure completely. In no case does such identification imply recommendation or endorsement by NIST, nor does it imply that the products are necessarily the best available for the purpose. 


\section{DATA FORMAT SHEETS}

INSTITUTE_Erancis Bitter National Magnet Laboratory (EBNML)

Sheet-1

1. MEASUREMENT CONDITIONS

\subsection{TEST SETUP}

a) magnetic field (water cooled bitter magnet, high homogeneity, $2 \mathrm{~V}$ )

magnet bore diameter

$52.5 \mathrm{~mm}$

accuracy of central field $\pm \underline{0.25 \%}$ at $14 \mathrm{~T}$

field measurement method(s)

Integrated coil

field variation over V-V taps (including mis-location of sample) $\pm 0.05 \%$ at $12 \mathrm{~T}$

rms ripple field $\pm 0.05 \%$ at $12 \mathrm{~T}$

field range covered $10 \mathrm{~T}$ to $14.5 \mathrm{~T}$

b) sample current

current calibration method

Zorn industries, NIST traceable shunt, $300 \mathrm{~A}-0.001 \Omega$

accuracy of sample current $\pm 0.2 \%$ at 100 A

rms ripple current $\pm 0.05 \%$ at $100 \mathrm{~A}$

current sweep rate $:<4 \mathrm{~A} / \mathrm{s}$ or seconds to $I_{c}$

c) sample voltage

voltage calibration method

EDC millivolt standard model MV $100 \mathrm{~N}$

accuracy of sample voltage $\pm 0.05 \%$ at $10 \mu \mathrm{V} / \mathrm{m}$

typical noise level $\pm 2 \mu \mathrm{V} / \mathrm{m}$

response time of voltmeter $\sec$

d) helium bath temperature

temperature measurement method(s)

Pressure MKS Instruments Barytron

accuracy of temperature \pm $\mathrm{K}$ at K

e) critical current measurement

measurement system verification

$\mathrm{I}_{\mathrm{c}}$ measurement: estimated uncertainty \pm ,estimated precision $\pm 0.5 \%$ $n$-value measurement: estimated uncertainty \pm ,estimated precision $\pm 5 \%$ 
f) measurement circuit diagram

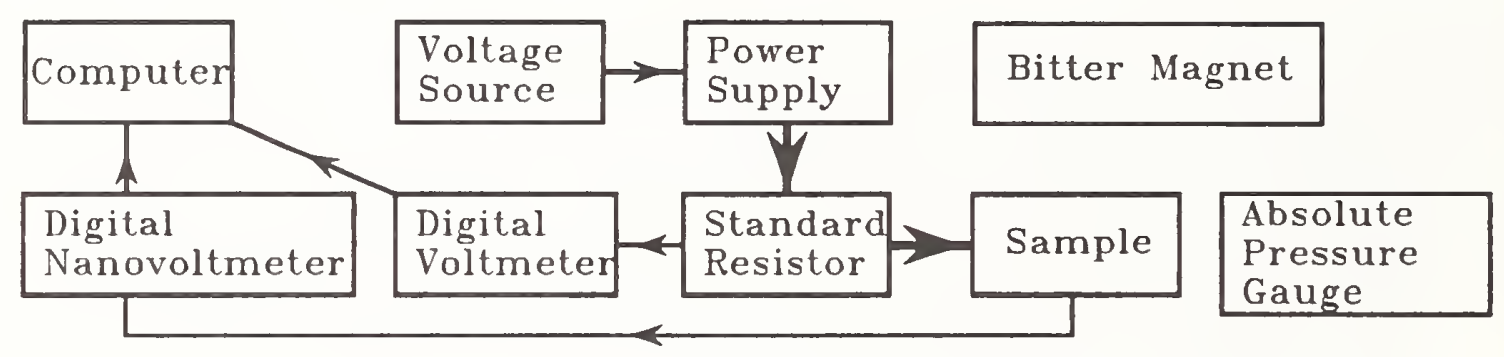

\subsection{SAMPLE HEAT TREATMENT}

a) reaction mandrel material Ti $6 / 4$

surface treatment graphite spray

groove geometry $60^{\circ}$

retainer stainless

pitch length $3.2 \mathrm{~mm}$

outer diameter $32 \mathrm{~mm}$

number of wind turns $131 / 2$

b) heat treatment furnace (used gettered He gas atmosphere)

temperature determination Chromel Alumel thermocouple

variation in space $\pm 3{ }^{\circ} \mathrm{C}$

variation in time $\pm-1-{ }^{\circ} \mathrm{C}$

\subsection{MEASUREMENT MANDREL AND MOUNTING DETAILS}

a) measurement mandrel =reaction mandrel

mandrel material $\mathrm{Ti} 6 / 4$

outer diameter of mandrel $32 \mathrm{~mm}$

inner diameter of mandrel $28 \mathrm{~mm}$

pitch length of spiral groove 3.2

groove geometry and angle $\mathrm{V} 60^{\circ}$

current terminal; material(s) $\mathrm{Cu}$

geometry cylindrical 
b) sample mounting bonding material _ not used

thin layer of bonding material? NA

mounting procedure after reaction retainer rings are removed and wire is wrapped tight around the mandrel in groove

solder material In

flux material stainless steel flux

soldering temperature $\simeq 180^{\circ} \mathrm{C}$

sample well seated in groove? yes

c) sample geometry and dimensions

wire length between $V$ taps (1) $50 \mathrm{~cm}$

wire length between an current junction and its nearest $V$ tap (2) $20 \mathrm{~cm}$

length of sample soldered to an current terminal ( 3 ) $10-20 \mathrm{~cm}$

total sample length $(1+2 x(2+3)) 135 \mathrm{~cm}$

winding diameter (outer) 32.3-32.5 mm (depends on wire diameter)

total number of winding turns $131 / 2$

d) sample cooling to $4.2 \mathrm{~K}$

cooling time from room temperature to $4.2 \mathrm{~K} \quad 5-10$ minutes

precooled with liquid nitrogen? yes

directly cooled with gas or liquid helium? yes

e) sketch of measurement mandrel setup

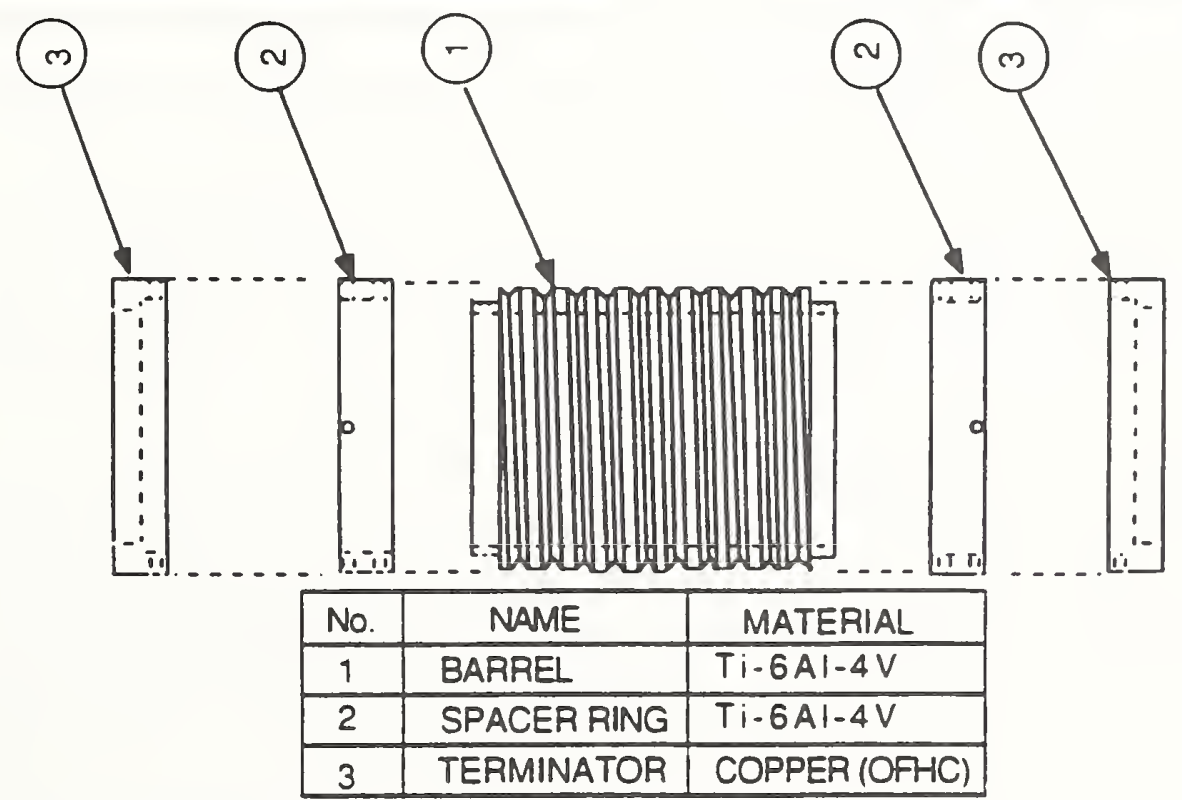




\section{MEASUREMENT CONDITIONS}

\subsection{TEST SETUP}

a) magnetic field

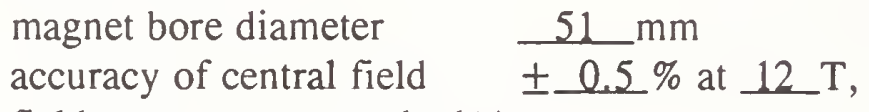
field measurement method(s)

Hall sensor

field variation over $\mathrm{V}-\mathrm{V}$ taps (including mis-location of sample) $\pm 0.05 \%$ at $12 \mathrm{~T}$ rms ripple field \pm $\%$ at $T$ Superconducting magnet field range covered $3 \mathrm{~T}$ to $12 \mathrm{~T}$

b) sample current current calibration method Calibrated resistor accuracy of sample current rms ripple current \pm $\%$ at current sweep rate : $<3 \mathrm{~A} / \mathrm{s}$ or $\_$seconds to $\mathrm{I}_{\mathrm{c}}$ A

c) sample voltage voltage calibration method Standard voltage source accuracy of sample voltage $\pm 1 \ldots$ at $10 \mu \mathrm{V} / \mathrm{m}$ typical noise level $\pm 0.05 \mu \mathrm{V} / \mathrm{m}$ response time $0.3 \mathrm{sec}$

d) helium bath temperature temperature measurement method(s)

Capacitance and CGR temperature sensor accuracy of temperature $\pm 0.01 \mathrm{~K}$ at $4.22 \mathrm{~K}$

e) critical current measurement measurement system verification

$I_{c}$ measurement: estimated uncertainty \pm ,estimated precision \pm $\mathrm{n}$-value measurement: estimated uncertainty \pm ,estimated precision \pm 
f) measurement circuit diagram

\subsection{SAMPLE HEAT TREATMENT}

a) reaction mandrel material $\mathrm{Ti}-6 \mathrm{Al}-4 \mathrm{~V}$

surface treatment Graphite

groove geometry $90^{\circ}$ " $\mathrm{V}$ " groove

retainer stainless steel wires

pitch length 8 perinch

outer diameter $32 \mathrm{~mm}$

number of wind turns 11

b) heat treatment furnace

temperature determination $\mathrm{K}$-type thermocouple

variation in space $\pm \ldots 2^{\circ} \mathrm{C}$

variation in time $\pm \underline{0.5}{ }^{\circ} \mathrm{C}$

\subsection{MEASUREMENT MANDREL AND MOUNTING DETAILS}

a) measurement mandrel

mandrel material Ti-6 Al-4 V

outer diameter of mandrel $32.0 \mathrm{~mm}$

inner diameter of mandrel $27.9 \mathrm{~mm}$

pitch length of spiral groove $3.175 \mathrm{~mm}$

groove geometry and angle $90^{\circ} " \mathrm{~V} "$ groove

current terminal; material(s)

geometry Cylinder 
INSTITUTE MIT Plasma Fusion Center

Sheet-3

b) sample mounting

bonding material none

thin layer of bonding material? no

mounting procedure Remove $\mathrm{Cr}$ mechanically, solder one end and tighten by hand.

Clamp and solder other end

solder material $80 \% \mathrm{In}-15 \% \mathrm{~Pb}-5 \% \mathrm{Ag}$

flux material Rosin

soldering temperature $\sim 200{ }^{\circ} \mathrm{C}$

sample well seated in groove? yes

c) sample geometry and dimensions

wire length between $V$ taps ( 1 ) $0.5 \mathrm{~m}$

wire length between an current junction and its nearest $V \operatorname{tap}(2) \underline{0.2 \mathrm{~m}}$

length of sample soldered to an current terminal ( 3$)>0.1 \mathrm{~m}$

total sample length $(1+2 \times(2+3))>1.1 \mathrm{~m}$

winding diameter (outer) $31 \mathrm{~mm}$

total number of winding turns

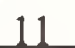

d) sample cooling to $4.2 \mathrm{~K}$

cooling time from room temperature to $4.2 \mathrm{~K} \sim 30$ minutes

precooled with liquid nitrogen? yes

directly cooled with gas or liquid helium?

e) sketch of measurement mandrel setup

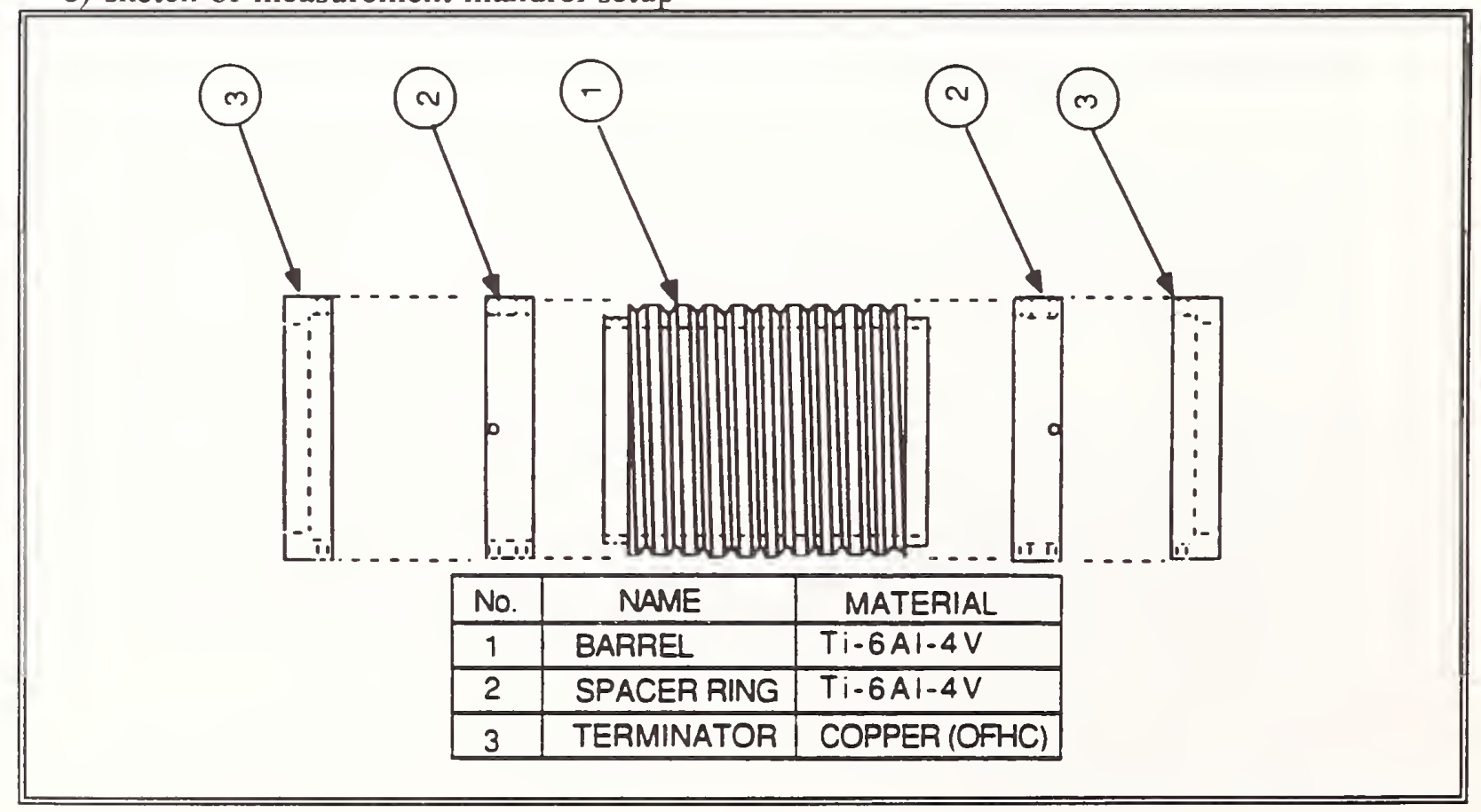




\section{DATA FORMAT SHEETS}

INSTITUTE National_Institute of Standards and Technology (NIST)

Sheet-1

\section{MEASUREMENT CONDITIONS}

\subsection{TEST SETUP}

a) magnetic field

magnet bore diameter $\quad \underline{52} \mathrm{~mm}$

accuracy of central field $\pm 0.1 \%$ at 2 T,$\pm \underline{0.05 \%} \%$ at $12 \mathrm{~T}$

field measurement method(s)

Nuclear Magnetic Resonance + four wire standard resistor

field variation over $\mathrm{V}-\mathrm{V}$ taps (including mis-location of sample) $\pm 0.1 \%$ at $12 \mathrm{~T}$

rms ripple field $\pm 0.01 \%$ at $12 \mathrm{~T}$

field range covered $2 \mathrm{~T}$ to $12 \mathrm{~T}$

b) sample current

current calibration method

Cross check with calibrated resistor

accuracy of sample current $\pm 0.02 \%$ at 50 A

rms ripple current $\pm 0.01 \%$ at $100 \mathrm{~A}$

current sweep rate $: \leq 0.1 \mathrm{~A} / \mathrm{s}$ or seconds to $I_{c}$

c) sample voltage

voltage calibration method

Voltage source and precision divider accuracy of sample voltage $\pm 0.5 \%$ at $10 \mu \mathrm{V} / \mathrm{m}$

typical noise level $\pm 0.3 \mu \mathrm{V} / \mathrm{m}$

response time of voltmeter $\underline{0.1 \mathrm{sec}}$

d) helium bath temperature

temperature measurement method(s)

Equilibrium vapor pressure, $1958 \mathrm{He}^{4}$ temperature scale, pressure traceable to NIST accuracy of temperature $\pm 0.01 \mathrm{~K}$ at $4.20 \mathrm{~K}$

e) critical current measurement measurement system verification

Periodic measurements made on SRM 1457 and passive critical current simulators $I_{c}$ measurement: estimated uncertainty $\pm 2 \%$, estimated precision $\pm 0.1 \%$ n-value measurement: estimated uncertainty $\pm 10 \%$, estimated precision $\pm 2 \%$ 
f) measurement circuit diagram

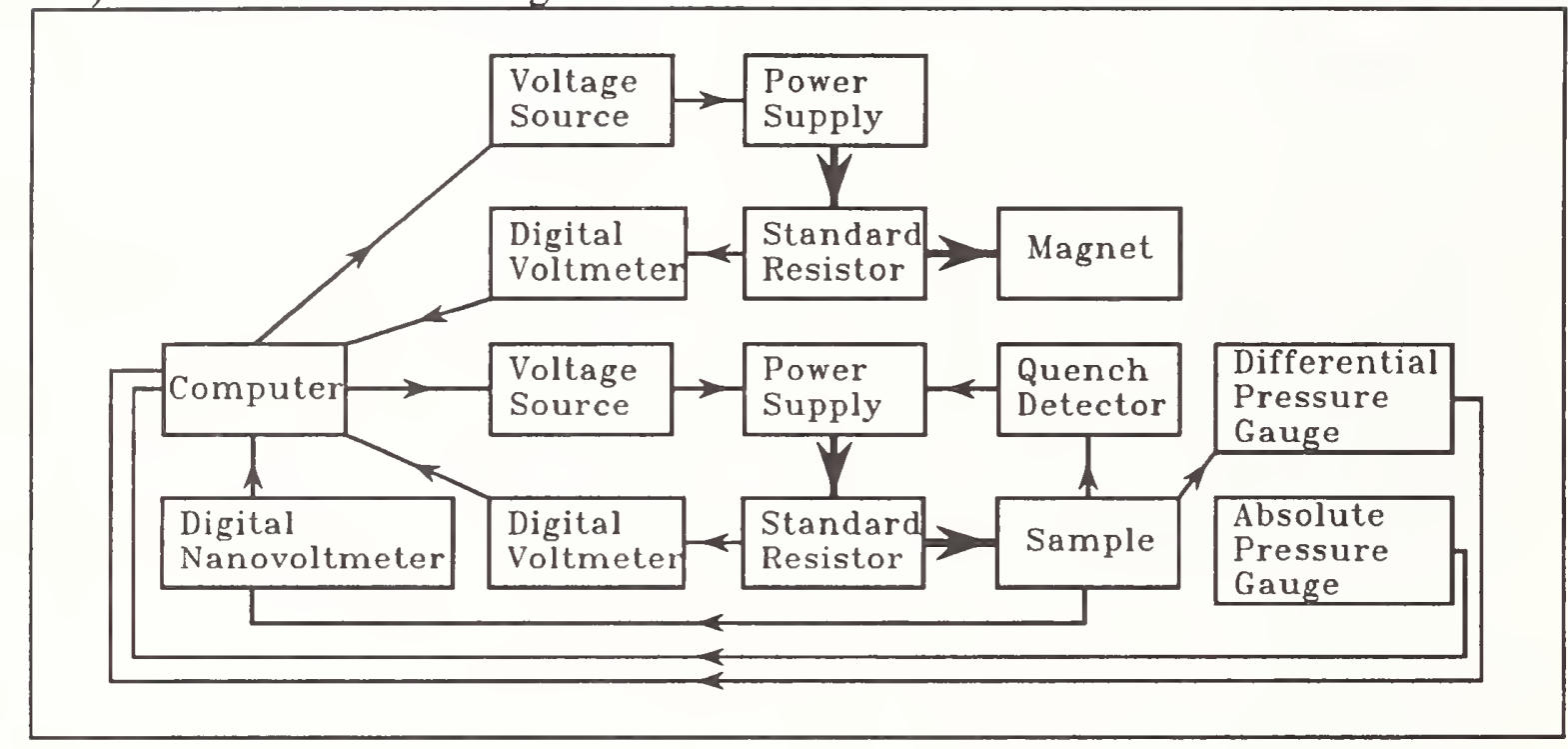

\subsection{SAMPLE HEAT TREATMENT}

a) reaction mandrel

material $\mathrm{Ti}-6 \% \mathrm{Al}-4 \% \mathrm{~V}$

surface treatment oxidized with graphite spray

groove geometry $20^{\circ} \mathrm{V}$ groove

retainer stainless steel wires

pitch length $3.175 \mathrm{~mm}$ ( 8 threads/inch)

outer diameter $32.0 \mathrm{~mm}$

number of wind turns 11

b) heat treatment furnace

temperature determination

variation in space \pm

variation in time \pm ${ }^{\circ} \mathrm{C}$

${ }^{\circ} \mathrm{C}$

\subsection{MEASUREMENT MANDREL AND MOUNTING DETAILS}

a) measurement mandrel

mandrel material $\mathrm{Ti}-6 \mathrm{Al}-4 \mathrm{~V}$ same as reaction material

outer diameter of mandrel $32.0 \mathrm{~mm}$

inner diameter of mandrel $27.9 \mathrm{~mm}$

pitch length of spiral groove $3.175 \mathrm{~mm}$

groove geometry and angle $20^{\circ} \mathrm{V}$ groove

current terminal; material(s) copper

geometry Cylinder 
b) sample mounting bonding material none

thin layer of bonding material? NA

mounting procedure Clamp one end of sample, sample taut, clamp other end of sample, solder current contacts, solder voltage taps.

solder material $\mathrm{Pb} 40 \%$ Sn $60 \%$

flux material Rosin core

soldering temperature $370{ }^{\circ} \mathrm{C}$

sample well seated in groove? yes

c) sample geometry and dimensions

wire length between $V$ taps ( 1 ) $\simeq 250 \mathrm{~mm}$

wire length between an current junction and its nearest $V$ tap ( 2$) \sim 320 \mathrm{~mm}$

length of sample soldered to an current terminal ( 3 ) $\sim 80 \mathrm{~mm}$

total sample length $(1+2 x(2+3)) \sim 1050 \mathrm{~mm}$

winding diameter (outer) $\sim 31 \mathrm{~mm}$

total number of winding turns $\sim 11$

d) sample cooling to $4.2 \mathrm{~K}$

cooling time from room temperature to $4.2 \mathrm{~K} 3$ to 5 minutes

precooled with liquid nitrogen? no

directly cooled with gas or liquid helium? yes

e) sketch of measurement mandrel setup

MIT Design

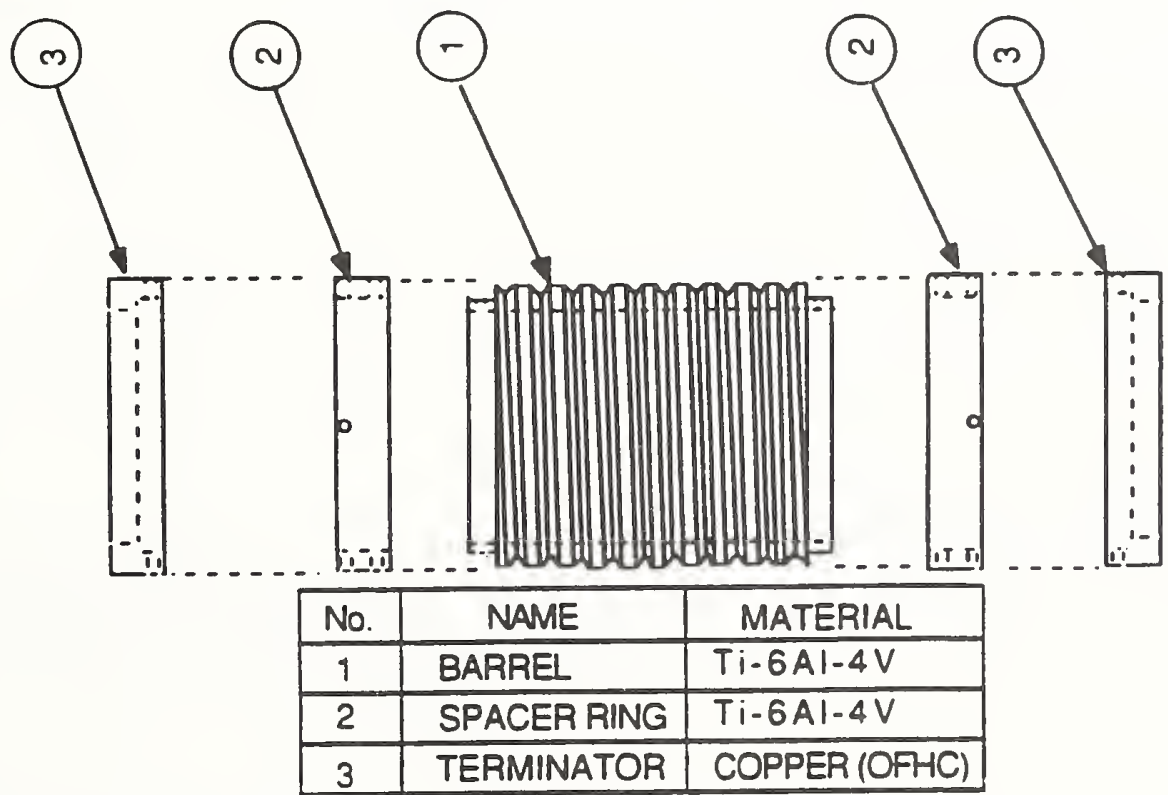




\section{DATA FORMAT SHEETS}

INSTITUTE_Oxford Superconducting Technology (OST)

Sheet-1

\section{MEASUREMENT CONDITIONS}

\subsection{TEST SETUP}

a) magnetic field magnet bore diameter $\quad 52 \mathrm{~mm}$
accuracy of central field $\quad \pm 1 \%$ at $12 \mathrm{~T}$ field measurement method(s) Magnet Current (Current-Field Calibration using calibrated Hall Probe) field variation over $\mathrm{V}-\mathrm{V}$ taps (including mis-location of sample) $\pm 0.5 \%$ at $12 \mathrm{~T}$ rms ripple field $\pm \ldots \ldots$ at $\ldots \mathrm{T}$

field range covered $0 \mathrm{~T}$ to $12 \mathrm{~T}$

b) sample current

current calibration method

Standard resistor

accuracy of sample current $\pm 0.2 \%$ at $500 \mathrm{~A}$

rms ripple current \pm $\%$ at

current sweep rate $:<25 \mathrm{~A} / \mathrm{s}$ or seconds to $I_{c}$

c) sample voltage

voltage calibration method

Keithley $\mathrm{nV}$ meter calibrated to NIST Tracable Voltage Standard

accuracy of sample voltage $\pm 0.2 \%$ at $0.1 \mu \mathrm{V} / \mathrm{m}$

typical noise level $\pm 0.5 \mu \mathrm{V} / \mathrm{m}$

response time of voltmeter $0.1 \mathrm{sec}$

d) helium bath temperature

temperature measurement method(s)

None

accuracy of temperature $\pm \ldots$ K at $\_$K

e) critical current measurement

measurement system verification

Nist I $I_{c}$ Standard Wire (SRM 1457)

$I_{c}$ measurement: estimated uncertainty $\pm \ldots 3 \%$, estimated precision $\pm \ldots 1 \%$

n-value measurement: estimated uncertainty $\pm 20 \%$ estimated precision $\pm 10 \%$ 
f) measurement circuit diagram
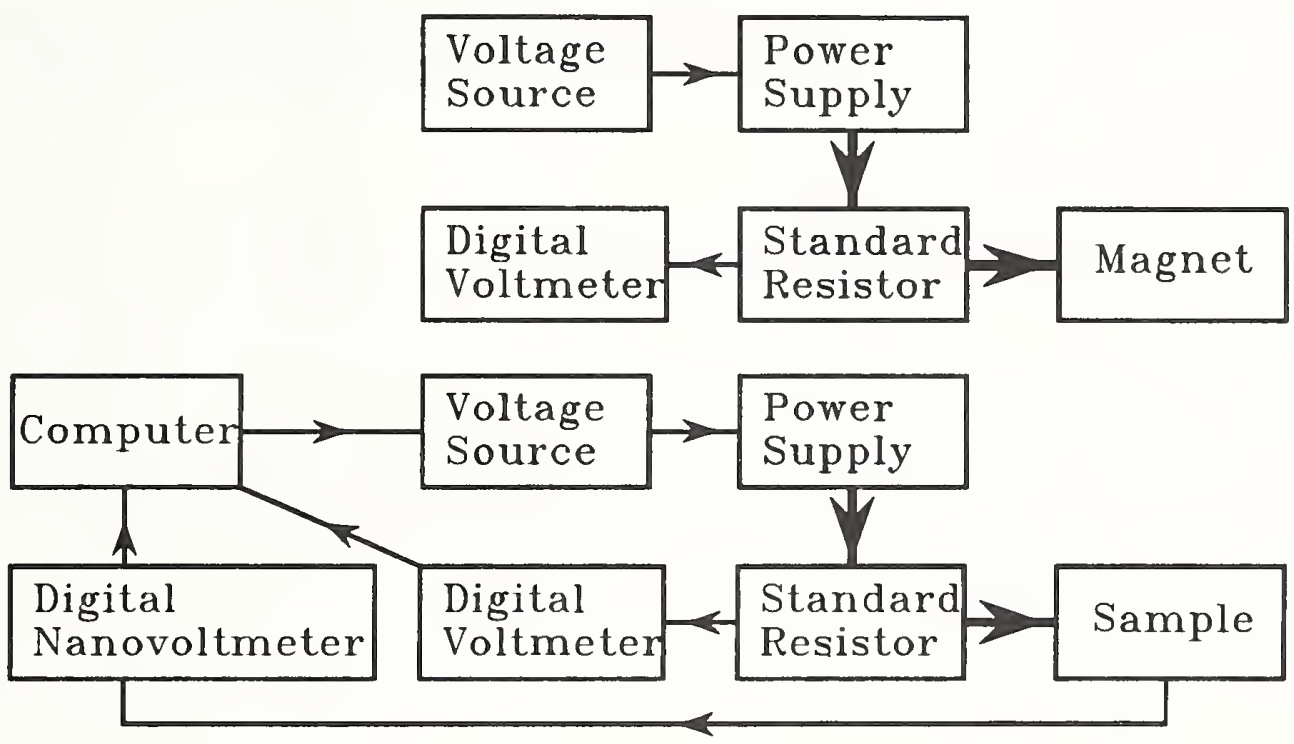

\subsection{SAMPLE HEAT TREATMENT}

a) reaction mandrel

material 304 or 316 stainless steel

surface treatment oxidized

groove geometry $1 / 32$ " radius

retainer

pitch length $4.2 \mathrm{~mm}$

outer diameter $3.5 \mathrm{~cm}$

number of wind turns 12

b) heat treatment furnace

temperature determination Calibrated type $\mathrm{K}$ thermocouple

variation in space $\pm 1^{\circ} \mathrm{C}$

variation in time $\pm 1^{\circ} \mathrm{C}$

\subsection{MEASUREMENT MANDREL AND MOUNTING DETAILS}

a) measurement mandrel

mandrel material 304 or 316 stainless steel

outer diameter of mandrel $3.5 \mathrm{~cm}$

inner diameter of mandrel $3.2 \mathrm{~cm}$

pitch length of spiral groove $4.2 \mathrm{~mm}$

groove geometry and angle $1 / 32^{\prime \prime}$ radius

current terminal; material(s) copper

geometry 
b) sample mounting bonding material $\mathrm{Pb}$-Sn solder

thin layer of bonding material? yes (may vary)

mounting procedure carefully screw sample onto measurement mandrel, fasten one end with clip, smooth wire into groove, fasten second end with clip, solder solder material $\mathrm{Pb}-\mathrm{Sn}$ flux material Copper-Mate soldering temperature $\sim 275^{\circ} \mathrm{C}$ sample well seated in groove? yes, usually

c) sample geometry and dimensions wire length between $V$ taps ( 1 ) $24 \mathrm{~cm}$ wire length between an current junction and its nearest $V$ tap ( 2 ) $24 \mathrm{~cm}$ length of sample soldered to an current terminal ( 3 ) $15 \mathrm{~cm}$ total sample length $(1+2 \mathrm{x}(2+3)) \sim 1 \mathrm{~m}$ winding diameter (outer) $3.4 \mathrm{~cm}$ total number of winding turns 11 to 12

d) sample cooling to $4.2 \mathrm{~K}$ cooling time from room temperature to $4.2 \mathrm{~K} \quad 2$ minutes precooled with liquid nitrogen? yes directly cooled with gas or liquid helium? yes

e) sketch of measurement mandrel setup

- Sketch not to scale

- Cu ends are welded to stainless

- Cu ears are integral part of end rings

- Cu ears solder to rig current leads, provide ample current transfer area

- Size and groove details provided in text above.

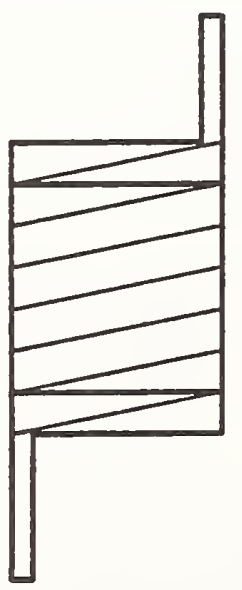

$\mathrm{Cu}$

Stainless

Steel

$\mathrm{Cu}$ 
INSTITUTE_Supercon Inc.

Sheet-1

\section{MEASUREMENT CONDITIONS}

\subsection{TEST SETUP}

a) magnetic field magnet bore diameter $\quad 50.8 \mathrm{~mm}$ accuracy of central field $\pm 0.5 \%$ at $2 \mathrm{~T}, \pm 3.5 \%$ at $7 \mathrm{~T}$ field measurement method(s)

Based on field to current ratio, which was calibrated using Hall probe (MUT \#9250 @60mAl

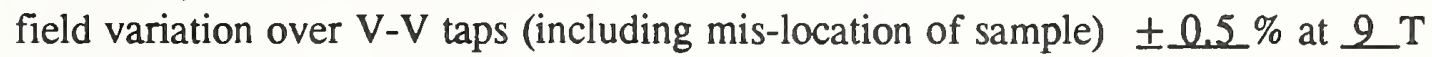
rms ripple field $\pm \ldots \%$ at _ $\mathrm{T}$ (not measured)

field range covered $0 \mathrm{~T}$ to $9 \mathrm{~T}$

b) sample current

current calibration method

Calibrated standard shunt (resistor) accuracy of sample current $\pm 0.25 \%$ at $1000 \mathrm{~A}$ rms ripple current $\pm \ldots \%$ at __ A (not measured) current sweep rate : ___ A/s or 60 seconds to $I_{c}$ (manual operation)

c) sample voltage voltage calibration method Null detector and X-Y plotter were calibrated by ESSCO and traced to NIST accuracy of sample voltage $\pm \ldots 1 \%$ at $450 \mu \mathrm{V} / \mathrm{m}$ typical noise level $\pm \ldots \ldots \mathrm{V} / \mathrm{m}$ (not measured) response time of voltmeter $\_$sec, rise time (10\%-90\%)

d) helium bath temperature temperature measurement method(s) Absolute pressure gauge accuracy of temperature $\pm 0.01 \_\mathrm{K}$ at $4.2 \mathrm{~K}$

e) critical current measurement measurement system verification Verified by two operators in multiple measurements using_NIST's SRM 1457 $I_{c}$ measurement: estimated uncertainty $\pm 3 \%$, estimated precision $\pm \leq 2 \%$ n-value measurement: estimated uncertainty \pm ,estimated precision $\pm 10 \%$ 
f) measurement circuit diagram

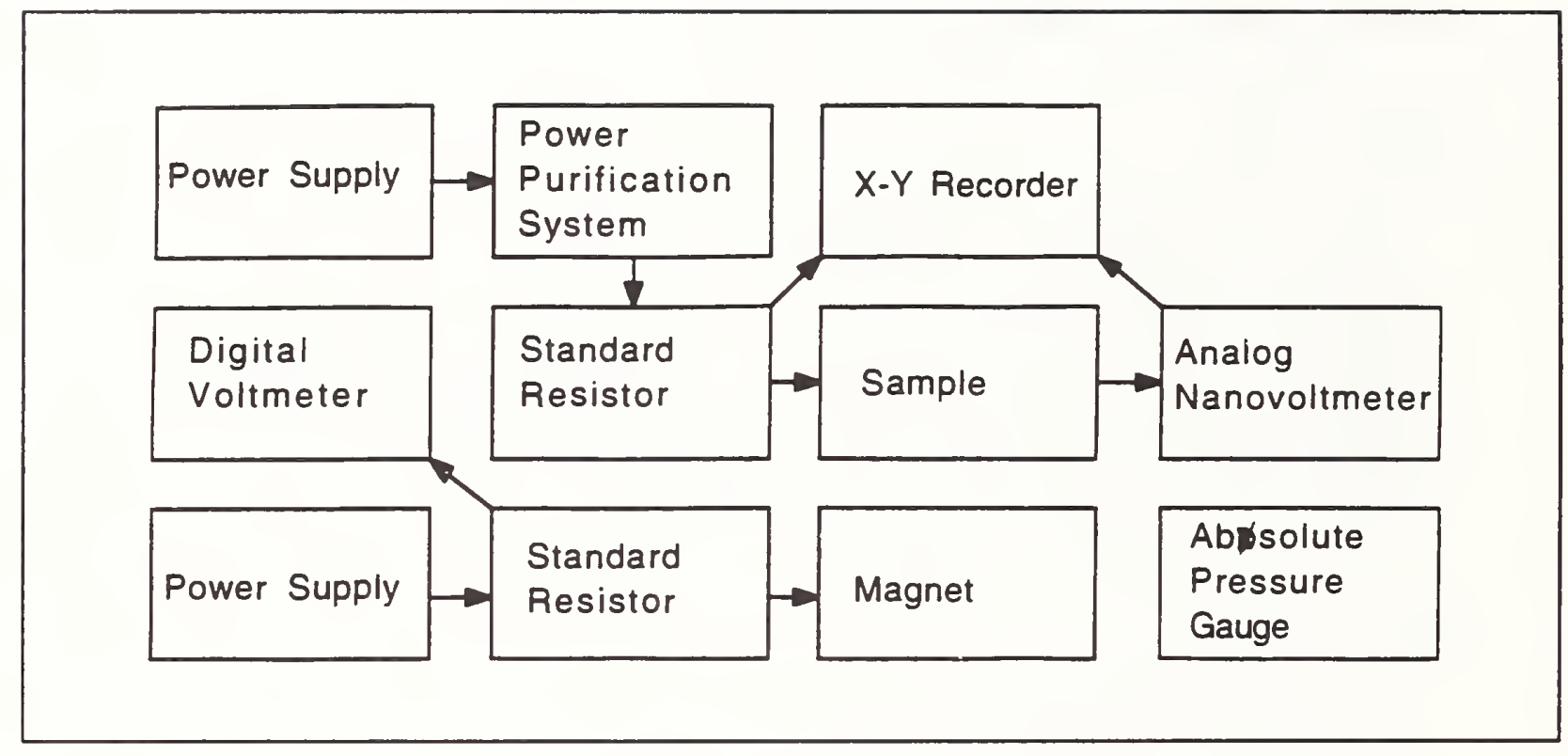

\subsection{SAMPLE HEAT TREATMENT}

a) reaction mandrel

material Ti-6 Al-4V

surface treatment none

groove geometry "V" shape

retainer heat treated in $\mathrm{Cu}$ boat

pitch length $0.125^{\prime \prime}$

outer diameter 1.260"

number of wind turns 9

b) heat treatment furnace

temperature determination $\mathrm{K}$ type thermocouple/digital thermometer

variation in space $\pm 2{ }^{\circ} \mathrm{C}$

variation in time $\pm 1-{ }^{\circ} \mathrm{C}$

\subsection{MEASUREMENT MANDREL AND MOUNTING DETAILS}

a) measurement mandrel

mandrel material $\mathrm{Ti}-6 \mathrm{Al}-4 \mathrm{~V}$

outer diameter of mandrel $1.260^{\prime \prime}$

inner diameter of mandrel $1.100^{\prime \prime}$

pitch length of spiral groove $0.125^{\prime \prime}$

groove geometry and angle "V" shape, $90^{\circ}$

current terminal; material(s) $\mathrm{Cu}$

geometry ring 
INSTITUTE_Supercon Inc.

b) sample mounting bonding material

thin layer of bonding material? no

mounting procedure As specified by $\mathrm{Dr}$. M. Takayasu of MIT's Plasma Fusion

Center

solder material $50 / 50 \mathrm{PbSn}$

flux material $\mathrm{ZnCl}_{2}+\mathrm{HCl}$

soldering temperature tip temperature of a $100 \mathrm{~W}$ soldering iron

sample well seated in groove? yes

c) sample geometry and dimensions

wire length between $V$ taps ( 1 ) $70 \mathrm{~cm}$

wire length between an current junction and its nearest $V$ tap ( 2 ) $10 \mathrm{~cm}$

length of sample soldered to an current terminal ( 3 ) $20 \mathrm{~cm}$

total sample length $(1+2 \times(2+3))+130 \mathrm{~cm}$

winding diameter (outer) $1.260^{\prime \prime}$

total number of winding turns 13

d) sample cooling to $4.2 \mathrm{~K}$

cooling time from room temperature to $4.2 \mathrm{~K} \sim 5$ minutes

precooled with liquid nitrogen? yes

directly cooled with gas or liquid helium? yes

e) sketch of measurement mandrel setup

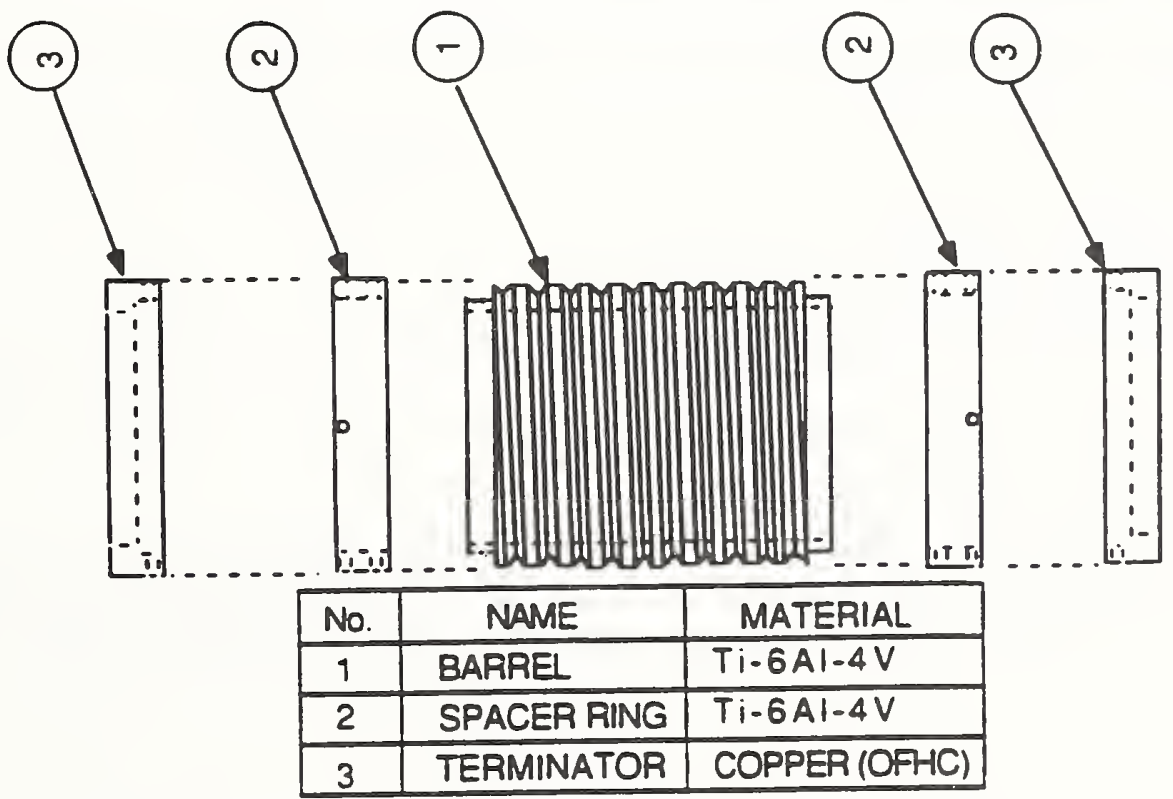




\section{INSTITUTE__Teledyne Wah Chang_Albany(TWCA)_ Sheet-1}

\section{MEASUREMENT CONDITIONS}

\subsection{TEST SETUP}

a) magnetic field

magnet bore diameter $\quad \underline{40} \mathrm{~mm}$

accuracy of central field $\quad \pm 22 \%$ at $12 \mathrm{~T}$

field measurement method(s)

Magnet current shunt; calibrated with hall probe

field variation over $\mathrm{V}-\mathrm{V}$ taps (including mis-location of sample) $\pm \underline{0.5 \%}$ at $\underline{12} \mathrm{~T}$

rms ripple field $< \pm 0.01 \%$ at $12 \mathrm{~T}$

field range covered $6 \mathrm{~T}$ to $14 \mathrm{~T}$

b) sample current

current calibration method

NIST Traceable Shunt and DVM

accuracy of sample current $\pm 0.2 \%$ at $100 \mathrm{~A}$

rms ripple current $< \pm 0.001 \%$ at 100 A (battery supply)

current sweep rate : $\mathrm{O} A / \mathrm{s}$ or $\_$seconds to $\mathrm{I}_{\mathrm{c}}$ (step, hold, sample)

c) sample voltage

voltage calibration method

NIST traceable DVM

accuracy of sample voltage $\pm 2 \%$ at $100 \mu \mathrm{V} / \mathrm{m}$

typical noise level $\pm 2 \mu \mathrm{V} / \mathrm{m}$

response time of voltmeter $<0.1 \mathrm{sec}$

d) helium bath temperature

temperature measurement method(s)

Pool boiling helium; open dewar

accuracy of temperature $\pm 0.002 \mathrm{~K}$ at $4.2 \mathrm{~K}$

e) critical current measurement

measurement system verification

NIST SRM 1457 on dedicated test probe w/ S.P.C. plot

$I_{c}$ measurement: estimated uncertainty $\pm 2 \%$,estimated precision $\pm 0.3 \%$

n-value measurement: estimated uncertainty $\pm 10 \%$,estimated precision $\pm 2 \% @ 1 \sigma$ 
f) measurement circuit diagram

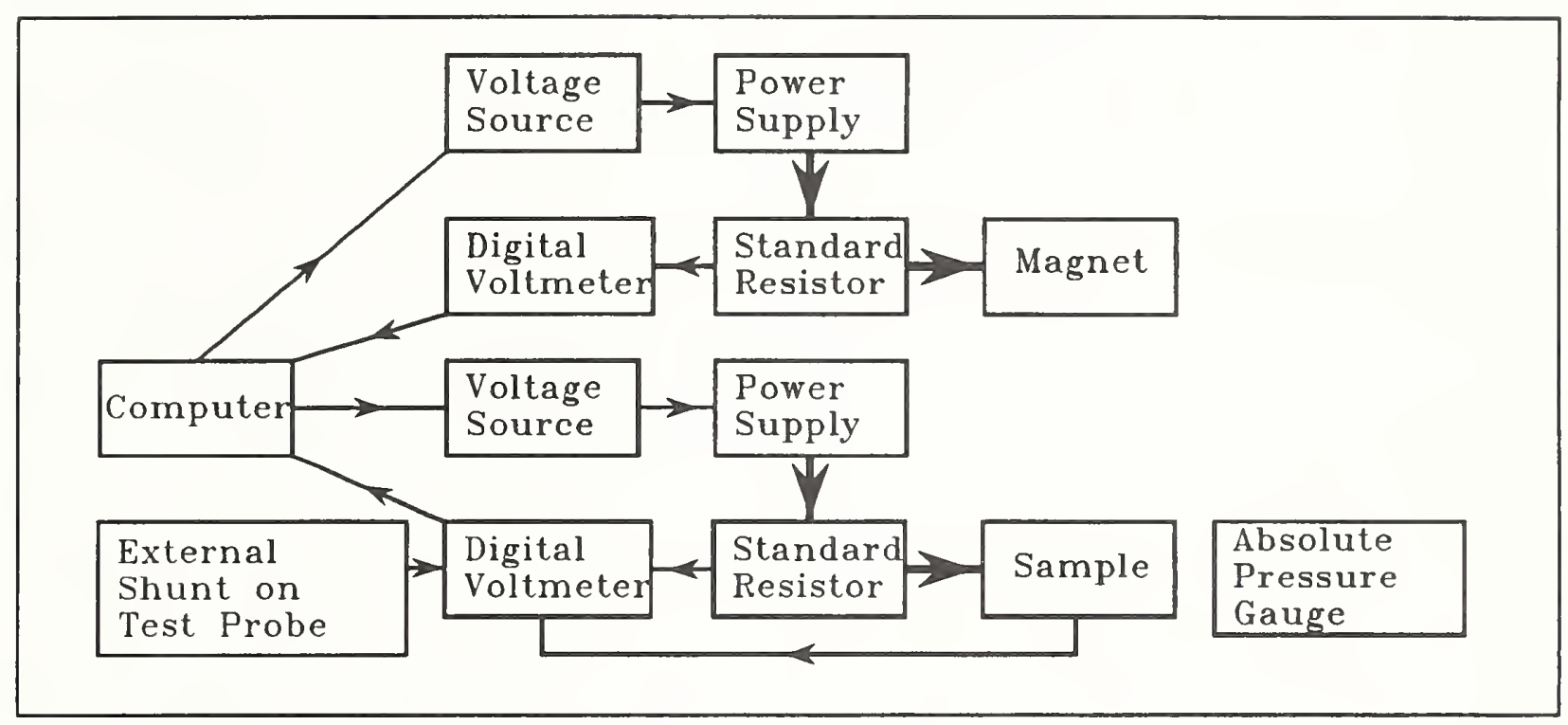

\subsection{SAMPLE HEAT TREATMENT}

a) reaction mandrel

material Ti-6 Al-4 V

surface treatment Graphite Coat

groove geometry per ITER specs

retainer per ITER specs

pitch length per ITER specs

outer diameter per ITER specs

number of wind turns 13.6

b) heat treatment furnace

temperature determination Thermocouple, type $\mathrm{K}$

variation in space $\pm 2{ }^{\circ} \mathrm{C}$

variation in time $\pm \underline{2}{ }^{\circ} \mathrm{C}$

\subsection{MEASUREMENT MANDREL AND MOUNTING DETAILS}

a) measurement mandrel

mandrel material $\mathrm{Ti}-6 \mathrm{Al}-4 \mathrm{~V}$

outer diameter of mandrel per ITER specs

inner diameter of mandrel per ITER specs

pitch length of spiral groove per ITER specs

groove geometry and angle per ITER specs

current terminal; material(s) copper

geometry ring with $5 / 8$ " inner diameter 
b) sample mounting bonding material thin layer of bonding material? yes mounting procedure Remove retainer ring; insert copper ring; mount on 5/8" mandrel; solder to mandrel; solder wire and taps.

solder material $60-40 \mathrm{Sn}-\mathrm{Pb}$

flux material 'Nokorrode' soldering paste

soldering temperature Just above melting point

sample well seated in groove? yes

c) sample geometry and dimensions

wire length between $\mathrm{V}$ taps ( 1 ) $0.5 \mathrm{~m}$

wire length between an current junction and its nearest V tap ( 2 ) $0.1 \mathrm{~m}$

length of sample soldered to an current terminal ( 3 ) $0.09 \mathrm{~m}$

total sample length $(1+2 x(2+3)) \underline{0.88 m}$

winding diameter (outer) $\simeq 32 \mathrm{~mm}$

total number of winding turns 8.8

d) sample cooling to $4.2 \mathrm{~K}$

cooling time from room temperature to $4.2 \mathrm{~K} \geq 15$ minutes

precooled with liquid nitrogen? yes $\left(\mathrm{N}_{2}\right.$ vapors above $\left.\mathrm{L} \mathrm{N}_{2}>10 \mathrm{~min}\right)$

directly cooled with gas or liquid helium? no (He vapors above L He $>5 \mathrm{~min}$ )

e) sketch of measurement mandrel set

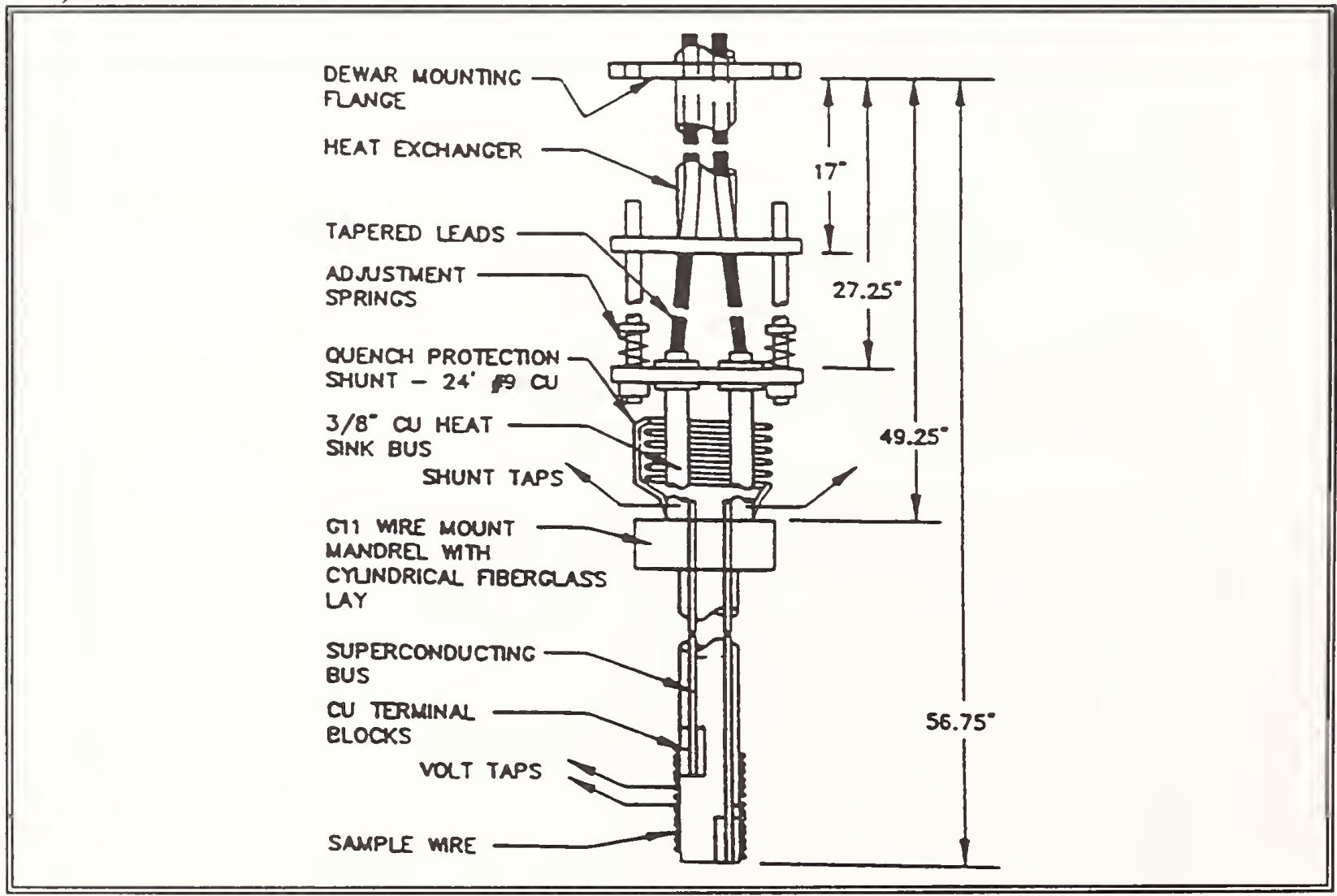


1. MEASUREMENT CONDITIONS

\subsection{TEST SETUP}

a) magnetic field

magnet bore diameter $\quad 52 \mathrm{~mm}$

accuracy of central field $\pm 0.2 \%$ at $12 \mathrm{~T}$,

field measurement method(s)

Axial Hall Probe and power supply control voltage

field variation over $\mathrm{V}-\mathrm{V}$ taps (including mis-location of sample) $\pm 0.15 \%$ at $12 \mathrm{~T}$

rms ripple field $\pm 0.05 \%$ at $12 \mathrm{~T}$

field range covered 0 T to $14 \mathrm{~T}$

b) sample current

current calibration method

Cross check to calibrated resistor

accuracy of sample current $\pm 0.1 \%$ at 50 A

rms ripple current $\pm 0.02 \%$ at $100 \mathrm{~A}$

current sweep rate : $<0.2 \mathrm{~A} / \mathrm{s}$ or seconds to $I_{c}$

c) sample voltage

voltage calibration method

Comparison with recently calibrated Keithley 180/2001 DVM

accuracy of sample voltage $\pm \_\%$ at $10 \_\mu \mathrm{V} / \mathrm{m}$

typical noise level $\pm 0.04 \_\mu \mathrm{V} / \mathrm{m}$

response time of voltmeter _ $\mathrm{sec}$

d) helium bath temperature

temperature measurement method(s)

Absolute pressure, manometer calibration traceable to NIST

accuracy of temperature $\pm 0.01 \mathrm{~K}$ at $4.2 \mathrm{~K}$

e) critical current measurement

measurement system verification

NIST SRM

$I_{c}$ measurement: estimated uncertainty $\pm 2 \%$, estimated precision $\pm 1 \%$

n-value measurement: estimated uncertainty $\pm 10 \%$, estimated precision $\pm 5 \%$ 
f) measurement circuit diagram

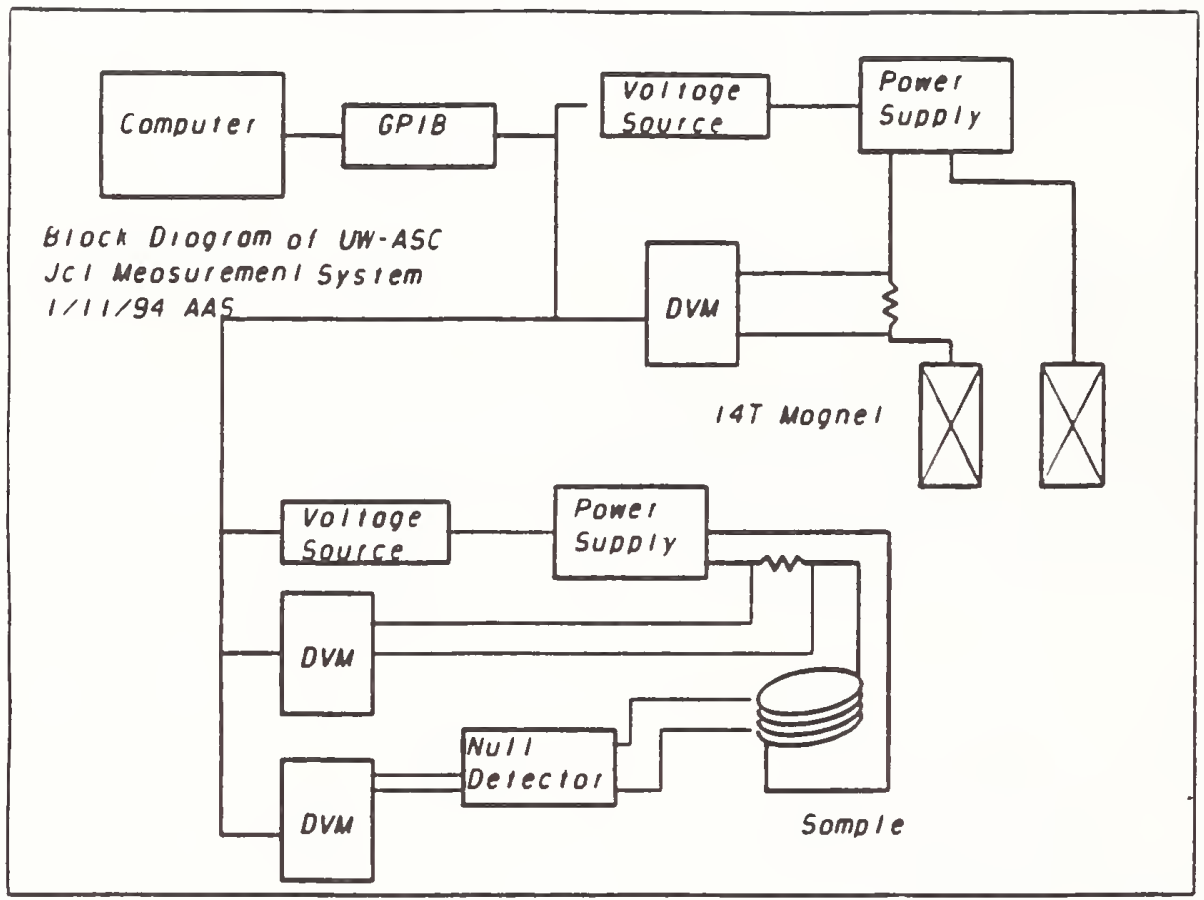

\subsection{SAMPLE HEAT TREATMENT}

a) reaction mandrel

material

surface treatment

groove geometry

retainer

pitch length

outer diameter

number of wind turns

b) heat treatment furnace

temperature determination

variation in space \pm

variation in time \pm

\subsection{MEASUREMENT MANDREL AND MOUNTING DETAILS}

a) measurement mandrel

mandrel material

outer diameter of mandrel

inner diameter of mandrel

pitch length of spiral groove

groove geometry and angle

current terminal; material(s)

geometry 
INSTITUTE_University of Wisconsin ASC

Sheet-3

b) sample mounting

bonding material _None

thin layer of bonding material?

mounting procedure

solder material $\quad$ Sn $60 / \mathrm{Pb} 40$

flux material Rosin

soldering temperature

sample well seated in groove? yes

c) sample geometry and dimensions

wire length between $V$ taps ( 1 ) $63 \mathrm{~cm}$

wire length between an current junction and its nearest $V$ tap $(2)>20 \mathrm{~cm}$

length of sample soldered to an current terminal ( 3 ) $15 \mathrm{~cm}$

total sample length $(1+2 \times(2+3))-133 \mathrm{~cm}$

winding diameter (outer)

total number of winding turns

d) sample cooling to $4.2 \mathrm{~K}$

cooling time from room temperature to $4.2 \mathrm{~K} \_3$ minutes (from $77 \mathrm{~K}$ to $4.2 \mathrm{~K}$ )

precooled with liquid nitrogen? yes, sits $5 \mathrm{~min}$ in bath

directly cooled with gas or liquid helium?

e) sketch of measurement mandrel setup

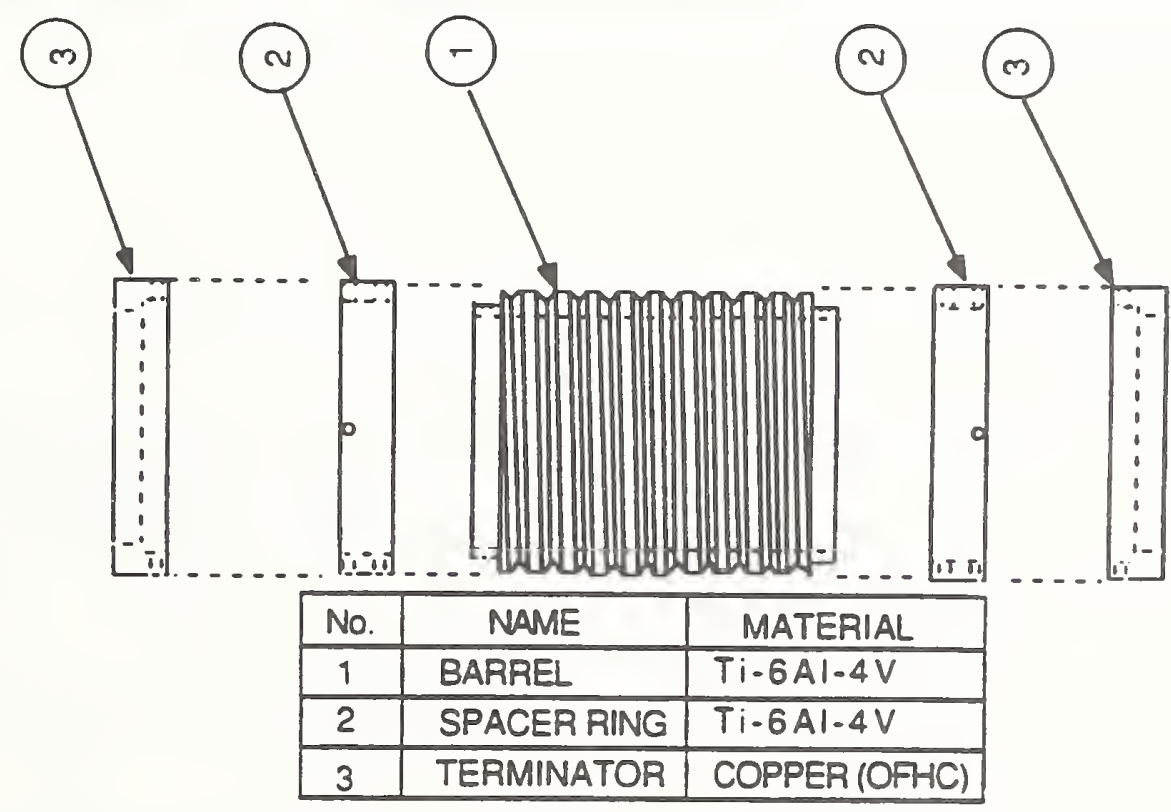


2. RESULTS

Magnetic Field $\mathrm{T}$

\begin{tabular}{||c|c|c|c|c|c||}
\hline $\begin{array}{c}\text { Sample } \\
\text { Name }\end{array}$ & $\begin{array}{c}\text { Barrel } \\
\#\end{array}$ & $\begin{array}{c}\text { Temp. } \\
(\mathrm{K})\end{array}$ & $\begin{array}{c}\mathrm{I}_{\mathrm{c}}(\mathrm{A}) \\
\text { at } 10 \mu \mathrm{V} / \mathrm{m}\end{array}$ & $\mathrm{n}$-value & Remarks \\
\hline \hline & & & & & \\
\hline & & & & & \\
\hline & & & & & \\
\hline & & & & & \\
\hline & & & & & \\
\hline & & & & & \\
\hline & & & & & \\
\hline & & & & & \\
\hline
\end{tabular}

${ }^{1} \mathrm{n}$-value is defined as an exponent in the V-I relation of $\mathrm{V}=\mathrm{bI}^{\mathrm{n}}$.

Voltages or voltage range used to estimate $n$-value $\mu \mathrm{V} / \mathrm{m}$

\section{Comments}

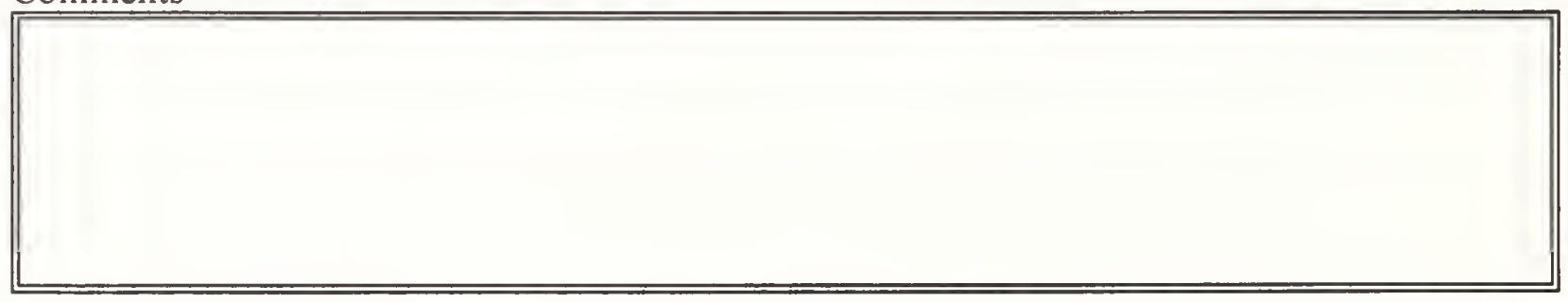

\section{HEAT TREATMENT}

atmosphere

temperature and time table:

\begin{tabular}{||l||l|l|l|l||}
\cline { 2 - 5 } \multicolumn{1}{c|}{} & Stage 1 & Stage 2 & Stage 3 & Stage 4 \\
\hline \hline Temperature & & & & \\
\hline Time & & & & \\
\hline $\begin{array}{c}\text { ramp } \\
\text { rate }\end{array}$ & & & & \\
\hline
\end{tabular}




\section{RESULTS}

Sample Name Barrel \#

Helium bath temp.

\begin{tabular}{|c|c|c|c|}
\hline $\mathrm{B}(\mathrm{T})$ & $\mathrm{I}_{c}$ at $10 \mu \mathrm{V} / \mathrm{m}(\mathrm{A})$ & n-value ${ }^{1}$ & Remarks \\
\hline 6 & & & \\
\hline 7 & & & \\
\hline 8 & & & \\
\hline 9 & & & \\
\hline 10 & & & \\
\hline 11 & & & \\
\hline 12 & & & \\
\hline 13 & & & \\
\hline 14 & & & \\
\hline
\end{tabular}

${ }^{1} \mathrm{n}$-value is defined as an exponent in the $\mathrm{V}$-I relation of $\mathrm{V}=\mathrm{bI} \mathrm{I}^{\mathrm{n}}$. Voltages or voltage range used to estimate n-value $\mu \mathrm{V} / \mathrm{m}$

\section{Comments}

\section{HEAT TREATMENT}

atmosphere temperature and time table:

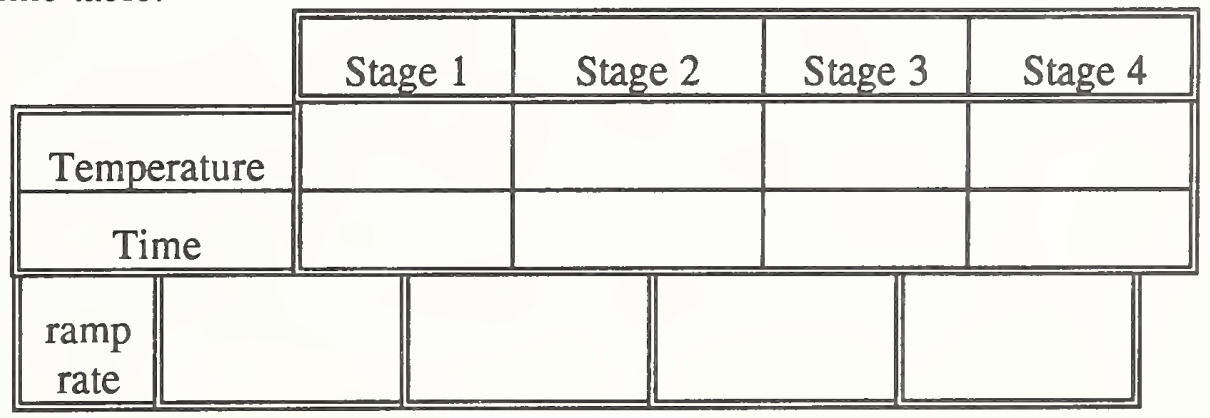




\title{
Appendix B
}

This paper was presented at the 7th International Workshop on Critical Currents in Superconductors (Alpbach, Tyrol, Austria, January 24-27, 1994). It will be published by World Scientific Publishing CO. PTE. LTD.

\section{A SIMPLE AND REPEATABLE TECHNIQUE FOR MEASURING THE CRITICAL CURRENT OF $\mathrm{Nb}_{3} \mathrm{Sn}$ WIRES*}

\author{
L. F. Goodrich and A. N. Srivastava \\ National Institute of Standards and Technology \\ 325 Broadway, Boulder CO, 80303, USA.
}

\begin{abstract}
We evaluated an alternate approach for measuring the critical current $\left(\mathrm{I}_{c}\right)$ of $\mathrm{Nb}_{3} \mathrm{Sn}$ wire which uses a standard mandrel geometry and apparatus interface. Preliminary data indicate that the tension in the conductor before reaction and measurement may affect the repeatability. We show preliminary summary statistics for measurements of conductors performed by five US laboratories. The reaction and measurement mandrel used was fabricated using a Ti-6 Al-4V alloy. This high temperature alloy was used to avoid transferring the specimen between mandrels, thus reducing the likelihood of inadvertent mechanical damage of the specimen. Besides this advantage, these holders are inexpensive and nonmagnetic, and have a low thermal expansion and a high electrical resistivity $(147 \mu \Omega \cdot \mathrm{cm}$ at $4 \mathrm{~K}$ ). Using the same mandrel for reaction and measurement improves the quality assurance of the $I_{c}$ measurement for data base creation and acceptance testing for large scale applications such as ITER (International Thermonuclear Experimental Reactor). The US ITER Home Team adopted this approach in a recent test because it was expected to be easily implemented and yield consistent results.
\end{abstract}

\section{Introduction}

The data presented here are $\mathrm{Nb}_{3} \mathrm{Sn}$ superconductor critical current and n-value measurements made during an interlaboratory comparison in which a common holder with standardized design was used for reaction and measurement. Our experience indicates that standardizing experimental variables reduces the uncertainty in the measurement and increases the repeatability of the overall experiment [1].

\section{Design of the Titanium Reaction/Measurement Holders}

The reaction mandrel consists of three Ti alloy parts: a main tube and two removable end rings. The main tube has a threaded groove $(3.15$ threads $/ \mathrm{cm})$ with a groove angle of $90^{\circ}$. The end rings are held onto the main tube with a stainless steel wire (spring clip) through mating holes in the main tube and end cap. The end rings are not threaded; their outer diameter was machined to hold the specimen at the same coil diameter as when seated in the grooves of the main tube. A small diameter retaining wire is used to tie the specimen to each end ring, thus holding the wire coil on the reaction mandrel.

After reaction the end rings are removed, and $\mathrm{Cu}$ current contact rings are put on and

* Publication of NIST, not subject to copyright. 
held in place with stainless steel wire. If there is a $\mathrm{Cr}$ coating on the wire, it is removed from the region of the current contacts and voltage taps. One end of the specimen is clamped, and the wire is seated into a groove starting from the clamped end and proceeding along the wire to the far end which is then clamped. The specimen is then soldered to the $\mathrm{Cu}$ current contact rings and voltage tap wires are soldered to the specimen. We call this fully instrumented unit, an instrumented specimen.

We also standardized the attachment of the instrumented specimen to the test fixture. In all cases, the current contacts to the instrumented specimen were made by pressure contacts to each $\mathrm{Cu}$ ring, thus making the instrumented specimen interchangeable and allowing for a classical round robin comparison where each specimen is measured by each laboratory. Identifying and separating the effects of specimen mounting from conductor inhomogeneity and different measurement conditions could be facilitated by combining and comparing the classical round robin and the more common method where each laboratory mounts and measures a different specimen.

The thermal contraction of this $\mathrm{Ti}$ alloy is $0.17 \%$ from 295 to $4 \mathrm{~K}$. This small contraction causes the $\mathrm{Nb}_{3} \mathrm{Sn}$ wire to tighten onto the mandrel as it cools to the measurement temperature. This tightened state reduces specimen motion and the need for a binding agent to hold the specimen, when the Lorentz force is directed into the mandrel. Differential contraction also puts the wire into hoop strain, and creates a transverse stress, and a slight bending strain. We expect that tensile hoop strain is the most significant strain effect. It will slightly increase the $I_{c}$ from the intrinsic value [2]. We have recently discovered that this holder is superconducting at $4.2 \mathrm{~K}$ and magnetic fields below $2 \mathrm{~T}$. Thus, reliable $\mathrm{I}_{\mathrm{c}}$ measurements can only be obtained at fields higher than $2 \mathrm{~T}$ at $4.2 \mathrm{~K}$ with this holder material.

\section{Experimental Results}

We conducted a repeatability study on two fully instrumented $\mathrm{Nb}_{3} \mathrm{Sn}$ specimens. The $I_{c}$ of each specimen was measured as a function of magnetic field two times. The percent difference in $I_{c}$ of each specimen from Specimen 1, Run A is shown as a function of magnetic field on Figure 1. The experiment consisted of measuring the critical current of a given specimen as a function of field (Run A), followed by thermal cycling, removal from test fixture, replacement on test fixture, and repeating the measurements (Run B). The results shown here are preliminary; however they indicate that high precision and accuracy in the measurement are possible if the standardized procedures are followed.

The curves corresponding to Specimen 2 (also Specimen 1 to a lesser extent) diverge from each other with increasing magnetic field; we suspect that this was caused by slight changes in the $\mathrm{Nb}_{3} \mathrm{Sn}$ stress state that occur during thermal cycling. These changes are not to be confused with the larger effects due to hoop strain. Although this cumulative effect is on the order of $0.5 \%$, it has implications in interpreting the results of an interlaboratory comparison. During a thermal cycle, the specimen is constrained by the mandrel. The thermal contraction of the composite wire is about $0.11 \%$ more than the Ti-alloy mandrel. The dynamic differential contraction between these two materials may be more than $0.11 \%$ in the cooling or warming cycles. Thus, the wire undergoes hoop 
stress and elongation as it is cooled to $4 \mathrm{~K}$. We suspect that the elongation has a cumulative effect, since the copper and/or bronze may exceed its elastic limit during the thermal cycle, and that would slightly relieve the precompression of the $\mathrm{Nb}_{3} \mathrm{Sn}$. This would explain the observed effect (see Fig. 1). The fact that the curves diverge with increasing magnetic field also suggests that the underlying effect is due to strain.

We conducted the second experiment to evaluate the effect of mounting a specimen with different initial seating conditions in the mandrel groove. Six $I_{c}$ measurements were made on Specimen 2 with different initial seating conditions. The seating conditions were changed by incrementally applying positive or negative torsion to the coiled conductor. We designed this experiment to model the effects of different initial seating conditions which may occur during an interlaboratory comparison of $I_{c}$.

Figure 2 shows the measured $I_{c}$ as a function of run number, where each run had a different initial torsion state. The points which are at the zero initial position (stars) fall on an asymptotic progression. The circle was at a position of $-0.07 \%$, the square at $-0.10 \%$, and the triangle at $0.03 \%$. For example, if the active length of the specimen is $95 \mathrm{~cm}$ (contact to contact), a $-0.10 \%$ change in position would correspond to shifting one end of specimen by $0.95 \mathrm{~mm}$ in the direction that makes the wire less tight on the holder. The results were consistent with the expected behavior, except for the enhanced sensitivity to the additional tension from the initial position.

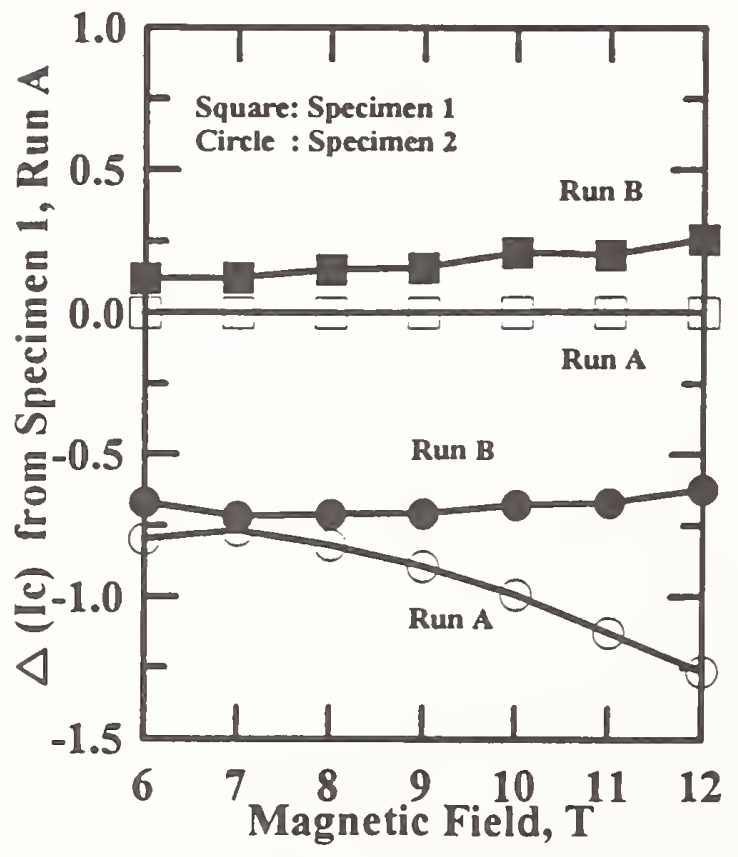

Figure 1. The percent difference in critical current relative to measured values of Specimen 1, Run A versus magnetic field.

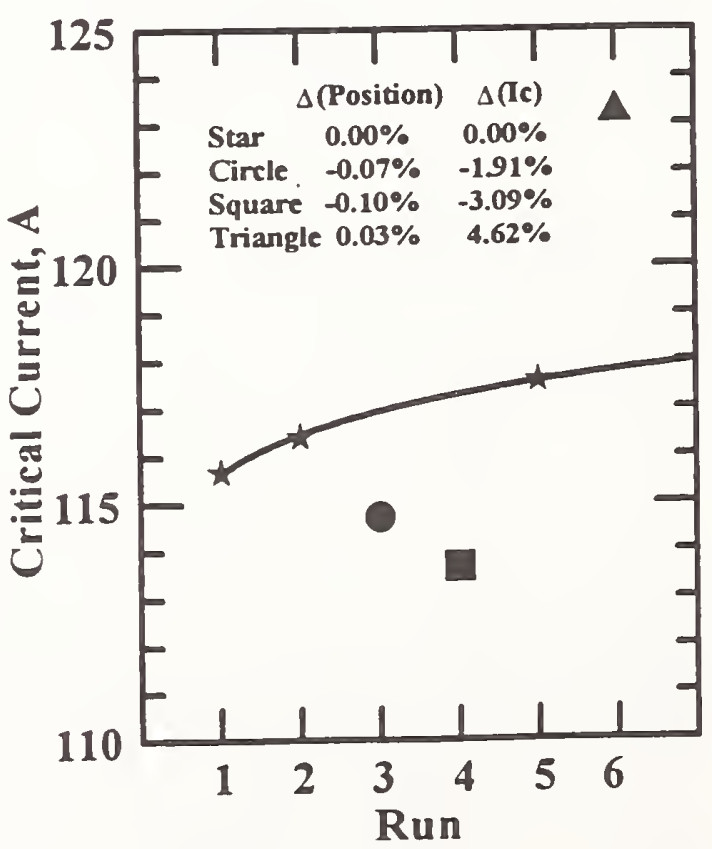

Figure 2. Measured $I_{c}$ of Specimen 2 versus run number. Symbols refer to the relative position; $\%$ differences are calculated relative to the baseline curve. 
In the interlaboratory comparison, the measured critical currents agreed. Thus, we suspect that the initial seating conditions of the laboratories were similar. These results are not unique to the Ti-alloy holders; Incoloy or any other mandrel material would exhibit similar effects. To standardize these effects, it might be necessary to develop an apparatus which applies a preset amount of tension to the specimen. We expect tension before reaction to have a smaller effect than tension after reaction since in the former case the main effect is a slight variation in bending strain.

Table 1 shows a statistical summary the results of an interlaboratory comparison of $I_{c}$ measurements for four conductors from five laboratories. These conductors were not designed to meet a certain specification and had different diameters. Each laboratory prepared two specimens and followed a procedure similar to that described here.

Table 1. Preliminary summary statistics for each sample measured at $4.2 \mathrm{~K}$ at $12 \mathrm{~T}$.

\begin{tabular}{|c|c|c|c|c|}
\hline & Sample W & Sample X & Sample Y & Sample Z \\
\hline \hline Mean I , A & 117.6 & 212.8 & 141.5 & 84.0 \\
\hline$\sigma, A$ & 4.3 & 6.1 & 6.4 & 2.7 \\
\hline$\sigma /$ mean, \% & 3.7 & 2.9 & 4.6 & 3.2 \\
\hline Mean $n$ & 29.0 & 29.2 & 27.8 & 14.9 \\
\hline$\sigma$ & 3.5 & 3.1 & 2.3 & 1.0 \\
\hline$\sigma /$ mean, \% & 12.2 & 10.6 & 8.3 & 6.9 \\
\hline
\end{tabular}

\section{Conclusions}

This standardization procedure yielded repeatable results during a recent interlaboratory comparison of critical current measurements on $\mathrm{Nb}_{3} \mathrm{Sn}$ wires. We also implemented a standardized holder for both reaction and measurement. We believe that the tension of the conductor before reaction and before measurement should be controlled in order to achieve high precision quality assurance. This procedure yields predictable results, as demonstrated in the repeatability and initial seating experiments.

\section{References}

1. H. Wada and K. Itoh, Cryogenics 32 ICMC Supplement (1992) 557.

2. J. W. Ekin, Cryogenics 20 (1980) 611.

\section{Acknowledgements}

The authors extend their thanks to M. Takayasu (MIT) for his contribution in the design of the common holder, J. Minervini (MIT) for his organization of the interlaboratory comparison, US ITER Home Team for their cooperation, T. C. Stauffer for assisting in the measurements, and J. A. Wiejaczka for assisting with data analysis. This work was supported by the Office of Fusion Energy (US Department of Energy) and the Plasma Fusion Center (MIT). 


